\title{
Circulation and Effluent Dilution Modeling in Massachusetts Bay: Model Implementation, Verification and Results
}

\author{
Richard P. Signell \\ U. S. Geological Survey \\ Woods Hole, Massachusetts \\ Harry L. Jenter \\ U. S. Geological Survey \\ Reston, Virginia \\ Alan F. Blumberg \\ HydroQual, Inc. \\ Mahwah, New Jersey \\ January, 1996
}

U. S. Geological Survey Open File Report 96-015

This report has not been reviewed for conformity with U. S. Geological Survey editorial standards 


\begin{abstract}
A three-dimensional hydrodynamic model was developed as part of a cooperative U.S. Geological Survey/Massachusetts Water Resources Authority program to study contaminated sediment accumulation and transport in Massachusetts Bay. This report details the development of the model and assesses how well the model represents observed currents and water properties in the bay. It also summarizes circulation and comparative effluent dilution simulations from existing and future Boston sewage outfalls over a three-year period from October 1, 1989 to December 31, 1992.

The ECOM-si model, a semi-implicit version of the Blumberg and Mellor (1987) Estuarine, Coastal and Ocean Model, is shown to reproduce many of the important hydrodynamical features of Massachusetts Bay: the seasonal evolution of the pycnocline, the mean flow pattern, and the strength of sub-tidal current fluctuations. Throughout the simulation period, during both vertically well-mixed and stratified conditions, the seasonal statistics of observed currents are wellrepresented by the model. The model is therefore appropriate for studying the average dilution of sewage effluent and other continuously discharged substances over seasonal time scales.

The ability of the model to reproduce individual flow events varies with season and location within the bay. Flow events during unstratified conditions in western Massachusetts Bay are particularly well-represented, indicating that the model is appropriate for studying processes such as the transport of suspended material from the future outfall site due to winter storms. Individual flow events during stratified conditions and in the offshore Stellwagen Bank region, however, are less well-represented due to small length scales (caused by upwelling and river discharge events) coupled with insufficient data to specify open boundary forcing from the Gulf of Maine. Thus while the model might be used to answer issues such as the frequency with which Gulf of Maine river plumes visit the new outfall site, attempting to predict whether a particular plume would visit the outfall site could be problematic.

Comparative simulations of effluent discharged from the existing and future Boston outfalls show that the region of relatively high effluent concentrations (1 part effluent to 200 parts sea water) is significantly smaller with the future outfall and is limited to Western Massachusetts Bay during both unstratified and stratified seasons. The region of even higher concentration (1 part effluent to 50 parts sea water) that covers much of Boston Harbor with the existing outfall is non-existent in the future outfall simulation. Additional simulations of chlorination plant failure predict that the offshore location of the future outfall will lead to dramatically lower levels of pathogens at area beaches.
\end{abstract}




\section{Contents}

1 Introduction 8

1.1 Rationale ................... 8

1.2 Physical Setting . . . . . . . . . . . . . . 8

1.3 Motivation for Realistic Simulations . . . . . . . . . . . 10

1.4 Organization .................... 11

2 Model Implementation 12

2.1 Numerical Scheme . . . . . . . . . . . . . . . . . . 12

2.2 Model Geometry and Bathymetry . . . . . . . . . . . . 14

2.3 Vertical Mixing . . . . . . . . . . . . . . . . . 14

2.4 Horizontal Mixing . . . . . . . . . . . . . . . 16

2.5 Surface and Bottom Stress . . . . . . . . . . . 17

2.6 Surface Heat Flux . . . . . . . . . . . . . . 20

2.7 Freshwater Input . . . . . . . . . . . . . . . . 20

2.8 Open Boundary Conditions . . . . . . . . . . . . . . 21

2.9 Adjunct Western Gulf of Maine Model . . . . . . . . . . . . 24

2.10 Boundary condition modifications for 1992 run . . . . . . . 27

2.11 Time Step . . . . . . . . . . . . . . . . . 27

2.12 Sigma-Coordinate Correction $\ldots \ldots \ldots \ldots . \ldots 27$

3 Model/Data Comparison 32

3.1 Temperature, Salinity and Density . . . . . . . . . . 32

3.2 Velocity Time Series Comparison at the Mooring Locations . . 41

3.3 Statistical Comparison of Currents at the Mooring Locations . 48

4 Effluent Modeling $\quad 57$ 
5 Simulation of chlorination breakdown at the existing and future outfall locations

6 Summary $\quad 68$

A Model/Data Comparison of Time Series Velocity at the Boston Buoy

$\begin{array}{ll}\text { B Mean Currents by Season } & 90\end{array}$

C Comparative Effluent Dilution Simulations for the Existing and Future Outfalls $\quad 104$

$\begin{array}{ll}\text { D References } & 119\end{array}$ 


\section{List of Figures}

1.1 The Massachusetts Bay region. . . . . . . . . . . . 9

2.1 Massachusetts Bay model grid. . . . . . . . . . . . 15

2.2 Data collection sites in Massachusetts Bay . . . . . . . . . 18

2.3 Meteorological Data . . . . . . . . . . . . . . . 19

2.4 Freshwater input to the Western Gulf of Maine . . . . . . . 22

2.5 Adjunct Western Gulf of Maine grid. . . . . . . . . . . 25

2.6 Model/data comparison of OBC driven flow . . . . . . 26

2.7 Inshore Massachusetts Bay boundary condition from WGOM model. . . . . . . . . . . . . . . . . . . 28

2.8 Offshore Massachusetts Bay boundary condition from WGOM model. . . . . . . . . . . . . . . . . . . . . 29

2.9 Observed and modeled vertical temperature difference. . . . . 30

3.1 Model/data comparison of near-surface salinity at Stations $\mathrm{BB}, \mathrm{BS}, \mathrm{SC}$ and $\mathrm{U} 6 . \ldots \ldots \ldots \ldots$

3.2 Model/data comparison of lower layer salinity at stations BB, BS, SC and U6. . . . . . . . . . . . . . . . . 34

3.3 Model/data comparison of lower layer salinity at stations U2, $\mathrm{MN}, \mathrm{RP}$ and U7. . . . . . . . . . . . . . . 35

3.4 Model/data comparison of near-surface temperature at stations $\mathrm{BB}, \mathrm{BS}, \mathrm{SC}$ and $\mathrm{U} 6 . \ldots \ldots \ldots . \ldots 36$

3.5 Model/data comparison of near-surface temperature at $\mathrm{U} 2$, $\mathrm{RP}, \mathrm{MN}$, and U7. . . . . . . . . . . . . 37

3.6 Model/data comparison of lower layer temperature at BB, BS, SC and U6. . . . . . . . . . . . . . . . . 38

3.7 Model/data comparison of lower layer temperature at U2, MN, $\mathrm{RP}$, and U7. . . . . . . . . . . . . . 39 
3.8 Model/data comparison of vertical density differences at stations BB, BS, SC and U6. . . . . . . . . . . . 40

3.9 Coherence between near-surface salinity time series. . . . . . 42

3.10 Coherence between near-surface temperature time series. . . . 43

3.11 Boston Buoy velocity comparison: Jan 28, 1991 - Mar 25, 1991. 44

3.12 Boston Buoy velocity comparison: Jun 18, 1990 - Aug 13, 1990. 45

3.13 Boston Buoy Model/Data velocity statistics at $5 \mathrm{~m}$ depth. . . 46

3.14 Boston Buoy Model/Data velocity statistics at $23 \mathrm{~m}$ depth. . . 47

3.15 Model/Data velocity correlations at selected regional stations. 49

3.16 Model/Data comparison of the 1st EOF structure of the velocity time series . . . . . . . . . . . . 50

3.17 Mean flow and low-frequency variability ellipses for Winter $1990-1991 \ldots \ldots \ldots \ldots \ldots \ldots$. . . . . . . . . . 51

3.18 Mean flow and low-frequency variability ellipses for Spring 199153

3.19 Mean flow and low-frequency variability ellipses for Summer $1990 \ldots \ldots \ldots \ldots \ldots \ldots$. . . . . . . . . . . 54

3.20 Mean flow and low-frequency variability ellipses for Fall 1990 . 55

4.1 Effluent comparison at $2 \mathrm{~m}$ depth during Winter $1990 . \ldots 59$

4.2 Effluent comparison at $2 \mathrm{~m}$ depth during Winter 1991. . . . . 60

4.3 Effluent comparison at $2 \mathrm{~m}$ depth during Summer 1990. . . . . 61

4.4 Effluent comparison at $16 \mathrm{~m}$ depth during Summer 1990. . . . 62

4.5 Residence time for effluent in Massachusetts Bay and Boston Harbor . . . . . . . . . . . . . . . . . 63

A.1 Boston Buoy velocity comparison: Jan 1, 1990 - Feb 26, 1990. 71

A.2 Boston Buoy velocity comparison: Feb 26, 1990 - Apr 23, 1990. 72

A.3 Boston Buoy velocity comparison: Apr 23, 1990 - Jun 18, 1990. 73

A.4 Boston Buoy velocity comparison: Jun 18, 1990 - Aug 13, 1990. 74

A.5 Boston Buoy velocity comparison: Aug 13, 1990 - Oct 8, 1990. 75

A.6 Boston Buoy velocity comparison: Oct 8, 1990 - Dec 3, 1991. . 76

A.7 Boston Buoy velocity comparison: Dec 3, 1990 - Jan 28, 1990. 77

A.8 Boston Buoy velocity comparison: Jan 28, 1991 - Mar 25, 1991. 78

A.9 Boston Buoy velocity comparison: Mar 25, 1991 - May 20, 1991. 79

A.10 Boston Buoy velocity comparison: May 20, 1991 - Jul 15, 1991. 80

A.11 Boston Buoy velocity comparison: Jul 15, 1991 - Sep 9, 1991. 81

A.12 Boston Buoy velocity comparison: Sep 9, 1991 - Nov 4, 1991.82 
A.13 Boston Buoy velocity comparison: Nov 4, 1991 - Dec 30, 1991. 83

A.14 Boston Buoy velocity comparison: Dec 30, 1991 - Feb 24, 1992. 84

A.15 Boston Buoy velocity comparison: Feb 24, 1992 - Apr 20, 1992. 85

A.16 Boston Buoy velocity comparison: Apr 20, 1992 - Jun 15, 1992. 86

A.17 Boston Buoy velocity comparison: Jun 15, 1992 - Aug 10, 1991. 87

A.18 Boston Buoy velocity comparison: Aug 10, 1992 - Oct 5, 1992. 88

A.19 Boston Buoy velocity comparison: Oct 5, 1992 - Nov 30, 1992. 89

B.1 Modeled mean flow at 2 and $20 \mathrm{~m}$ depth for Winter 1989-1990. 91

B.2 Modeled mean flow at 2 and $20 \mathrm{~m}$ depth for Spring 1990. . . . 92

B.3 Modeled mean flow at 2 and $20 \mathrm{~m}$ depth for Summer 1990. . . 93

B.4 Modeled mean flow at 2 and $20 \mathrm{~m}$ depth for Fall $1990 . \quad \ldots . .94$

B.5 Modeled mean flow at 2 and $20 \mathrm{~m}$ depth for Winter 1990-1991. 95

B.6 Modeled mean flow at 2 and $20 \mathrm{~m}$ depth for Spring 1991. . . . 96

B.7 Modeled mean flow at 2 and $20 \mathrm{~m}$ depth for Summer 1991. . . 97

B.8 Modeled mean flow at 2 and $20 \mathrm{~m}$ depth for Fall 1991. . . . . 98

B.9 Modeled mean flow at 2 and $20 \mathrm{~m}$ depth for Winter 1991-1992. 99

B.10 Modeled mean flow at 2 and $20 \mathrm{~m}$ depth for Spring 1992. . . 100

B.11 Modeled mean flow at 2 and $20 \mathrm{~m}$ depth for Summer 1992. . 101

B.12 Modeled mean flow at 2 and $20 \mathrm{~m}$ depth for Fall 1992. . . . 102

B.13 Modeled mean flow at 2 and $20 \mathrm{~m}$ depth for Winter 1992. . . 103

C.1 Effluent comparison during Winter 1989-90 at $2 \mathrm{~m}$ depth . . . 105

C.2 Effluent comparison during Winter 1989-90 at $16 \mathrm{~m}$ depth. . . 106

C.3 Effluent comparison during Spring 1990 at $2 \mathrm{~m}$ depth. . . . . 107

C.4 Effluent comparison during Spring 1990 at $16 \mathrm{~m}$ depth. . . . 108

C.5 Effluent comparison during Summer 1990 at $2 \mathrm{~m}$ depth. . . . 109

C.6 Effluent comparison during Summer 1990 at $16 \mathrm{~m}$ depth. . . . 110

C.7 Effluent comparison during Fall 1990 at $2 \mathrm{~m}$ depth. . . . . . . 111

C.8 Effluent comparison during Fall 1990 at $16 \mathrm{~m}$ depth. . . . . . 112

C.9 Effluent comparison during Winter 1990-91 at $2 \mathrm{~m}$ depth. . . . 113

C.10 Effluent comparison during Winter 1990-1991 at $16 \mathrm{~m}$ depth. . 114

C.11 Effluent comparison during Spring 1991 at $2 \mathrm{~m}$ depth. . . . . . 115

C.12 Effluent comparison during Spring 1991 at $16 \mathrm{~m}$ depth. . . . 116

C.13 Effluent comparison during Summer 1991 at $2 \mathrm{~m}$ depth. . . . 117

C.14 Effluent comparison during Summer 1991 at $16 \mathrm{~m}$ depth. . . 118 


\section{List of Tables}

2.1 Freshwater inputs for the model. . . . . . . . . . . . . . 21

2.2 Modeled and observed mean flow speed on the eastern flank of Stellwagen Bank . . . . . . . . . . . 26

5.1 Locations monitored in chlorination failure simulations. . . . . 66

5.2 Bacteria concentrations for breakdown of existing plant. . . . 67

5.3 Bacteria concentrations for breakdown of future plant. . . . 67 


\section{Chapter 1}

\section{Introduction}

\subsection{Rationale}

A broad theme of the U.S. Geological Survey (USGS) National Marine and Coastal Geology Program is understanding geologic factors which influence the long-term quality and preservation of environments in their natural state. Toward this goal, the USGS is developing an integrated package of wave, circulation and sediment transport models that can be used to study the movement of polluted material in coastal waters. As a first step of this development, we have implemented and tested a three-dimensional circulation model in Massachusetts Bay, a prototypical region of interest.

\subsection{Physical Setting}

Massachusetts Bay is a semi-enclosed embayment that opens into the Gulf of Maine at its eastern boundary (Figure 1.1). It is roughly $100 \mathrm{~km}$ long, $50 \mathrm{~km}$ wide and has an average water depth of $35 \mathrm{~m}$. The bay is bounded on the east by Stellwagen Bank, which rises to within $20 \mathrm{~m}$ of sea surface. Boston Harbor empties into western Massachusetts Bay, providing a significant source of contaminants to the region.

Circulation in Massachusetts Bay is driven by a combination of local and remote processes that vary with season (Geyer et al, 1992). Throughout the year water flows southward in the western Gulf of Maine, and although most of this current continues flowing southward over the eastern flank of Stellwagen Bank (largely bypassing Massachusetts Bay), a small branch flows into the bay and drives a weak counter-clockwise flow that enters at Cape 


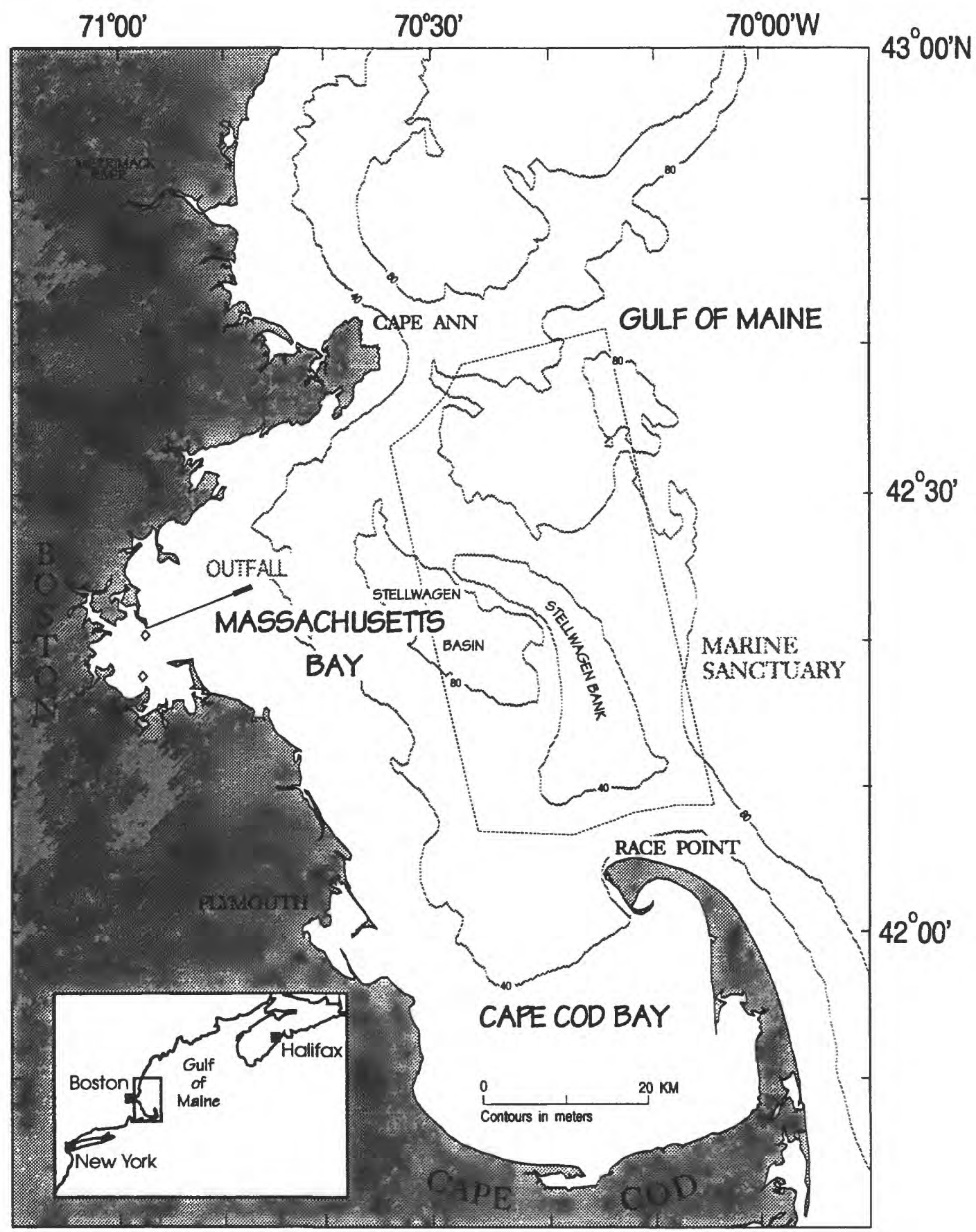

Figure 1.1: Bathymetric map showing Massachusetts and Cape Cod Bays, present sewage outfalls in Boston Harbor (diamonds), location of future ocean outfall for treated Boston sewage in western Massachusetts Bay, and the approximate boundary of the Stellwagen Bank Marine Sanctuary. 
Ann and exits at Race Point. The magnitude of this flow varies from less than $1 \mathrm{~cm} \mathrm{~s}^{-1}$ off Boston to about $3-4 \mathrm{~cm} \mathrm{~s}^{-1}$ along the western shore of Massachusetts Bay.

The remotely driven mean circulation pattern is modified by seasonal current regimes. During the winter, the bay is well-mixed vertically, and the wind is principally from the northwest, reinforcing the counterclockwise circulation. In the spring, surface warming and freshwater intrusions from Gulf of Maine rivers cause the bay to become stratified, and the surface currents in the bay are dominated by the strong and variable density driven flow associated with these intrusions. By summer, the stratification has intensified due to further surface warming. The dominant wind direction in summer is from the southwest, which drives strong upwelling events along the western and northern shores of the bay. In the fall, rapid cooling on the shallow western side of the bay results in a density field that temporarily reverses the surface mean flow.

Tidal currents in Massachusetts Bay are dominated by the semi-diurnal $\mathrm{M}_{2}$ constituent (period $=12.42$ hours). The currents are largely bidirectional and the magnitude ranges from about $10 \mathrm{~cm} \mathrm{~s}^{-1}$ in the interior of Massachusetts Bay to more than $50 \mathrm{~cm} \mathrm{~s}^{-1}$ off the tip of Cape Cod and in the entrances to Boston Harbor and Plymouth Harbor (Blumberg et al, 1993, Irish and Signell, 1992). Although the transport due to tides is generally oscillatory and therefore doesn't give rise to net transport of material, they are an important source of bottom-generated turbulent mixing.

\subsection{Motivation for Realistic Simulations}

A major sewage treatment project is currently underway in Boston, principal components of which include upgrade to secondary treatment and relocation of sewage outfall pipes from Boston Harbor to a site 9 miles offshore (hereafter referred to as the future outfall site). Discharge at the future outfall site is currently estimated to begin in 1997. The impact of the new treatment project on Massachusetts Bay is of critical concern to the Massachusetts Water Resources Authority (MWRA), which is responsible for the project, and to the citizens of Massachusetts. Selection of the future outfall location was based in part on steady, two-dimensional (depth-averaged) modeling results that showed improved dilution of effluent at the offshore location. Lacking in this model, however, was the ability to simulate flow 
under stratified and time-variable conditions (although attempts were made to parameterize these effects). With the pressing need to better understand and simulate transport processes in Massachusetts Bay, the region was chosen by the USGS as a testbed for developing a prototype transport model.

To address water-column effects of the future outfall, the MWRA contracted HydroQual, Inc in the Spring of 1992 to develop a three-dimensional water quality model of the bay. To avoid duplication of effort, since threedimensional circulation is required by both sediment transport and water quality models, the USGS agreed (as part of a cooperatively-funded set of studies with MWRA) to supply HydroQual with the necessary hydrodynamic calculations for their water quality model.

October 1, 1989 - July 1, 1991 was selected for testing and calibration of the circulation and water quality models due to a large data collection effort during this period by the Massachusetts Bays Program (Geyer, 1992). By the fall of 1992, the USGS had made significant progress on hydrodynamic modeling. As water quality results were not yet available, comparative dilution simulations were made to assess the difference between the existing and future outfall locations. Using a conservative tracer, the results suggested that the future outfall would result in a significantly smaller region affected by high concentrations of effluent. These results played a significant role in the EPA environmental assessment of the impact of the future outfall on endangered species on Stellwagen Bank (EPA, 1993). Although the impact of the outfall is now more realistically represented by the water quality model which includes biochemical processes (HydroQual and Battelle, 1995), the comparative dilution simulations still provide important insight into the transport and dispersion of material in Western Massachusetts Bay, and are thus presented in this report.

\subsection{Organization}

This report is organized as follows: The model and its configuration are described in chapter 2. The model is then compared to data in chapter 3 to assess its capability to represent temperature, salinity, density and circulation in Massachusetts Bay. The modeled effluent fields from the existing and future outfall are presented in chapter 4 . Simulated chlorination plant failures at the existing and future outfall sites are shown in chapter 5 . 


\section{Chapter 2}

\section{Model Implementation}

\subsection{Numerical Scheme}

The model used in this study is called ECOM-si, a semi-implicit variant of the three-dimensional Estuary, Coastal and Ocean Model (ECOM) described by Blumberg and Mellor (1987). ECOM-si was selected because it includes a free surface, nonlinear advective terms, coupled density and velocity fields, river runoff, heating and cooling of the sea surface, a 2.5 level turbulence closure scheme to represent vertical mixing (Mellor and Yamada, 1982), and is designed to easily allow "realistic" simulations. In addition, the combination of orthogonal curvilinear coordinates in the horizontal plane and sigma-coordinates in the vertical dimension allows grid refinement in regions of interest without sacrificing the well-known characteristics of Cartesian grid schemes.

The basic equations are expressed in a sigma coordinate system

$$
\sigma=\frac{z-\eta}{H+\eta}
$$

where $H(x, y)$ is the bottom topography and $\eta(x, y)$ is the surface elevation. The basic governing equations are presented here in Cartesian coordinates to facilitate discussion. The equations as expressed in curvilinear coordinates may be found in Blumberg and Mellor (1987).

The continuity equation is

$$
\frac{\partial \eta}{\partial t}+\frac{\partial u D}{\partial x}+\frac{\partial v D}{\partial y}+\frac{\partial \omega}{\partial \sigma}=0
$$


the $x$ momentum equation is

$$
\begin{array}{r}
\frac{\partial u D}{\partial t}+\frac{\partial u^{2} D}{\partial x}+\frac{\partial u v D}{\partial y}+\frac{\partial u \omega}{\partial \sigma}-f v D+g D \frac{\partial \eta}{\partial x}= \\
\frac{\partial}{\partial \sigma}\left\{\frac{K_{M}}{D} \frac{\partial u}{\partial \sigma}\right\}-\frac{g D^{2}}{\rho_{0}} \frac{\partial}{\partial x} \int_{\sigma}^{0} \rho d \sigma+\frac{g D}{\rho_{0}} \frac{\partial D}{\partial x} \int_{\sigma}^{0} \sigma \frac{\partial \rho}{\partial \sigma} d \sigma+F_{x}
\end{array}
$$

and the $y$ momentum equation is

$$
\begin{array}{r}
\frac{\partial u D}{\partial t}+\frac{\partial u v D}{\partial x}+\frac{\partial v^{2} D}{\partial y}+\frac{\partial v \omega}{\partial \sigma}+f u D+g D \frac{\partial \eta}{\partial y}= \\
\frac{\partial}{\partial \sigma}\left\{\frac{K_{M}}{D} \frac{\partial v}{\partial \sigma}\right\}-\frac{g D^{2}}{\rho_{0}} \frac{\partial}{\partial y} \int_{\sigma}^{0} \rho d \sigma+\frac{g D}{\rho_{0}} \frac{\partial D}{\partial y} \int_{\sigma}^{0} \sigma \frac{\partial \rho}{\partial \sigma} d \sigma+F_{y}
\end{array}
$$

where $\eta$ is the surface elevation, $u$ and $v$ are the $x$ and $y$ components of velocity, $D$ is the total water depth $D=H+\eta, \omega$ is the transformed vertical velocity (normal to sigma surfaces), $K_{M}$ is the vertical eddy viscosity, $\rho$ is the water density, $\rho_{0}$ is a reference water density, and $F_{x}$ and $F_{y}$ are the horizontal viscous terms defined by

$$
F_{x}=\frac{\partial}{\partial x}\left(2 A_{M} D \frac{\partial u}{\partial x}\right)+\frac{\partial}{\partial y}\left[A_{M} D\left(\frac{\partial u}{\partial y}+\frac{\partial v}{\partial x}\right)\right]
$$

and

$$
F_{y}=\frac{\partial}{\partial x}\left[A_{M} D\left(\frac{\partial u}{\partial y}+\frac{\partial v}{\partial x}\right)\right]+\frac{\partial}{\partial y}\left(2 A_{M} D \frac{\partial v}{\partial y}\right) .
$$

where $A_{M}$ is the horizontal viscosity. The parameterizations of $K_{M}$ and $A_{M}$ are discussed in chapters 2.3 and 2.4 , respectively. The model also solves prognostically for temperature, salt, concentration (used here to model sewage effluent), turbulence kinetic energy and turbulence macroscale.

ECOM-si differs from the Blumberg and Mellor (1987) ECOM model in that it uses a semi-implicit scheme for calculating the free surface, therefore avoiding the gravity wave CFL condition required by explicit schemes (eg Casulli, 1990). This has the advantage that larger time steps may be taken (on the order of minutes, rather than tens of seconds). A potential disadvantage of implicit schemes is that they more readily damp free wave motions, but in strongly forced and damped shallow regions such as Massachusetts Bay, the effect is small. This was determined by halving the time 
step and observing negligible differences in simulation results. Another disadvantage is that because the calculation of surface elevation requires solving a large matrix equation at each time step and efficient solution of this equation requires positive definiteness; boundary conditions for elevation must be formulated in matrix form and must not destroy the positive definiteness of the matrix. We use a combination of clamped and gravity wave radiation conditions on the open boundary, made possible by the implementation of the partially-clamped formulation of Blumberg and Kantha (1985) discussed in chapter 2.8 .

\subsection{Model Geometry and Bathymetry}

The model was configured on a $68 \times 68$ horizontal curvilinear orthogonal grid (Figure 2.1). The grid spacing ranges from approximately $600 \mathrm{~m}$ in Boston Harbor to about $6000 \mathrm{~m}$ along the open boundary with the Gulf of Maine. The grid spacing in the vicinity of the future outfall site is approximately $1000 \mathrm{~m}$. The grid extends well offshore of Massachusetts Bay to allow exchange with the Gulf of Maine inside the model domain, and extends far enough north to include the Merrimack River, a large source of fresh water to the region. Initially 10 evenly spaced sigma levels were used in the vertical dimension, but final runs utilized 2 additional near-surface layers at 1 and $4 \%$ of the water depth to better resolve river plumes and the surface mixed layer.

The bathymetry for the model was obtained by interpolating NOAA sounding data on to the model grid using an inverse distance method. The resulting grid was Shapiro filtered (Shapiro, 1975) to remove 2 grid length variability, and a maximum depth of $140 \mathrm{~m}$ was set to eliminate the deep complex topography offshore of Massachusetts Bay. The minimum depth was set to $3 \mathrm{~m}$ to avoid flooding and drying.

\subsection{Vertical MiXing}

The vertical mixing parameterization was the level 2.5 turbulence closure scheme of Mellor and Yamada (1982) with the extensions by Galperin et al (1988). An important feature of these extensions include a length-scale limitation that prevents the mixing length from becoming too large during strongly stratified conditions. The minimum "background mixing" value, below which the eddy viscosity never falls, was set to $5 \times 10^{-6} \mathrm{~m}^{2} \mathrm{~s}^{-1}$. This 


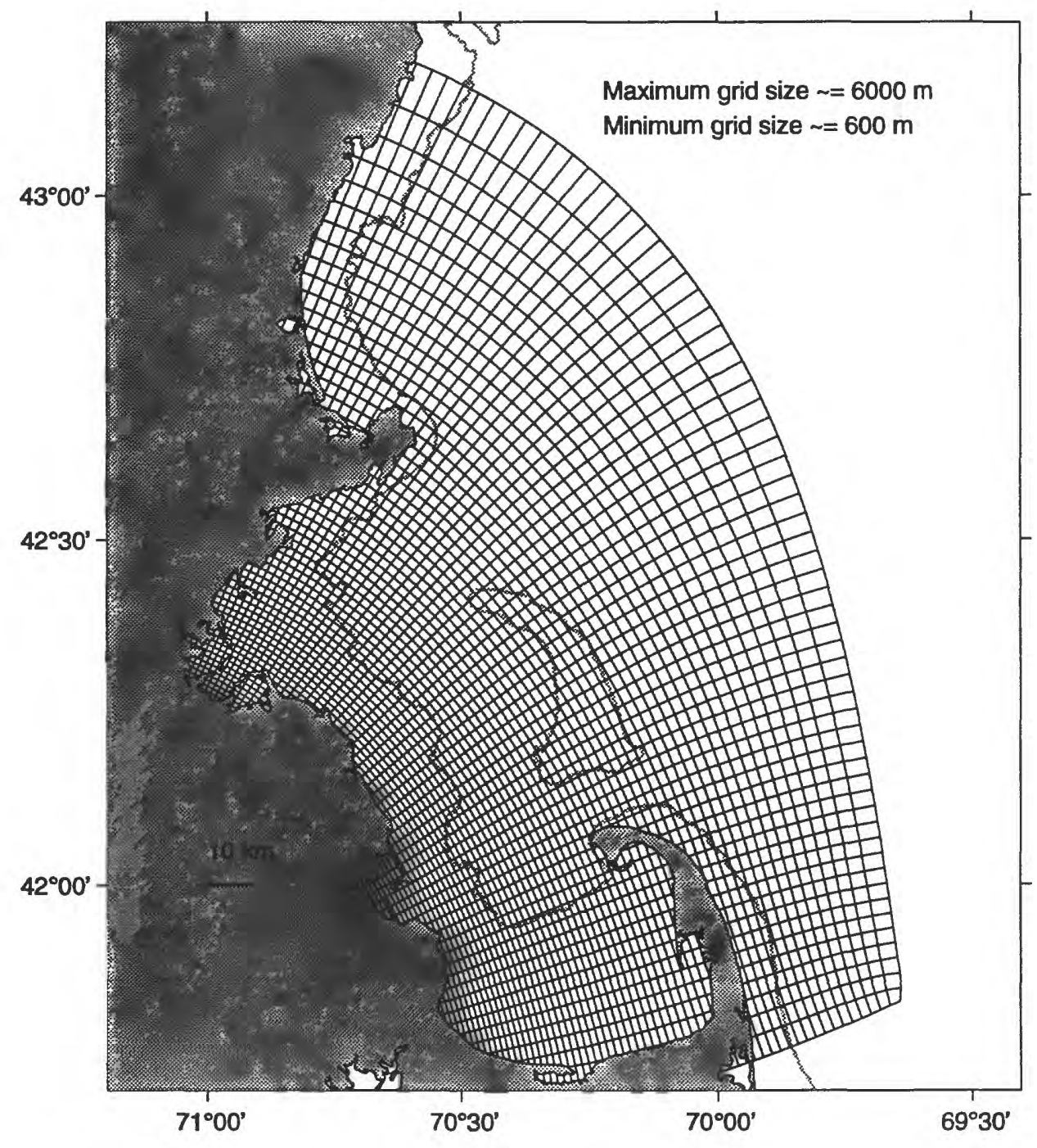

Figure 2.1: Model grid for the three-dimensional circulation model of Massachusetts and Cape Cod Bays. The curvilinear orthogonal grid allows the mesh resolution to vary spatially, having a minimum grid spacing of $600 \mathrm{~m}$ and a maximum spacing of $6000 \mathrm{~m}$. The grid spacing in the vicinity of the future outfall is roughly $1000 \mathrm{~m}$. The $40 \mathrm{~m}$ isobath is represented by the thick grey line. 
value is comparable to the value of vertical mixing observed by Geyer and Ledwell (1994) from a dye experiment near the future outfall site.

\subsection{Horizontal Mixing}

The horizontal mixing parameterization used the Smagorinsky (1963) formulation in which the magnitude of the horizontal mixing is proportional to horizontal current shear. For the water quality runs, the Smagorinsky coefficient was set to 0.1 , which results in typical horizontal eddy viscosities and diffusivities between $5-20 \mathrm{~m}^{2} \mathrm{~s}^{-1}$ over much of Massachusetts Bay. Ideally, the magnitude of this mixing would represent processes occurring at scales smaller than the mesh can resolve. In western Massachusetts Bay the grid cell spacing is $1-2 \mathrm{~km}$, and using the rule of thumb that $6-8$ grid cells motions are the minimum length that are realistically represented, the model should well resolve mixing processes occurring at scales of $10 \mathrm{~km}$ or so. From Okubo (1971), we expect that observed horizontal mixing at a scale of $10 \mathrm{~km}$ should be about $10 \mathrm{~m}^{2} \mathrm{~s}^{-1}$, and at a scale of $1 \mathrm{~km}$ should be about $1 \mathrm{~m}^{2} \mathrm{~s}^{-1}$. Since the model partially resolves shear (and thus produces mixing) at scales between 1 and $10 \mathrm{~km}$, the ideal mixing level should probably be somewhere between 1 and $10 \mathrm{~m}^{2} \mathrm{~s}^{-1}$. To test the sensitivity to the mixing level in this range, the model was subsequently rerun for a 3 month period using a Smagorinsky coefficient of 0.02 (five times smaller than the water quality run), and only small quantitative differences were observed in the resulting velocity, temperature, salinity and effluent concentration fields. This indicates that the modeled fields are dominated by resolved mixing and transport processes rather than the parameterized mixing of the Smagorinsky formulation. This is consistent with observations made during the outfall siting process, where it was concluded that a value of $45 \mathrm{~m}^{2} \mathrm{~s}^{-1}$ best represented the dispersion of material over the $20 \mathrm{~km}$ scale of western Massachusetts Bay (Adams et al, 1990), suggesting that the effective mixing in this region may be a bit higher than Okubo's empirical curve. This would not be surprising considering the strong current shears in this region. The level of $45 \mathrm{~m}^{2} \mathrm{~s}^{-1}$ was also used in the outfall siting model studies described by Walton et al (1990).

In addition to the specified horizontal viscosity, the velocity field was Shapiro filtered every 2 hours to remove 2 grid length energy. This was necessary to prevent 2 grid length energy along the open boundary from growing large enough to violate the advective CFL condition. By applying a 
4th order Shapiro filter at 2 hour intervals, the longer wavelength energy is largely unaffected. For example, it can be shown over 20 filter applications (two days of simulation), the amplitude of 6 grid length structure is reduced less than 5\% (see appendix of Signell, 1989).

\subsection{Surface ANd Bottom Stress}

The surface wind stress was assumed to be uniform over the model domain and was determined from wind measurements at the Boston Buoy (Station BB in Figure 2.2) using the Large and Pond (1981) formulation.

Although the scale of the bay is relatively small compared to most synoptic scale wind features, there is certainly some variability over the bay, caused in part by local effects such as the seabreeze. Some of the discrepancies between model and data, especially during the summer, are undoubtably the result of the idealized wind stress field. Observations were available at 1 hourly intervals from the Boston Buoy (anemometer height $13.6 \mathrm{~m}$ ) except for the period 8/31/90 - 10/4/90, when wind data from Logan Airport was used instead. A comparison between Boston Buoy and Logan Airport winds (Figure 2.1-1, Geyer et al, 1992) suggests that the winds are comparable during this time period, although the wind at Boston Buoy is weaker during the summer and stronger during the winter than winds at Logan. The hourly averaged winds were converted to wind stress, then averaged over 4 hourly intervals before input to the model to reduce the size of the input file.

The bottom stress is determined from the quadratic drag law applied at the point closest to the bed where there is a velocity estimate. This is the middle of the lowest grid cell. Because the distance between the the lowest velocity point and the bed varies with location, the bottom roughness length $z_{o}$ is specified at each location, and then a constant stress layer is assumed so that an effective drag coefficient can be computed at the velocity point. For this study, $z_{o}$ was assumed to be uniform throughout the domain with a value of $0.003 \mathrm{~m}$, which is equivalent to a drag coefficient of $2.5 \times 10^{-3}$ at $10 \mathrm{~m}$ above the bottom (which is in turn a typical value used for depth-averaged models of coastal seas). In these runs, the bottom sigma layer thickness is $10 \%$ of the water depth, so the lowest velocity point is $5 \%$ of the water depth above the bed. Within Massachusetts Bay, the maximum distance between the lowest velocity point and the bed is $4.8 \mathrm{~m}$ in Stellwagen Basin, where the model water depth reaches $96 \mathrm{~m}$. 


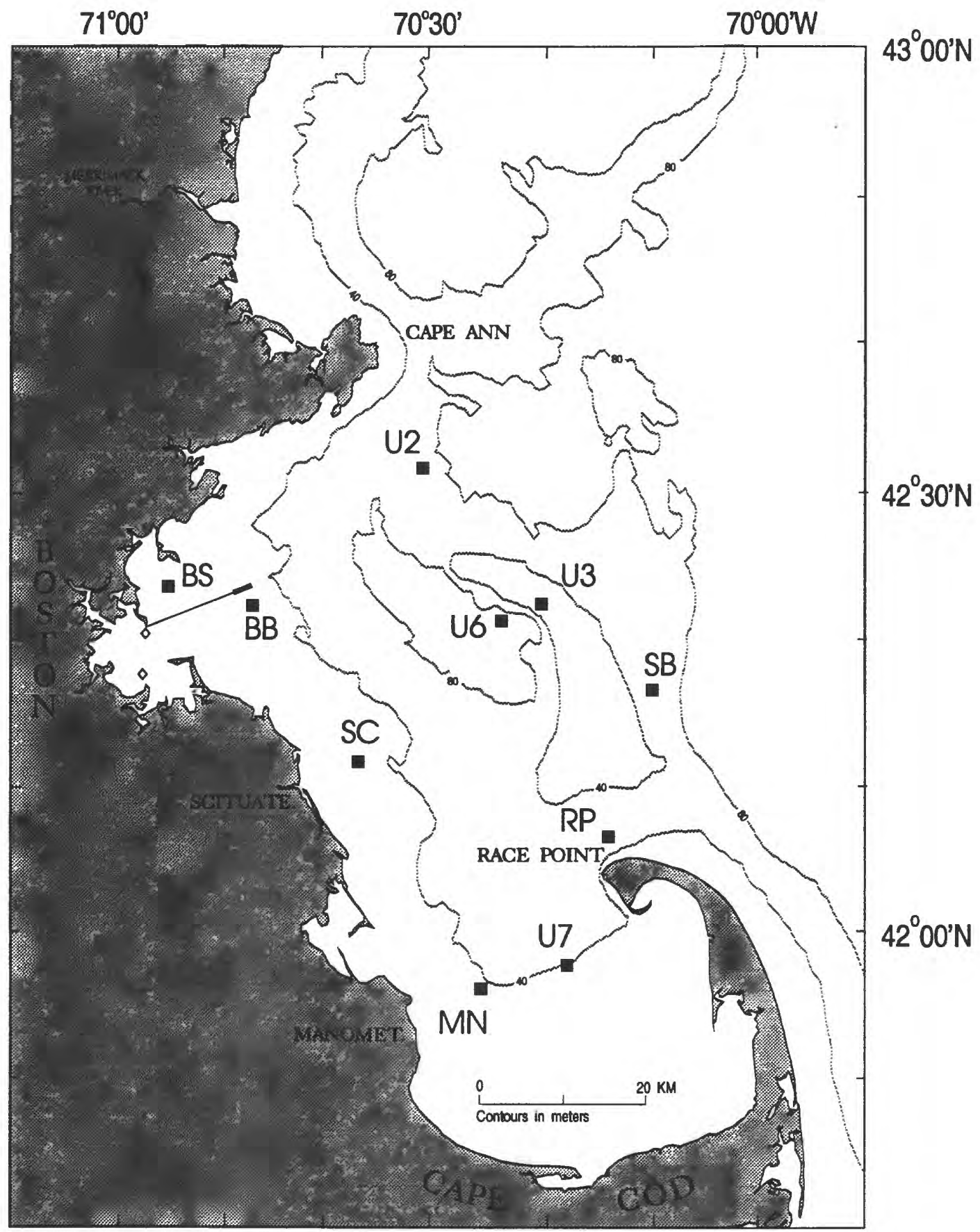

Figure 2.2: Data collection sites in Massachusetts Bay. Time series of currents, salinity, and temperature were collected at the 10 locations indicated. Meteorlogical information was obtained from the Boston Buoy, Station BB. 
Surface Meteorological Boundary Conditions
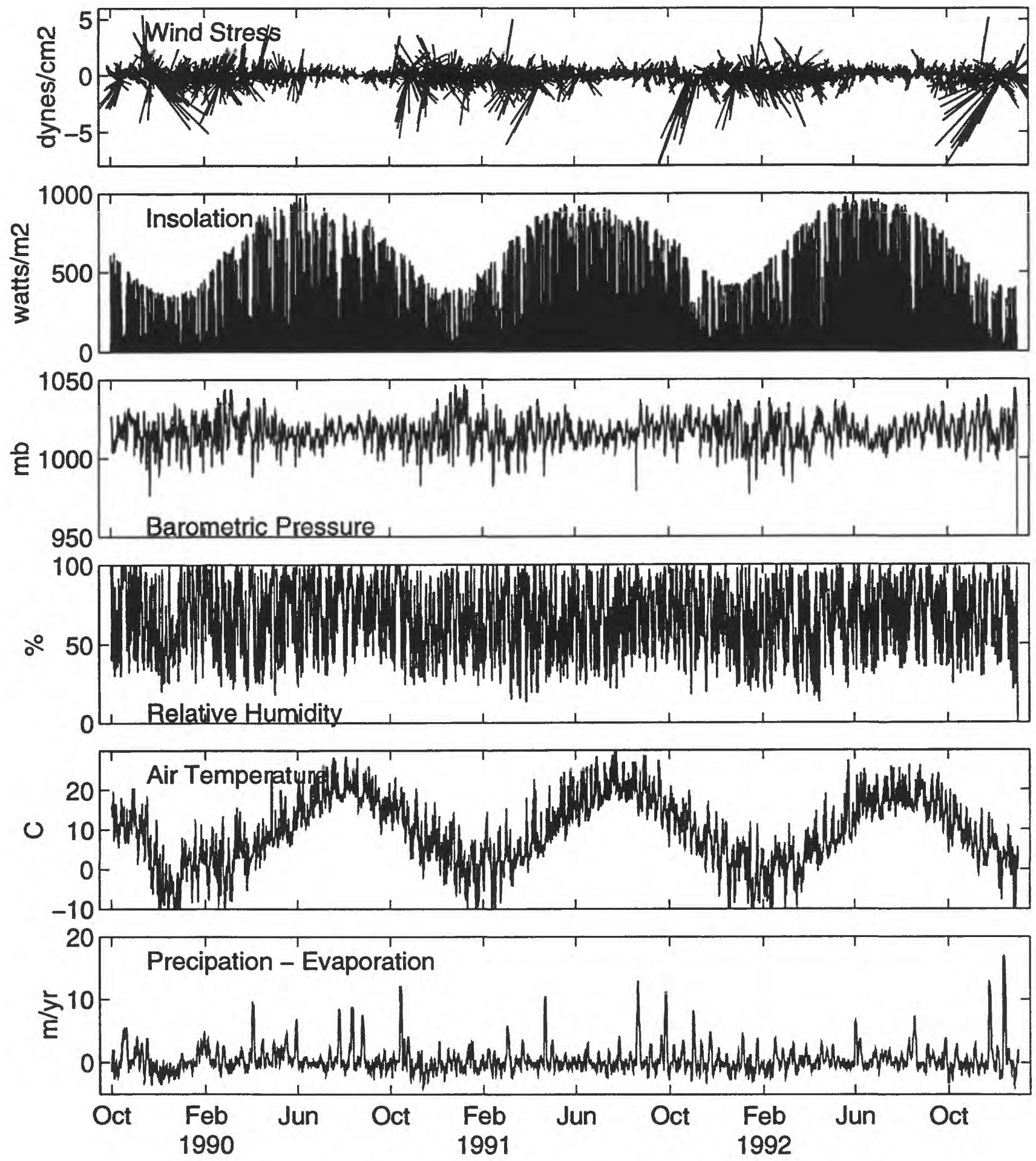

Figure 2.3: Meteorological data used to specify wind stress, buoyancy flux and heat flux boundary conditions at the sea surface. 


\subsection{Surface Heat Flux}

The surface heat flux was calculated using techniques described by Weller et al (1995), and the flux was introduced into the top sigma layer at each grid location. These techniques produce bulk estimates of latent, sensible and longwave radiation, given sea surface temperature, air temperature, insolation, relative humidity, barometric pressure and wind. The limited availability of these data led us to use air temperature, barometric pressure and wind data at the Boston Buoy, relative humidity at Logan Airport and insolation at Woods Hole to represent bay-wide conditions (Figure 2.3). The sea surface temperature used in the heat flux estimates was initially determined from observations at the Boston Buoy. This proved problematic, because Cape Cod Bay is significantly warmer than the Boston Buoy site during most of the summer, which should result in reduced heat flux (all else being equal), but there was no feedback mechanism to allow this. The result was that model temperatures in Cape Cod Bay became too warm. To address this problem, later runs used model-generated sea surface temperature fields to calculate surface heat flux. Using the modeled sea surface temperature field allows spatial variability in sea-surface temperatures to feed back into the heat flux routines. Under upwelling conditions, for example, there can be $10^{\circ}$ or more difference between surface water temperatures in the Bay, which can in turn result in heat flux differences of $200 \mathrm{~W} \mathrm{~m}^{-2}$ or more. Allowing for spatial differences in the surface heat flux due to varying water temperatures led to a significantly improved correspondence between modeled and observed water temperatures in Cape Cod Bay. Hourly estimates of heat flux obtained from the bulk formulae were averaged over 4 hours to reduce the size of the model input file.

\subsection{FRESHWATER INPUT}

Fresh water was introduced directly into the model at grid cell locations representing the mouths of the Merrimack, Charles, Neponset and Mystic rivers as well as at the existing sewage effluent discharges at Nut and Deer Islands. In addition, input from the Penobscot, Androscoggin, Kennebec, and Saco Rivers were used to drive an adjunct model of the western Gulf of Maine that was used to help improve salinity open boundary conditions for the Massachusetts Bay model described here. (The western Gulf of Maine adjunct model is described in the open boundary condition chapter 2.9.) 


\begin{tabular}{lrrrr} 
& $\begin{array}{r}\text { Discharge } \\
\left(\mathrm{m}^{3} \mathrm{~s}^{-1}\right)\end{array}$ & Agency & Location & $\begin{array}{r}\text { Scale } \\
\text { Factor }\end{array}$ \\
\hline Merrimack & 321.8 & USGS & Lowell, MA & 1.08 \\
Charles & 15.2 & USGS & Waltham, MA & 1.37 \\
Deer Island & 11.8 & MWRA & Deer Island & 1.00 \\
Nut Island & 6.0 & MWRA & Nut Island & 1.00 \\
Neponset & 6.5 & - & Inferred from Charles & 1.00 \\
Mystic & 3.0 & - & Inferred from Charles & 1.00 \\
Penobscot & 548.5 & USGS & Eddington, ME & 1.10 \\
Andro/Kenn & 611.6 & USGS & N. Sidney/Aubern, ME & 1.15 \\
Saco & 119.2 & USGS & Cornish, ME & 1.31
\end{tabular}

Table 2.1: Average freshwater inputs for the model during 1990. The scale factor is the amount that the gauged discharge was multiplied by to account for drainage area downstream of the gauge.

To indicate the relative importance of these sources, the mean flow during 1990 is shown in Table 2.1 and indicates that the Penobscot, Androscoggin/Kennebec and Merrimack River systems dominate the freshwater input to this region. The Androscoggin and Kennebec Rivers are combined because they merge before discharge into the Gulf of Maine. The daily flows from the Neponset and Mystic Rivers were inferred by multiplying the daily flow from the Charles River by 0.431 and 0.195 respectively, factors determined by the ratio of the annual average.

Examination of the daily discharge over the three year simulation period shows that although the maximum discharge occurs during the spring of each year, there are secondary maxima in the fall (Figure 2.4). Fall 1990 in particular has unusually high discharge, almost as large as the preceding and following spring discharges.

\subsection{OPEN BOUNDARY CONDITIONS}

Open boundary conditions are required for elevation, temperature, salinity and tracer concentration (used here to represent effluent). Because the elevation field at each time step is solved for with a fully implicit scheme, the boundary condition must be specified as part of the matrix solution for the 
Freshwater Input
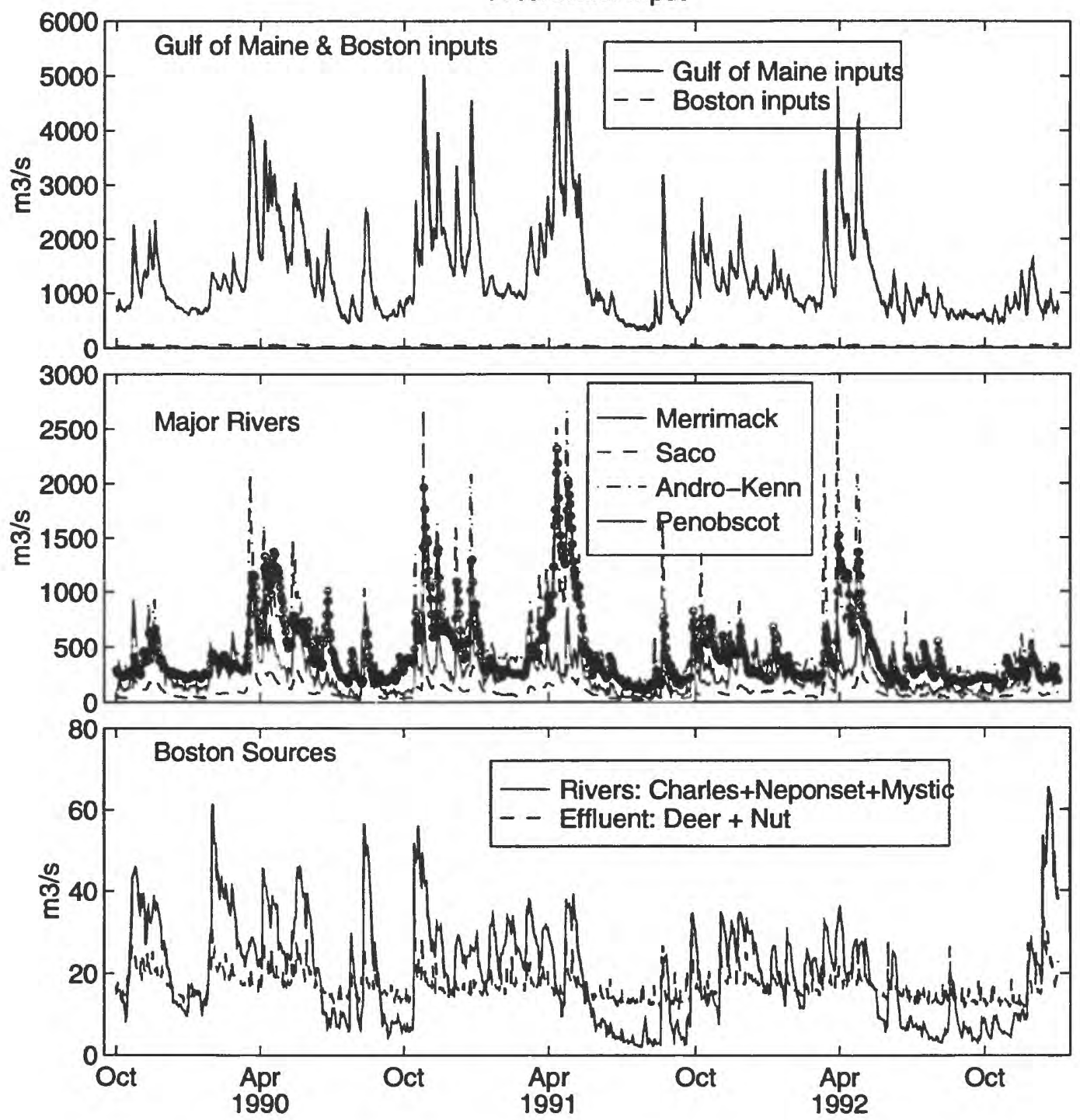

Figure 2.4: Freshwater input to the Western Gulf of Maine. The top panel shows the combined discharge due to the Kennebec, Androscoggin, Penobscot and Merrimack Rivers compared to the Boston discharge. The middle panel shows the individual contributions of the major rivers, and the lower panel show the relative contributions of rivers and effluent to discharge in Boston Harbor. 
elevation field. In addition, the matrix solver used in this code requires the matrix to be symmetric and positive definite, which puts further restraints on the type of boundary condition imposed. The partially clamped boundary condition of Blumberg and Kantha (1985) can be shown to satify these conditions, and is expressed as

$$
\frac{\partial \eta}{\partial t}+\sqrt{g D} \frac{\partial \eta}{\partial x}=\frac{\eta-\eta_{\text {data }}}{T_{\text {lag }}}
$$

where $\eta_{\text {data }}$ is specified from data. If $T_{\text {lag }}$ is very large a pure radiation condition is approached, and if $T_{\text {lag }}$ is very small a purely clamped (specified) condition is approached. In the Massachusetts Bay model, the offshore boundary elevation was clamped while the southern boundary radiated gravity waves. The values for elevation used along the offshore boundary were a combination of $M_{2}, N_{2}$, and $S_{2}$ tidal elevations derived from the tidal model of Lynch and Naimie (1993) and low-frequency fluctuations obtained from the adjunct Gulf of Maine model described in chapter 2.9. The $M_{2}$ tidal elevations obtained from Lynch (personal communication, 1993) were used to synthesize $S_{2}$ and $N_{2}$ constituents by scaling the $M_{2}$ amplitudes by the observed $S_{2} / M_{2}$ and $N_{2} / M_{2}$ ratios at the Boston Buoy and shifting the $S_{2}$ and $N_{2}$ phases by the amount observed at the Boston Buoy. This is a reasonable approximation since the $M_{2}, S_{2}$ and $N_{2}$ amplitude and phase vary in much the same manner in the Gulf of Maine (e.g. Moody et al, 1984).

Temperature, salinity and effluent are also specified along the open boundaries. If the flow is directed out of the domain, the interior values are simply advected out of the domain. When outflow turns to inflow, the water property values slowly move toward specified values over a defined relaxation time to avoid artificial fronts from developing. In the Massachusetts Bay model, the relaxation time was specified to vary linearly from 3 days at the most northern boundary cell to 30 days at the southern boundary cell.

Initially the temperature and salinity values along the boundary were specified by climatology interpolated from the Bedford Institute of Oceanography AFAP database (Drinkwater, 1992), while the effluent concentration field was set to zero. Although it was hoped that most local river effects would be due to the Merrimack and the Charles, early runs showed that the gross salinity picture for Massachusetts Bay could not be adequately specified by parameterizing the other Gulf of Maine rivers by seasonal climatology. To 
address this problem, an adjunct model of the western Gulf of Maine was developed to provide better salinity boundary conditions for the Massachusetts Bay model.

\subsection{Adjunct Western Gulf of Maine Model}

The western Gulf of Maine model grid is $90 \times 45$ cells and has a typical grid spacing of $2-4 \mathrm{~km}$ (Figure 2.5). The bathymetry was generated in identical fashion to the Massachusetts Bay model and the model was driven by the same wind and heat flux forcing. The elevation boundary conditions were specified as $M_{2}, S_{2}$ and $N_{2}$ tides derived from Lynch and Naimie (1993). There were no subtidal fluctuations specified, so the low-frequency elevation was effectively clamped at zero along the offshore boundary. At the northern boundary, a mean sea surface slope is imposed to drive a coastal current. Along this boundary the low-frequency elevation varied linearly from 0.06 $\mathrm{m}$ at the coast to $0.00 \mathrm{~m}$ at the open boundary $45 \mathrm{~km}$ offshore. This was picked to drive a mean alongshore flow of $5-10 \mathrm{~cm} \mathrm{~s}^{-1}$ at locations where mean currents were observed by Vermersch et al (1979). The mean flow in the Gulf of Maine model is held constant throughout the year. Recent data collected on the eastern flank of Stellwagen Bank at a location determined to be a good measure of the large-scale circulation in the Gulf of Maine (Bogden et al, 1995) suggests, encouragingly, that there might be little variability in the seasonal mean flow. A comparison of the mean flow observed in spring, summer and fall of 1994 at the Stellwagen Bank mooring with seasonallyaveraged mean flow obtained from the model at this location over 1990-1992 shows remarkable agreement (Figure 2.6). Outside of the buoyant surface layer, the observed mean flow due to large scale circulation in the Gulf of Maine changes very little with season (Table 2.2). The mean flow at $27 \mathrm{~m}$, for example, appears to be about $10 \mathrm{~cm} \mathrm{~s}^{-1}$ throughout the year, and the mean flow at $50 \mathrm{~m}$ is nearly constant at $4 \mathrm{~cm} \mathrm{~s}^{-1}$.

The temperature and salinity along the open boundary were specified by monthly climatology determined from the Bedford Institute of Oceanography AFAP database. Model output averaged over the tidal cycle was output along the cells that constituted the open boundary for the Massachusetts Bay model, the converted into low-frequency elevation boundary conditions and temperature and salinity boundary conditions at standard levels $(1,2.5$, $5.0,7.5,10,15,20,30,40,50,75$ and $140 \mathrm{~m})$. The resulting boundary 


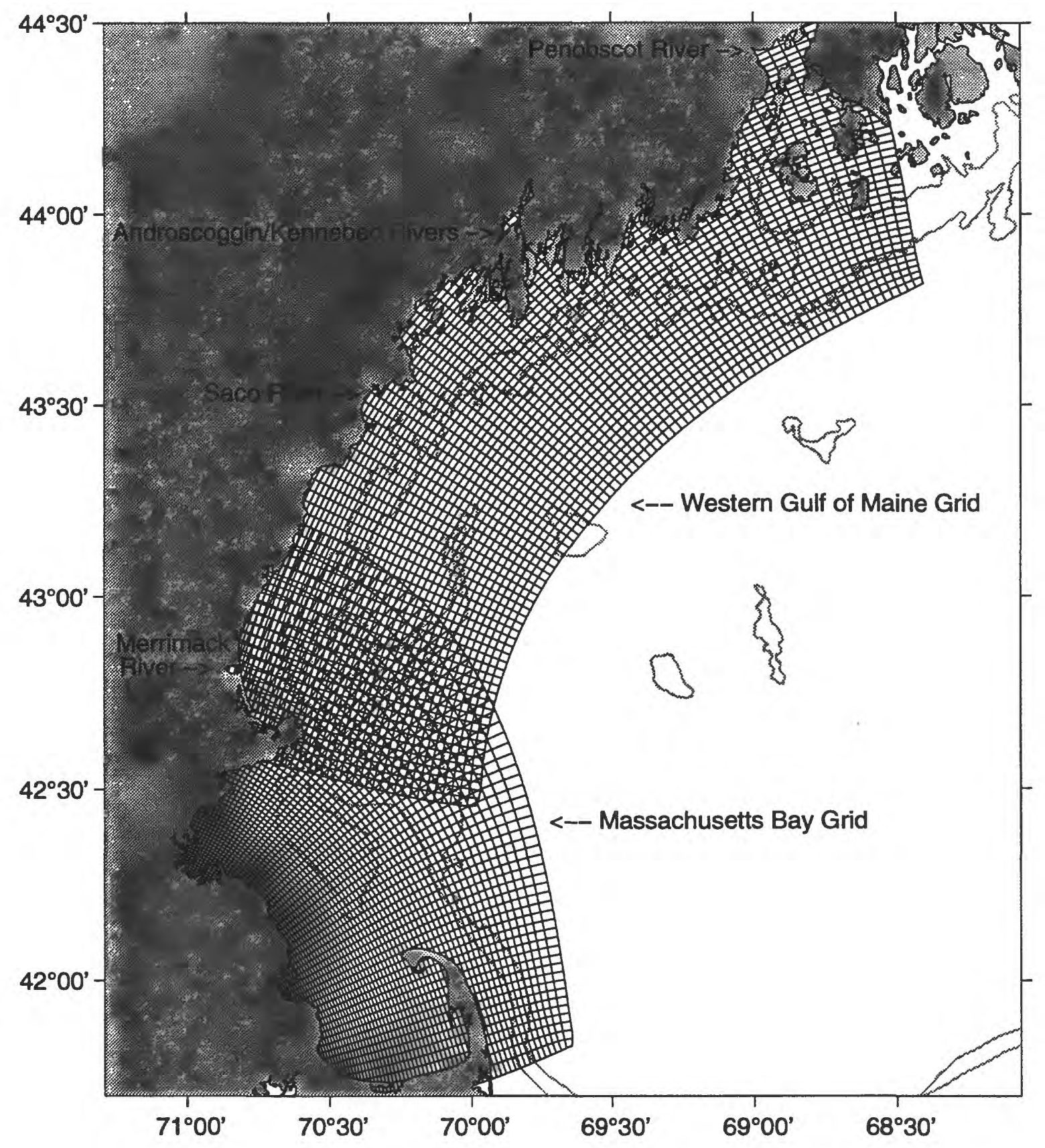

Figure 2.5: Western Gulf of Maine grid, showing major rivers. Grid spacing is $2-4 \mathrm{~km}$. The isobaths shown are 60,100 and $200 \mathrm{~m}$. 


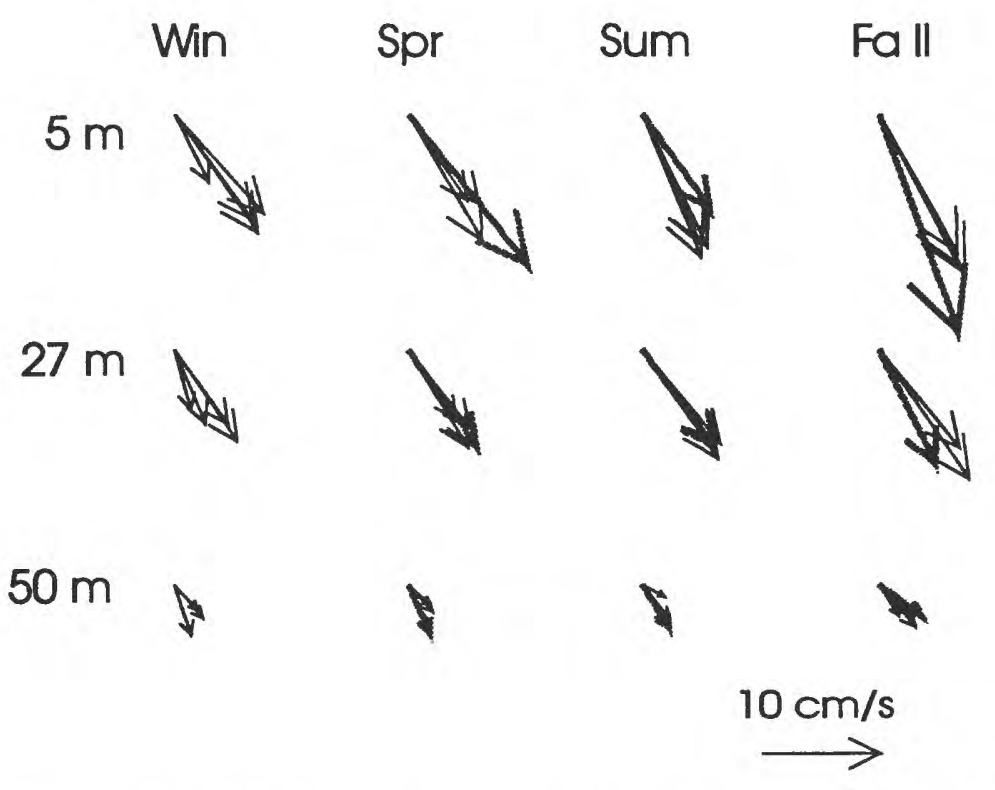

Figure 2.6: Model/data comparison of mean flow on the east flank of Stellwagen Bank. The thick grey arrows are observed means from 1994, while the thin black arrows are modeled means from 1990, 1991 and 1992. The flow at this location is strongly controlled by large-scale circulation in the Gulf of Maine that is parameterized in the model through the open boundary conditions.

\begin{tabular}{|l||rrr|rrr|}
\hline \multicolumn{1}{|c||}{} & \multicolumn{3}{c|}{$\begin{array}{c}\text { MODEL (1990-1992) } \\
\mathrm{cm} \mathrm{s}^{-1}\end{array}$} & \multicolumn{3}{c|}{$\begin{array}{c}\text { DATA (1994) } \\
\mathrm{cm} \mathrm{s}^{-1}\end{array}$} \\
\hline & $5 \mathrm{~m}$ & $27 \mathrm{~m}$ & $50 \mathrm{~m}$ & $5 \mathrm{~m}$ & $27 \mathrm{~m}$ & $50 \mathrm{~m}$ \\
\hline Winter & 10.1 & 7.2 & 3.3 & nd & nd & nd \\
Spring & 10.2 & 8.4 & 2.6 & 16.1 & 10.0 & 4.3 \\
Summer & 12.5 & 10.4 & 3.1 & 9.7 & 10.2 & 4.1 \\
Fall & 14.3 & 11.6 & 3.7 & 19.5 & 10.8 & 4.3 \\
\hline
\end{tabular}

Table 2.2: Modeled and observed mean flow speed on the eastern flank of Stellwagen Bank at 5, 27 and $50 \mathrm{~m}$ depths. Below the river plume influenced surface layer, the mean flow at $27 \mathrm{~m}$ is relatively constant at $10 \mathrm{~cm} \mathrm{~s}^{-1}$. 
conditions for Massachusetts Bay, as intended, represent more variability and Gulf of Maine discharge-driven events than would have been possible with open boundary conditions based on climatology (Figures 2.7, 2.8).

Inter-annual variability at frequencies less than the synoptic scale weather band (3-10 days) is not dramatic, although certain events stand out, such as the sustained decrease in surface salinities near the coast during the fall of 1990 , consistent with the abnormally large runoff during this time period.

\subsection{BOUNDARY CONDITION MODIFICATIONS FOR 1992 RUN}

Although the temperature and salinity boundary conditions obtained from the climatology and the western Gulf of Maine adjunct model result in a quite realistic representation of the observed temperature and salinity structure in Massachusetts Bay, actual data obtained near the boundary during the simulation time period can further improve the representation. To improve the 1992 water quality "verification run", several sets of CTD data were obtained from the National Marine Fisheries Service (Holzwarth-Davis and Taylor, 1993) and used to make very low-frequency (weeks to months) corrections to the temperature and salinity conditions.

\subsection{TIME STEP}

To achieve optimal efficiency for these multi-year runs, the time step was varied with season and forcing conditions as determined by trial and error. Although ECOM-si is not restricted by the gravity wave CFL condition, it is limited by the advective CFL condition. During the spring and summer months in particular, the time step needed to be decreased. During the winter, the time step was usually $414 \mathrm{~s}$ (108 steps per $M_{2}$ tidal cycle), except for a few short periods generally coinciding with winter storms. During the summer, the time step was usually $207 \mathrm{~s}$ (216 steps per $M_{2}$ tidal cycle).

\subsection{Sigma-Coordinate Correction}

In regions of steep topography, sigma-coordinate models are prone to errors in the calculation of pressure gradient and horizontal diffusion terms (Beckman and Haidvogel, 1993). In the modeling here, initial stratification results were not encouraging in that the modeled temperature stratification during the summer was $50 \%$ weaker than observed at the future outfall site (Figure 2.9) and in Stellwagen Basin. Although vertical mixing was initially 

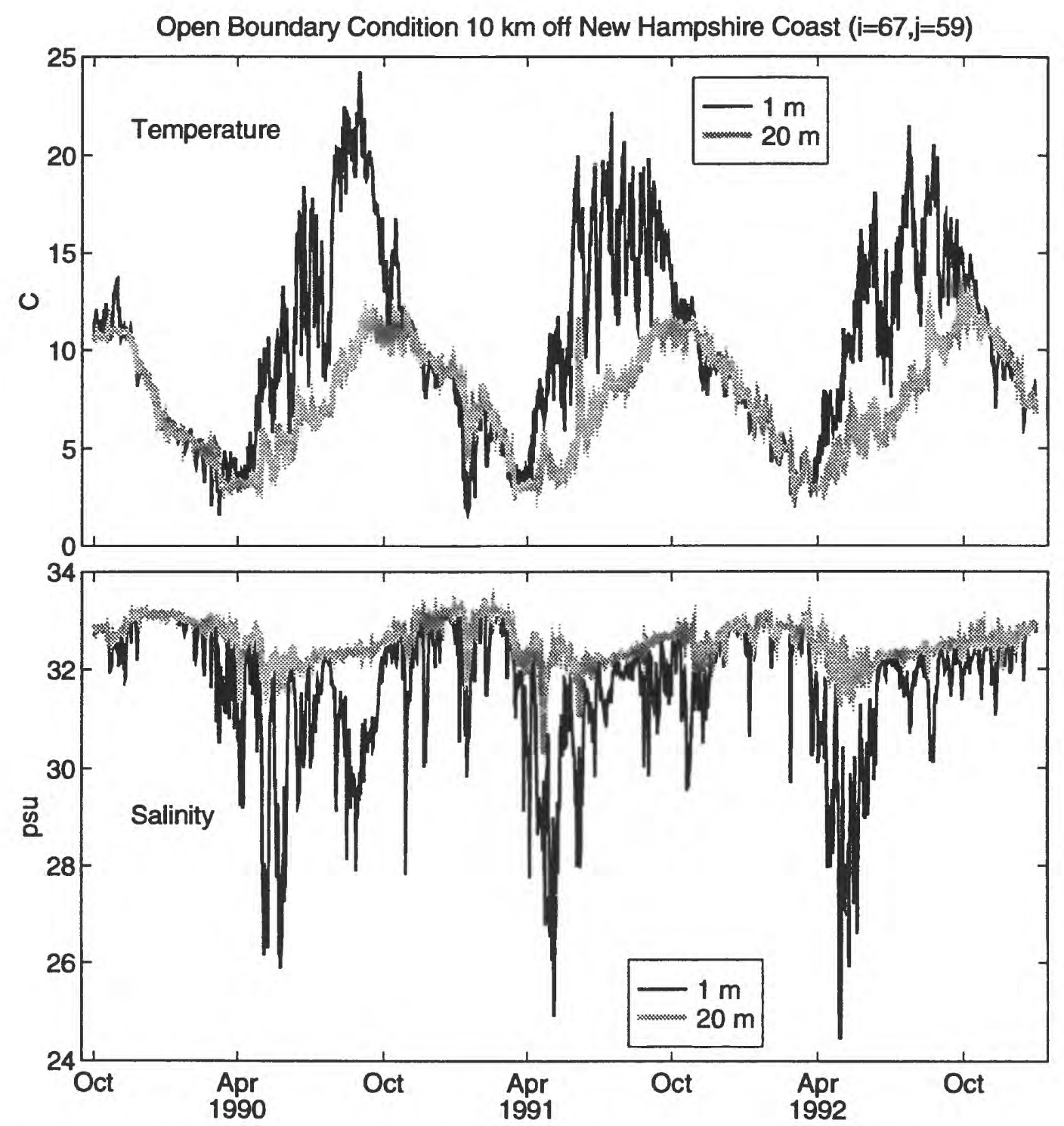

Figure 2.7: Inshore Massachusetts Bay boundary condition from WGOM model. 


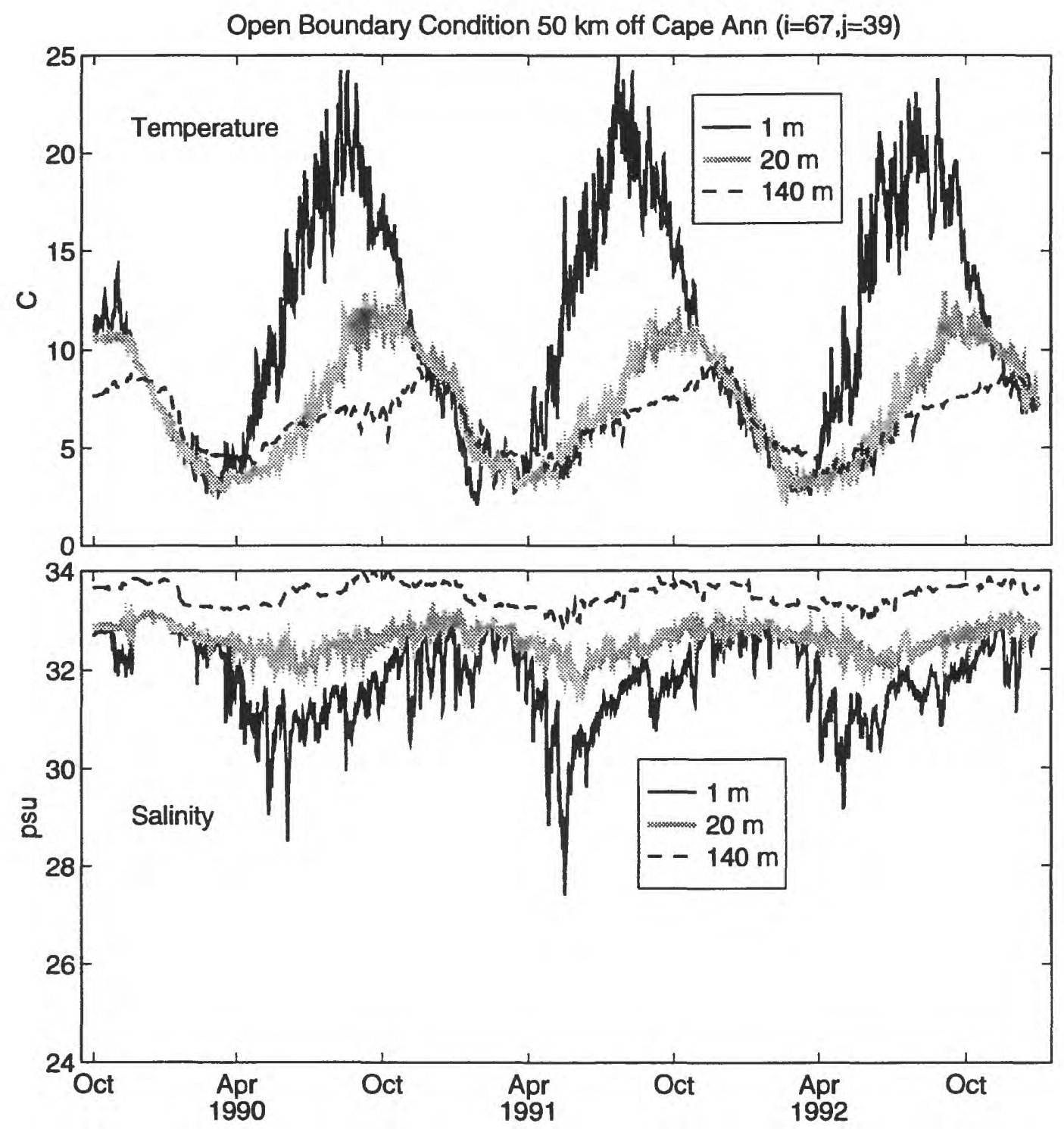

Figure 2.8: Offshore Massachusetts Bay boundary condition from WGOM model. 


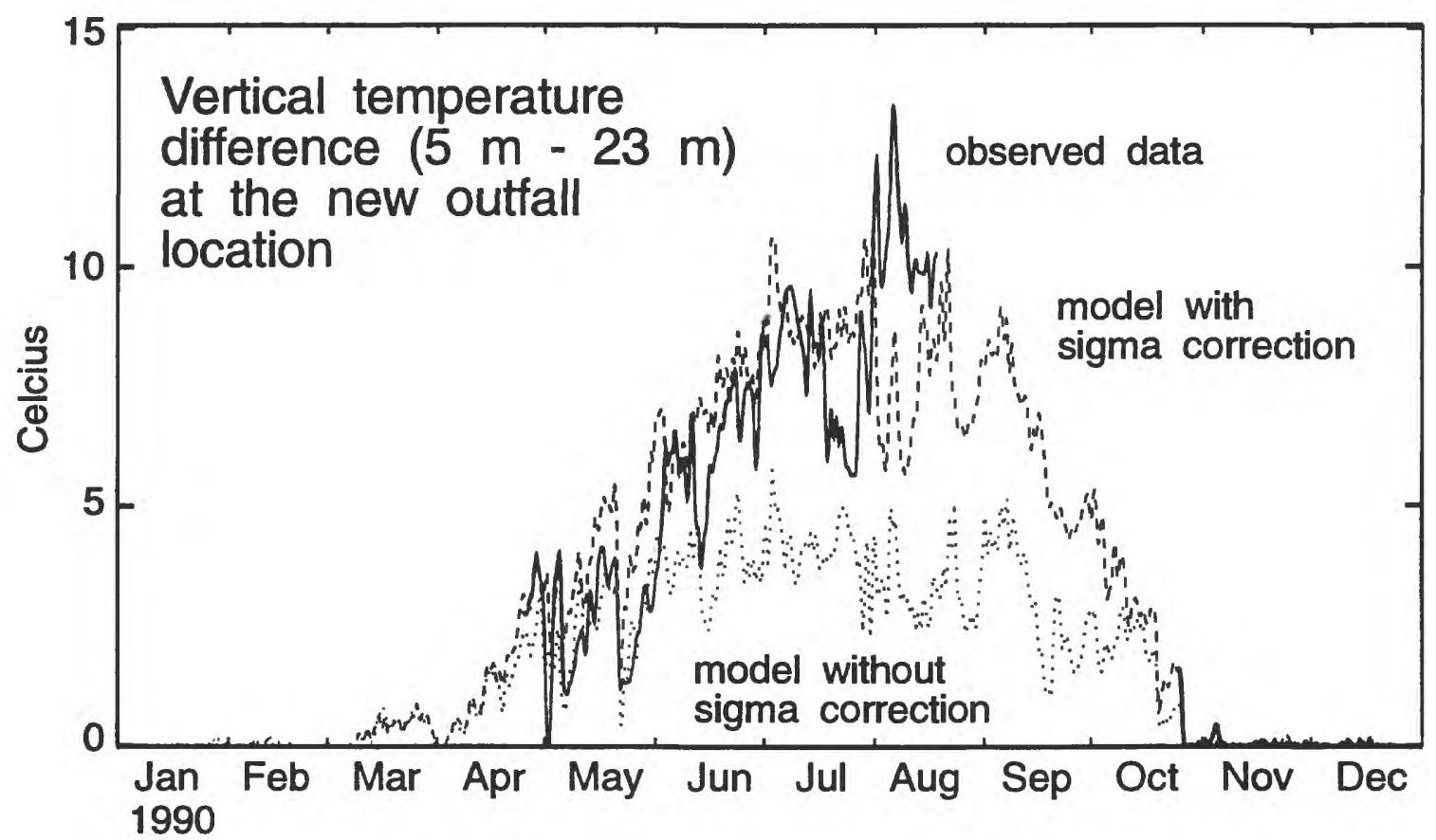

Figure 2.9: Observed and modeled temperature difference $(5 \mathrm{~m}-23 \mathrm{~m})$ at Station BB (see Figure 2.2). Before the $\sigma$ correction, the model greatly underpredicted the degree of temperature stratification in the summer months. Observed data is missing from late August to November. 
suspected, the problem turned out to be caused by spurious up-slope mixing caused by $\sigma$-coordinate errors. These errors were significantly reduced by removing the domain-averaged vertical salinity, temperature, and density profiles before calculating horizontal differences (e.g. Beckmann and Haidvogel, 1993). The effectiveness of this technique depends upon the degree to which the vertical structure varies over the domain. In domains such as Massachusetts Bay, in which the stratification is nearly uniform over the region, this technique greatly improves the model prediction in comparison to observed data (Figure 2.9). The more the vertical structure varies over the domain, however, the less useful the technique in reducing $\sigma$-coordinate errors. In domains where both stratified and well-mixed regions exist, errors would actually increase in the well-mixed region since subtracting the domain-averaged vertical profile would result in more vertical structure locally. 


\section{Chapter 3}

\section{Model/Data Comparison}

\subsection{Temperature, Salinity and Density}

The comparison between modeled and observed temperature, salinity and density at most sites shows that the model generally does a good job at reproducing seasonal cycles and top to bottom density differences (Figures 3.13.8). There are some clear differences however. While most of surface salinity variations during the spring and summer are well represented (Figure 3.1), the salinity drop associated with the large fall 1990 discharge appears in the model about three weeks too late, and during spring of 1991 the surface salinities in the model are $0.5-1.0$ psu too salty. The lower layer salinities (Figures 3.2 and 3.3) during this time period are also 0.5-1.0 psu too salty, so the vertical density structure is minimally affected. It does suggest, however, that if a better match of the salinity magnitude was desired it would be necessary to improve upon the climatological salinity boundary conditions for the western Gulf of Maine model. These boundary conditions specified a fixed seasonal cycle, assuming that all interannual variability was due to local river discharge in the western Gulf of Maine. It is reasonable to expect that interannual variability in discharge from the St. Lawrence river and variations in the Gulf of Maine circulation would also be responsible for interannual salinity fluctuations in the water entering Massachusetts Bay.

The modeled temperatures and salinities appear to track some of the observed shorter period fluctuations in addition to the general seasonal cycle. The coherence between modeled and observed water properties is generally significant at $95 \%$ confidence over periods of 2-20 days (Figures 3.9 and 3.10). 

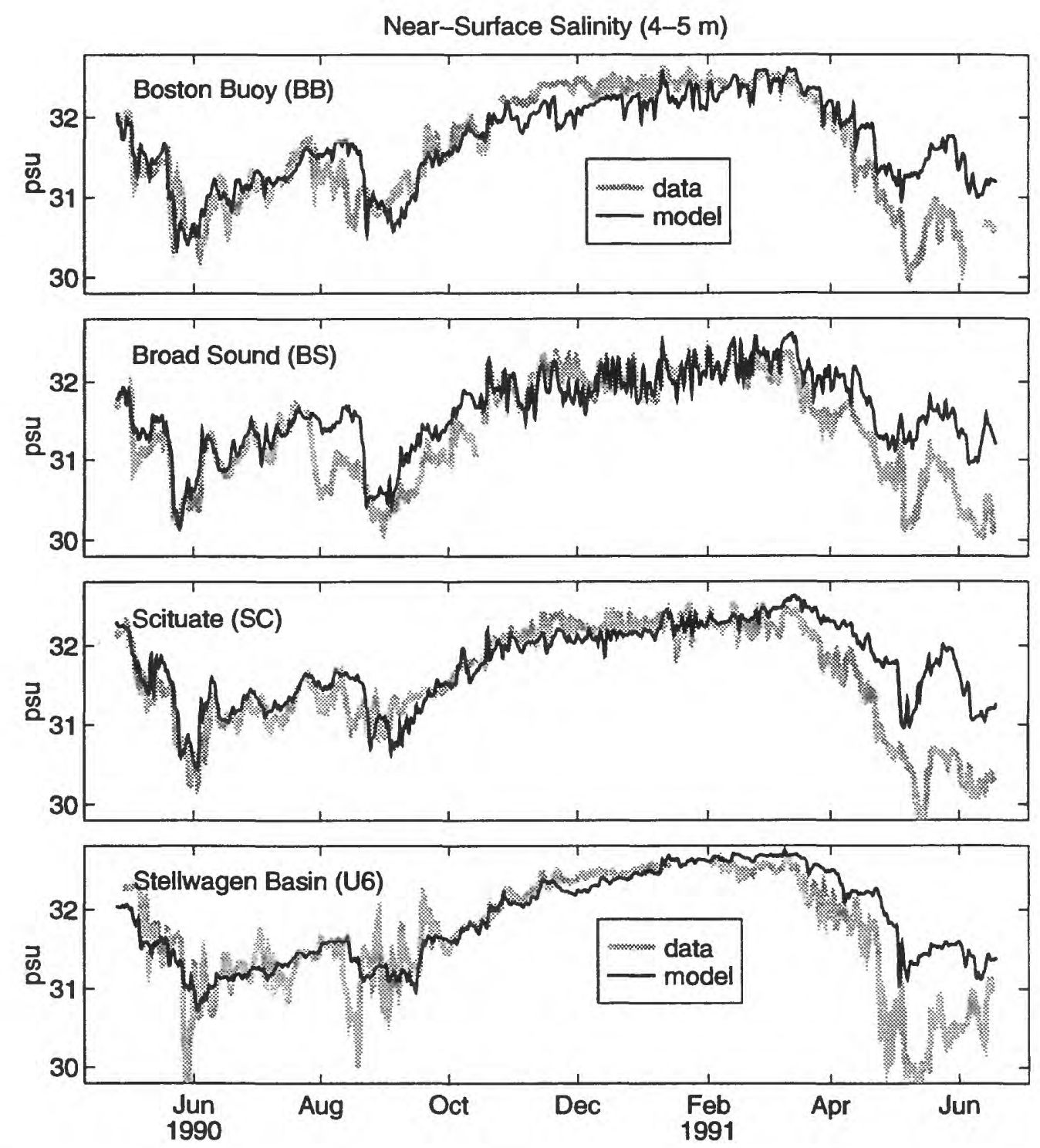

Figure 3.1: Model/data comparison of near-surface salinity at Stations BB, $\mathrm{BS}, \mathrm{SC}$ and U6. 

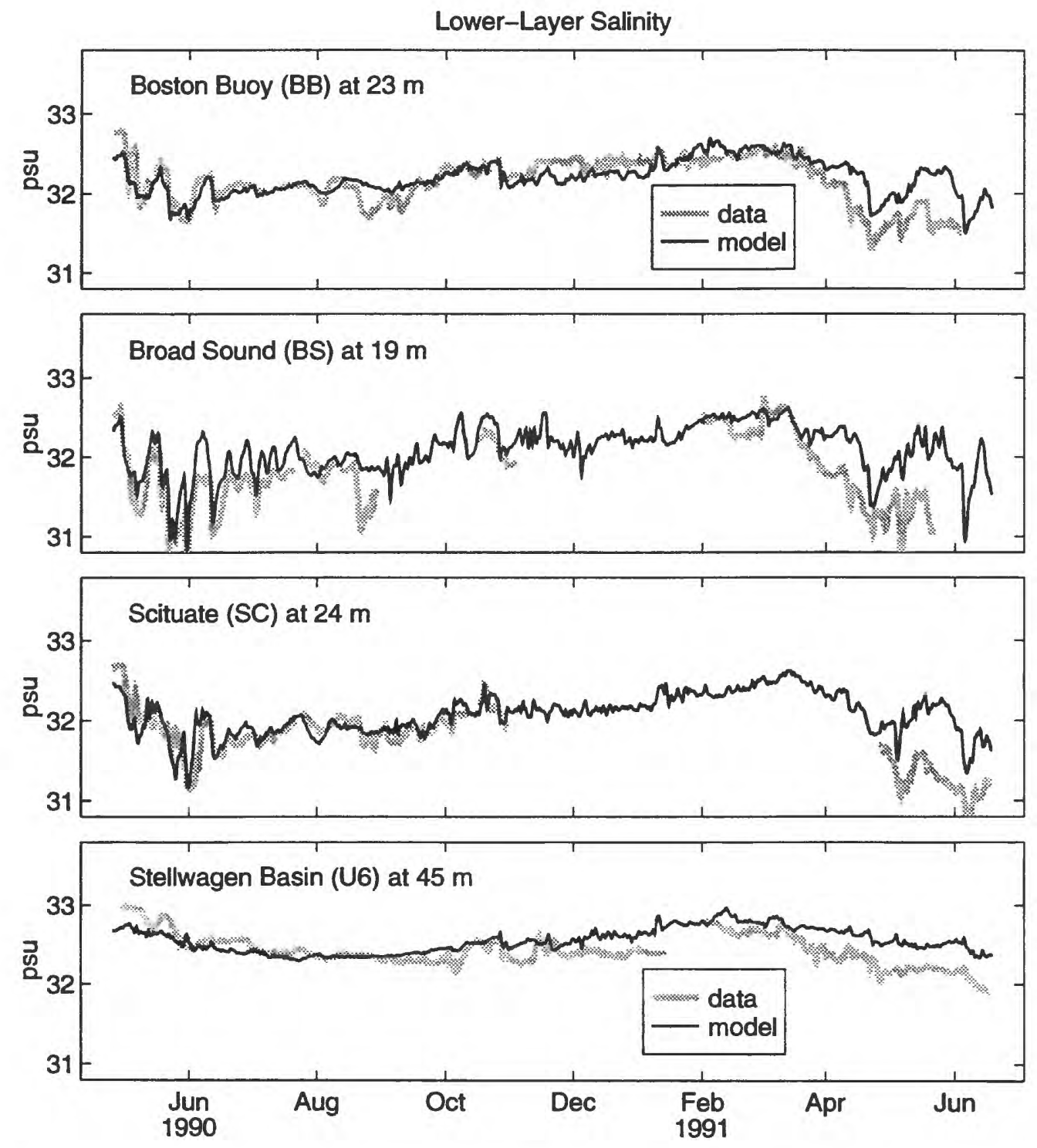

Figure 3.2: Model/data comparison of lower layer salinity at stations BB, $\mathrm{BS}, \mathrm{SC}$ and U6. 

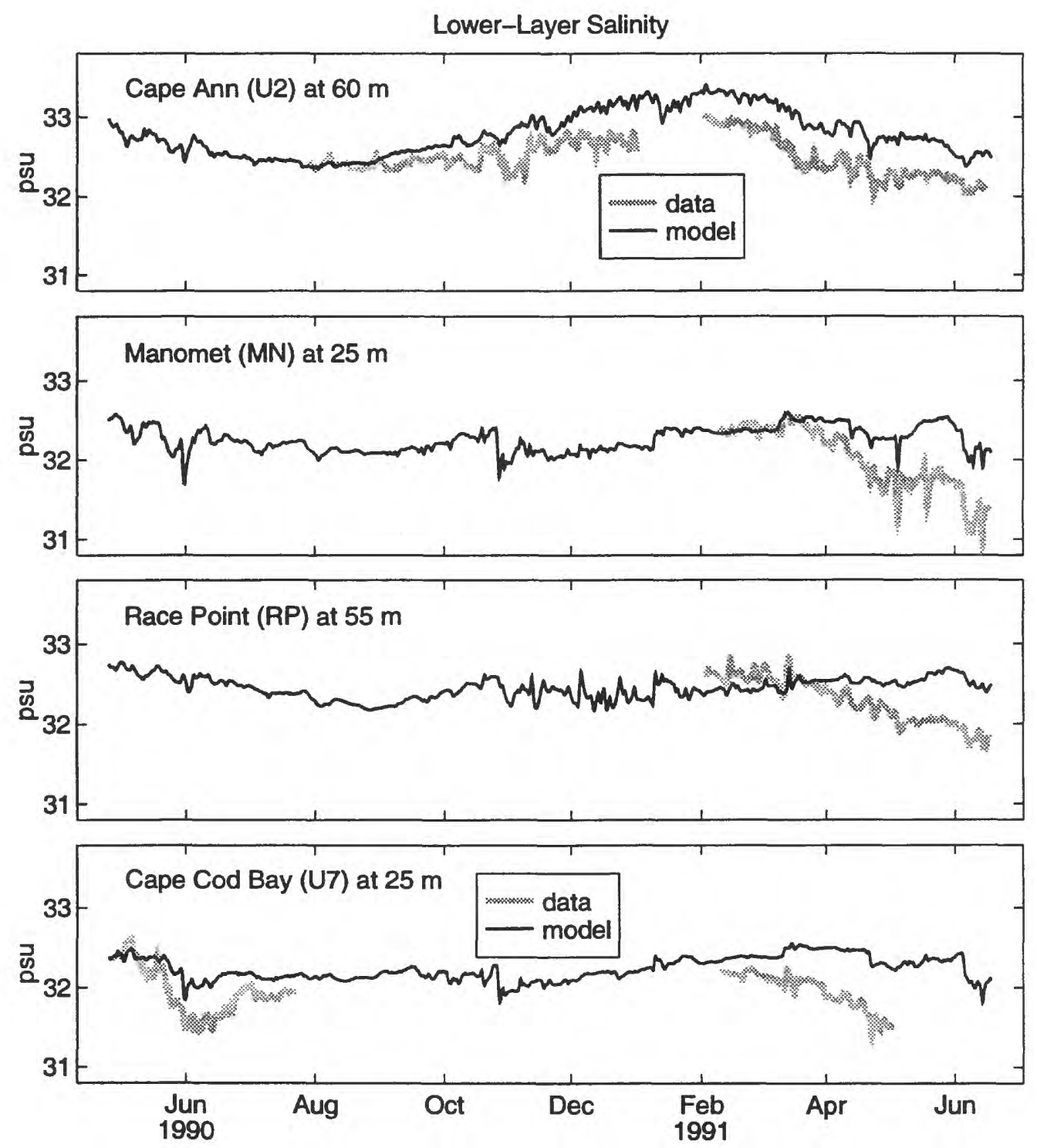

Figure 3.3: Model/data comparison of lower layer salinity at stations U2, MN, RP and U7. 
Near-Surface Temperature (4-5 m)
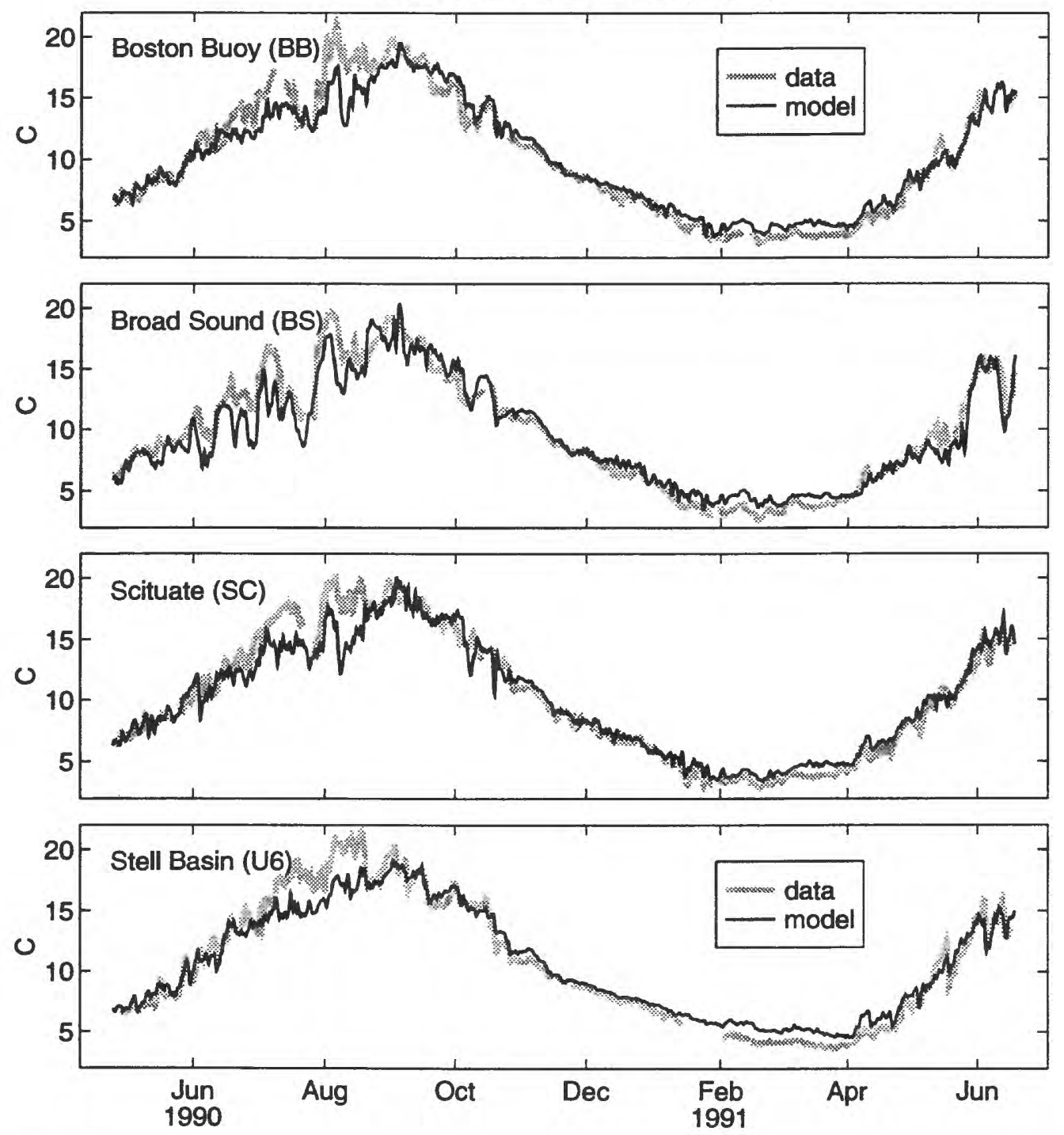

Figure 3.4: Model/data comparison of near-surface temperature at stations $\mathrm{BB}, \mathrm{BS}, \mathrm{SC}$ and $\mathrm{U} 6$. 

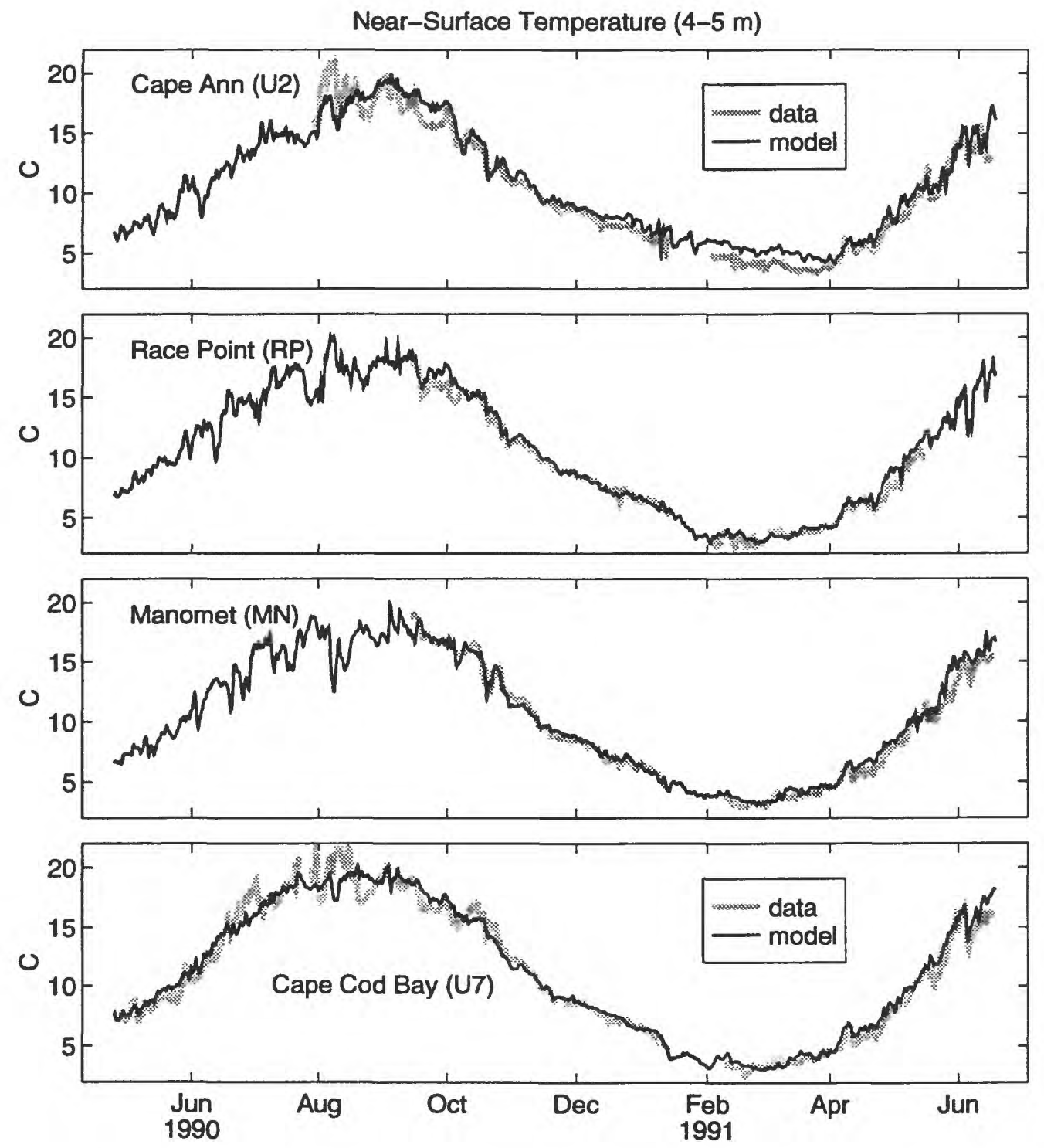

Figure 3.5: Model/data comparison of near-surface temperature at U2, RP, $\mathrm{MN}$, and U7. 


\section{Lower-Layer Temperature}
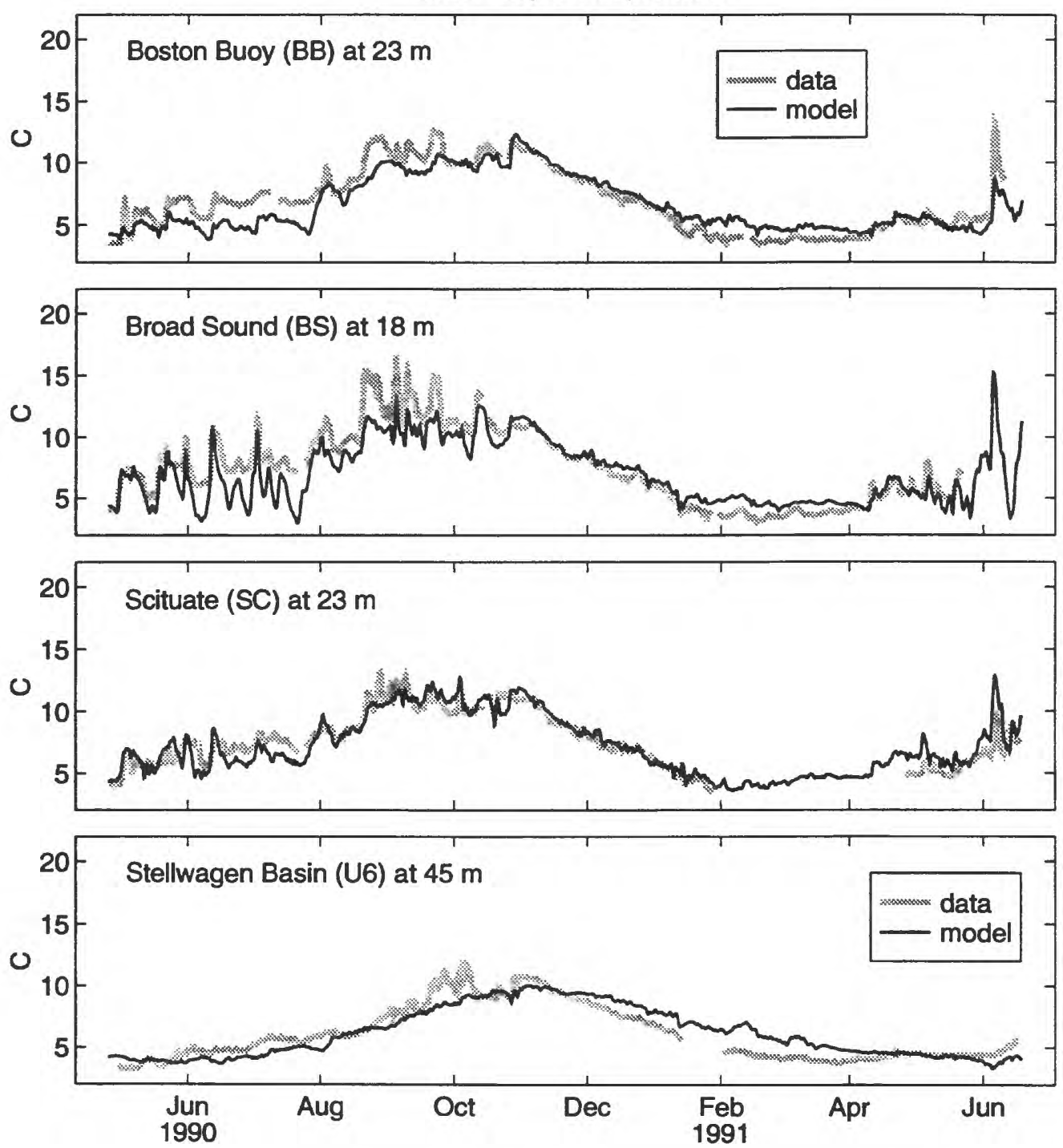

Figure 3.6: Model/data comparison of lower layer temperature at BB, BS, $\mathrm{SC}$ and $\mathrm{U} 6$. 

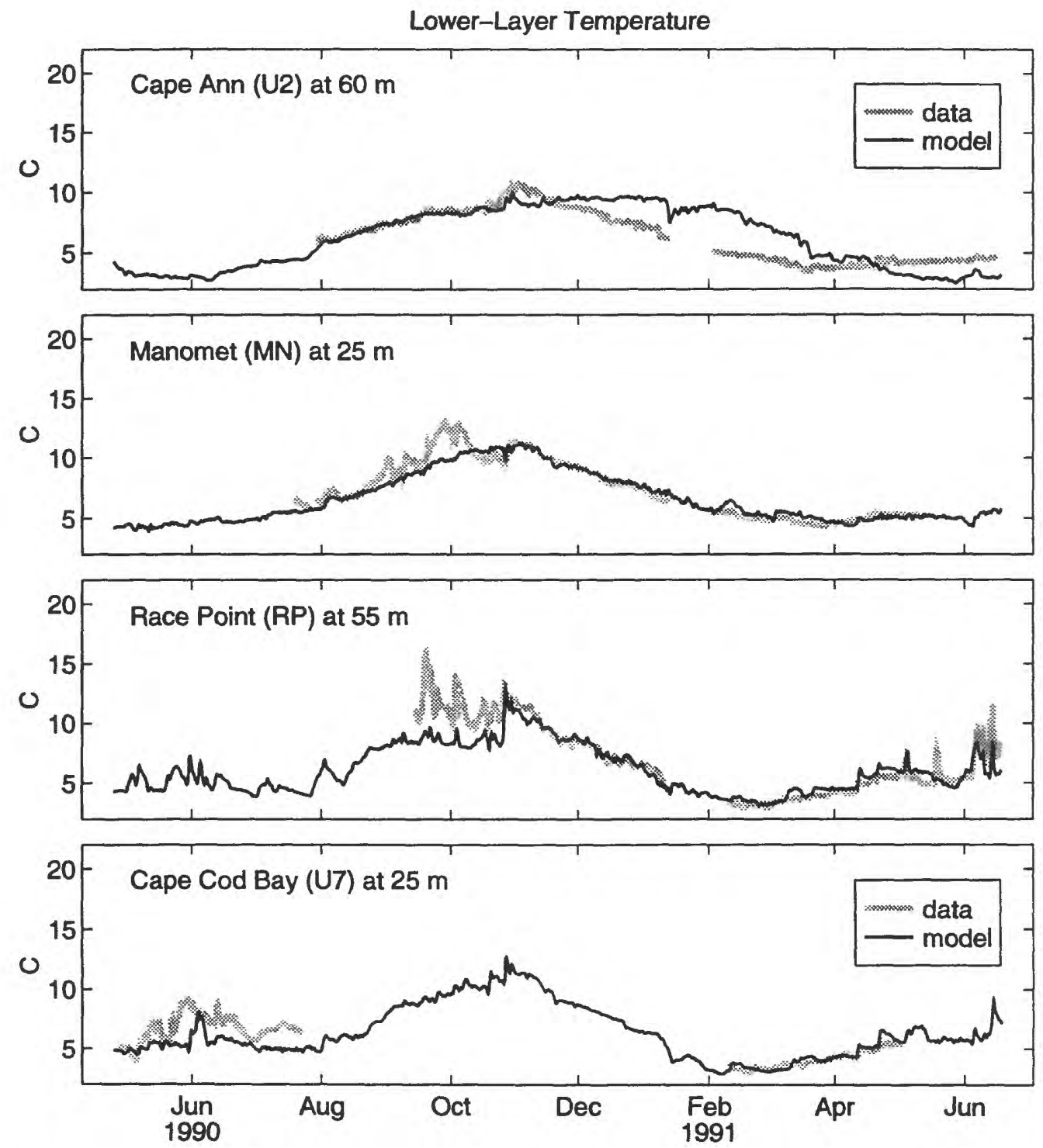

Figure 3.7: Model/data comparison of lower layer temperature at U2, MN, $\mathrm{RP}$, and U7. 

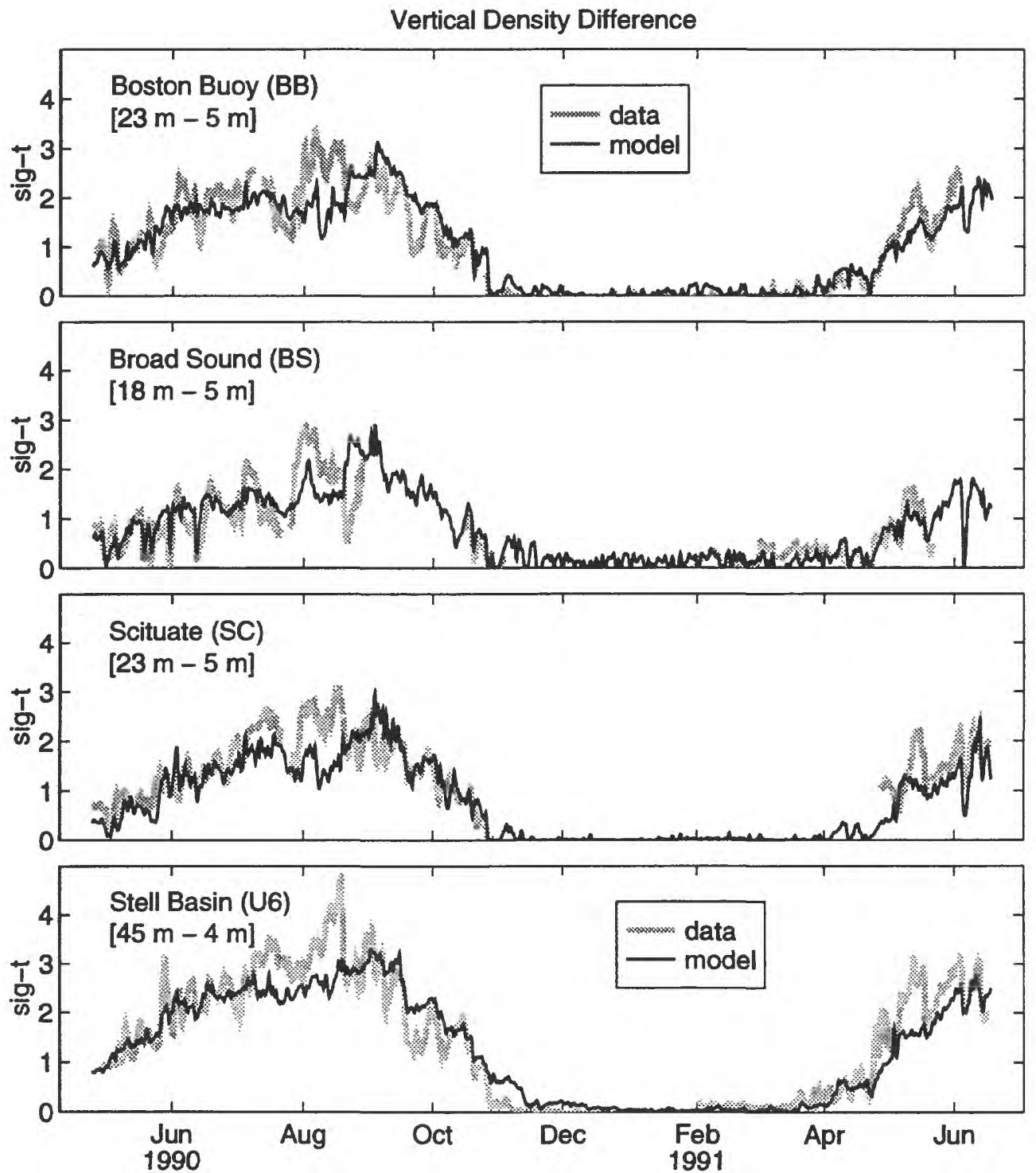

Figure 3.8: Model/data comparison of vertical density differences at stations $\mathrm{BB}, \mathrm{BS}, \mathrm{SC}$ and U6. 
The temperature coherence decreases somewhat with increasing frequency, but the salinity coherence doesn't show any obvious dependence on frequency.

Model fluctuations in salinity are comparable in strength to observations (Figure 3.9) except over Stellwagen Basin (U6), where the modeled salinity fluctuations are less that half the strength of the observations. The strong observed fluctuations of near-surface salinity at U6 (Figure 3.1) are associated with intrusions of low-salinity water from the Gulf of Maine (Geyer et al. 1992), and it appears that these intrusions are either under-represented or are somewhat smeared out by the model.

Model fluctuations in temperature are comparable in strength to observations (Figure 3.10) except at Scituate (SC) and Broad Sound (BS), where the modeled temperature fluctuations are about $50 \%$ stronger than the observations. The strong modeled fluctuations of near-surface temperature at these near-shore locations are associated with upwelling events, so one explanation is that the model surface layer responds a bit too strongly to upwelling winds.

\subsection{Velocity Time Series Comparison at the Mooring LOCATIONS}

The quality of the comparison between modeled and observed currents varies substantially with space and time. At the Boston Buoy, for example, events are frequently well-represented during the winter (Figure 3.11), but are only occasionally well-represented during the summer (Figure 3.12). As explained in Signell et al (1994), this is because the flow regime in winter is largely wind-driven with large spatial scales. Thus small deviations in the structure or timing of the circulation between between the model and reality will not result in large errors at the mooring locations. During the stratified seasons, however, the spatial scales are considerably smaller due to upwelling, intrusions of Gulf of Maine river water, etc. Small deviations in the structure or timing during the stratified seasons will therefore result in larger errors at the mooring locations. For example, if the model representation of an intrusion is off by $5 \mathrm{~km}$, the whole signal could be missed at a particular site like the future outfall location.

The degree of agreement between model and data can be quantified by the complex correlation coefficient, which is high during the winter and considerably lower during the summer (Figures 3.13 and 3.14). Although the 

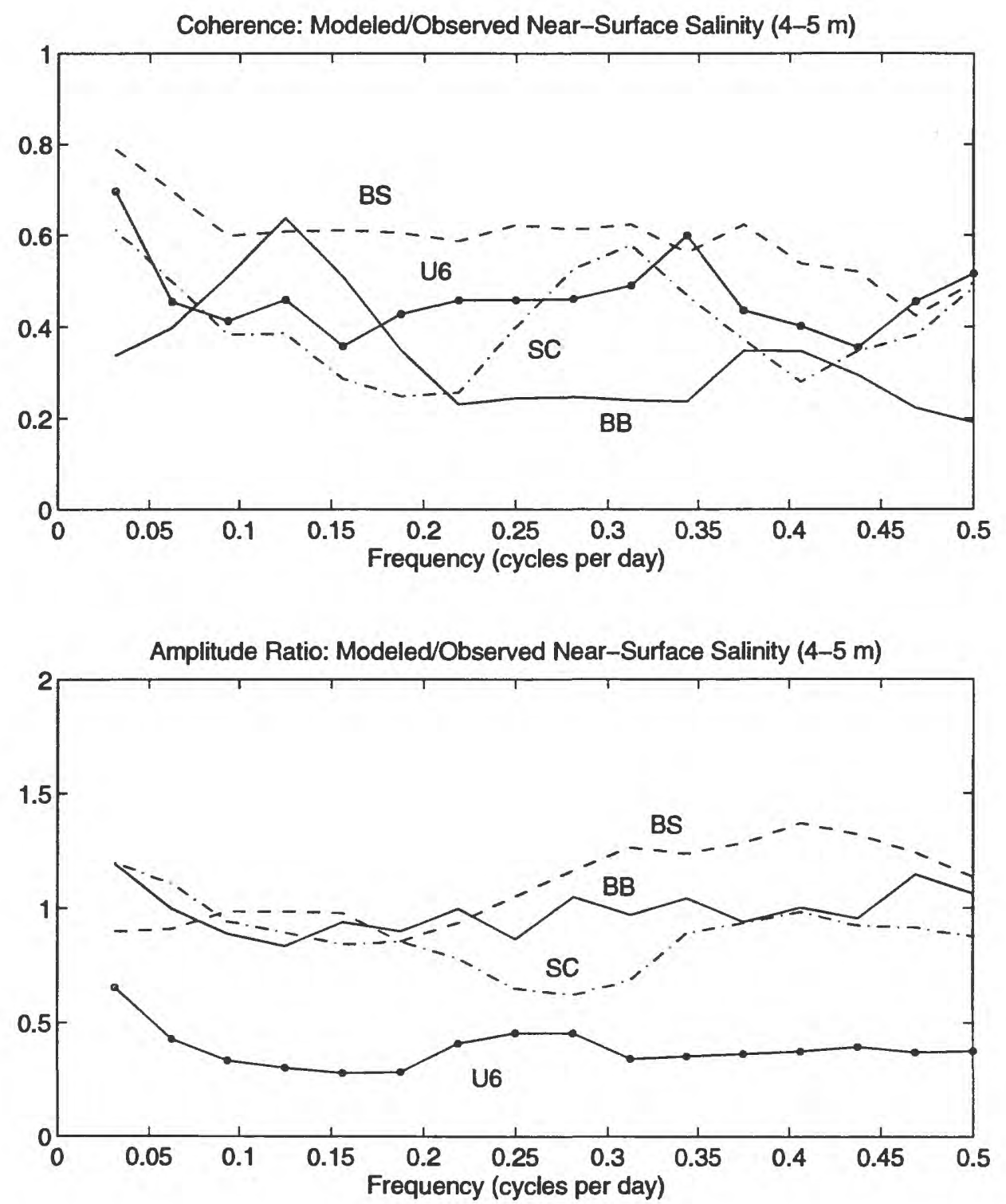

Figure 3.9: Top Panel: Coherence between modeled and observed nearsurface salinities at Broad Sound (BS), Boston Buoy (BB), Scituate (SC) and Stellwagen Basin (U6). The 95\% confidence level is 0.3. Lower Panel: The amplitude ratio of model salinity fluctuations to observed salinity fluctuations. 

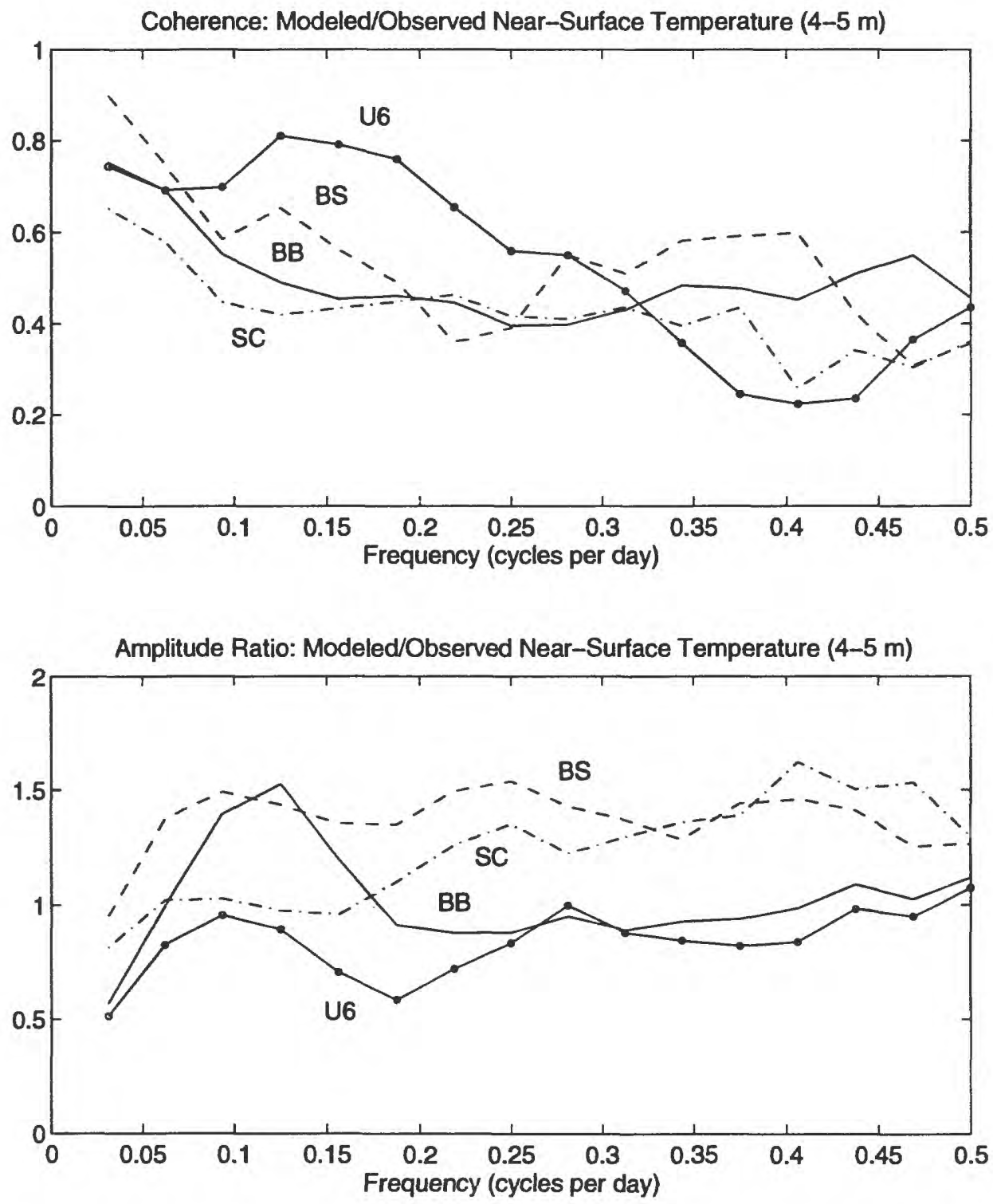

Figure 3.10: Top Panel: Coherence between modeled and observed nearsurface temperatures at Broad Sound (BS), Boston Buoy (BB), Scituate (SC) and Stellwagen Basin (U6). The 95\% confidence level is 0.3. Lower Panel: The amplitude ratio of model temperature fluctuations to observed temperature fluctuations. 

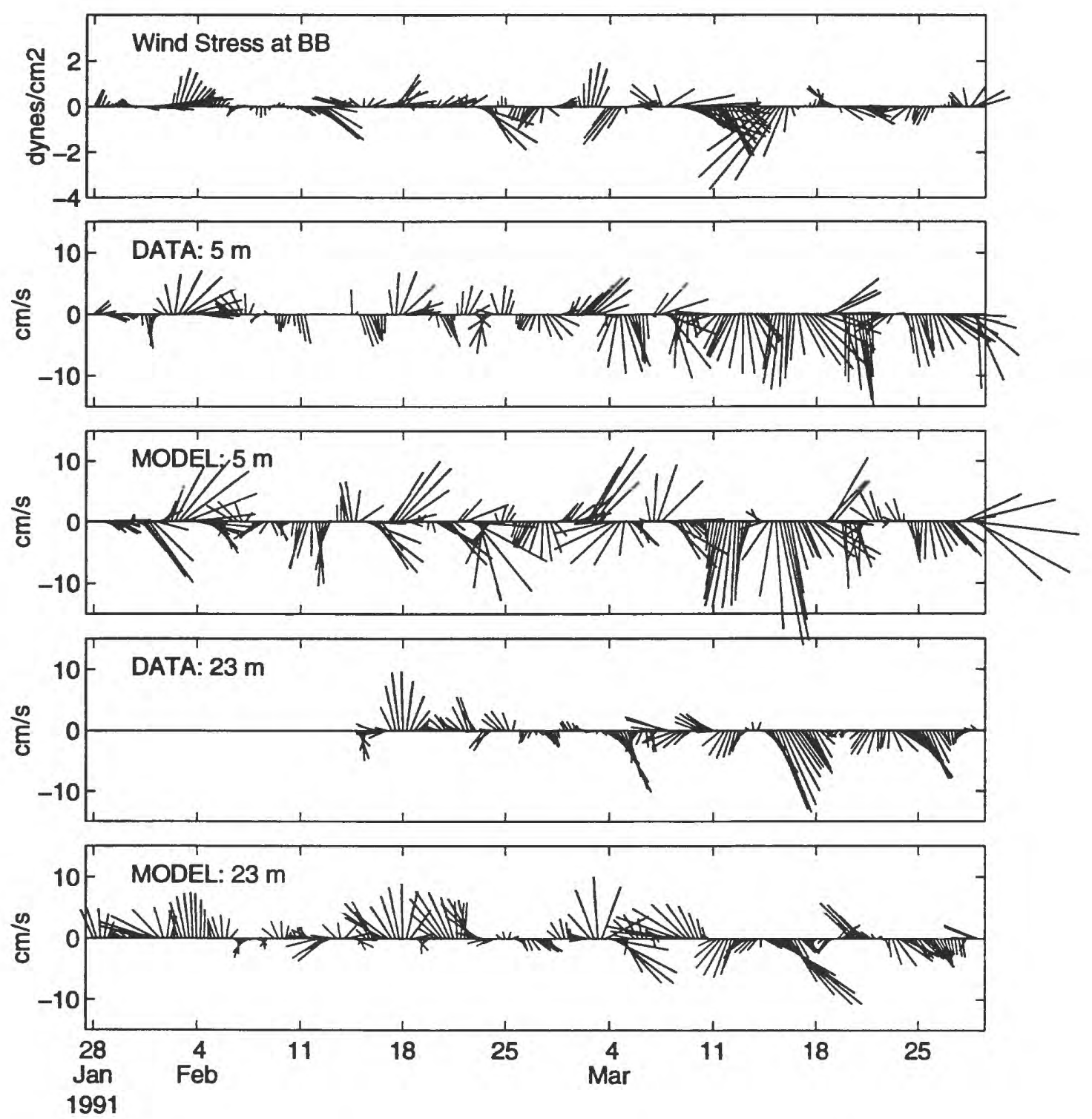

Figure 3.11: Boston Buoy velocity comparison: Jan 28, 1991 - Mar 25, 1991. 

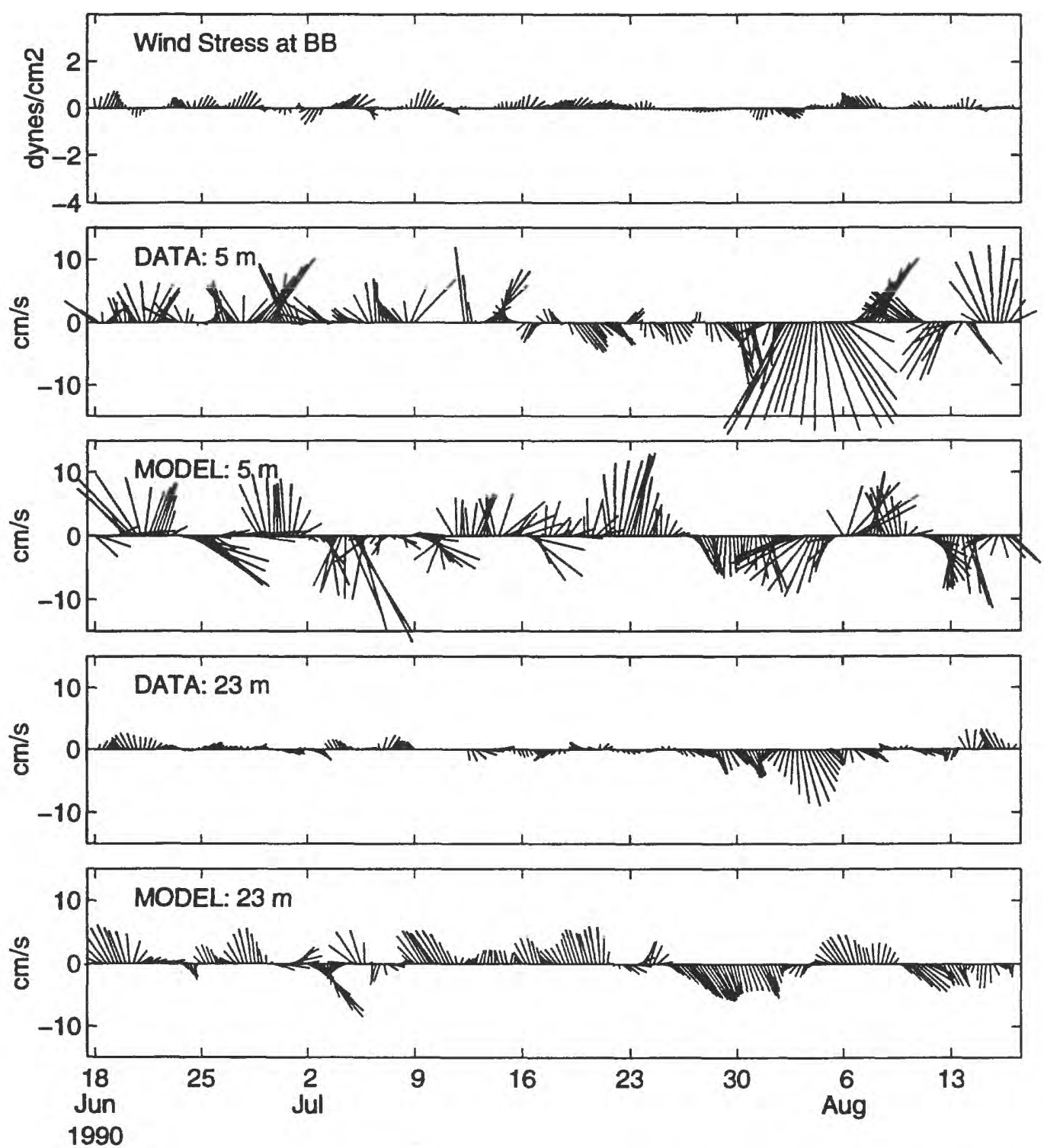

Figure 3.12: Boston Buoy velocity comparison: Jun 18, 1990 - Aug 13, 1990. 
Statistical Comparison of Model/Data Velocity at BB_05
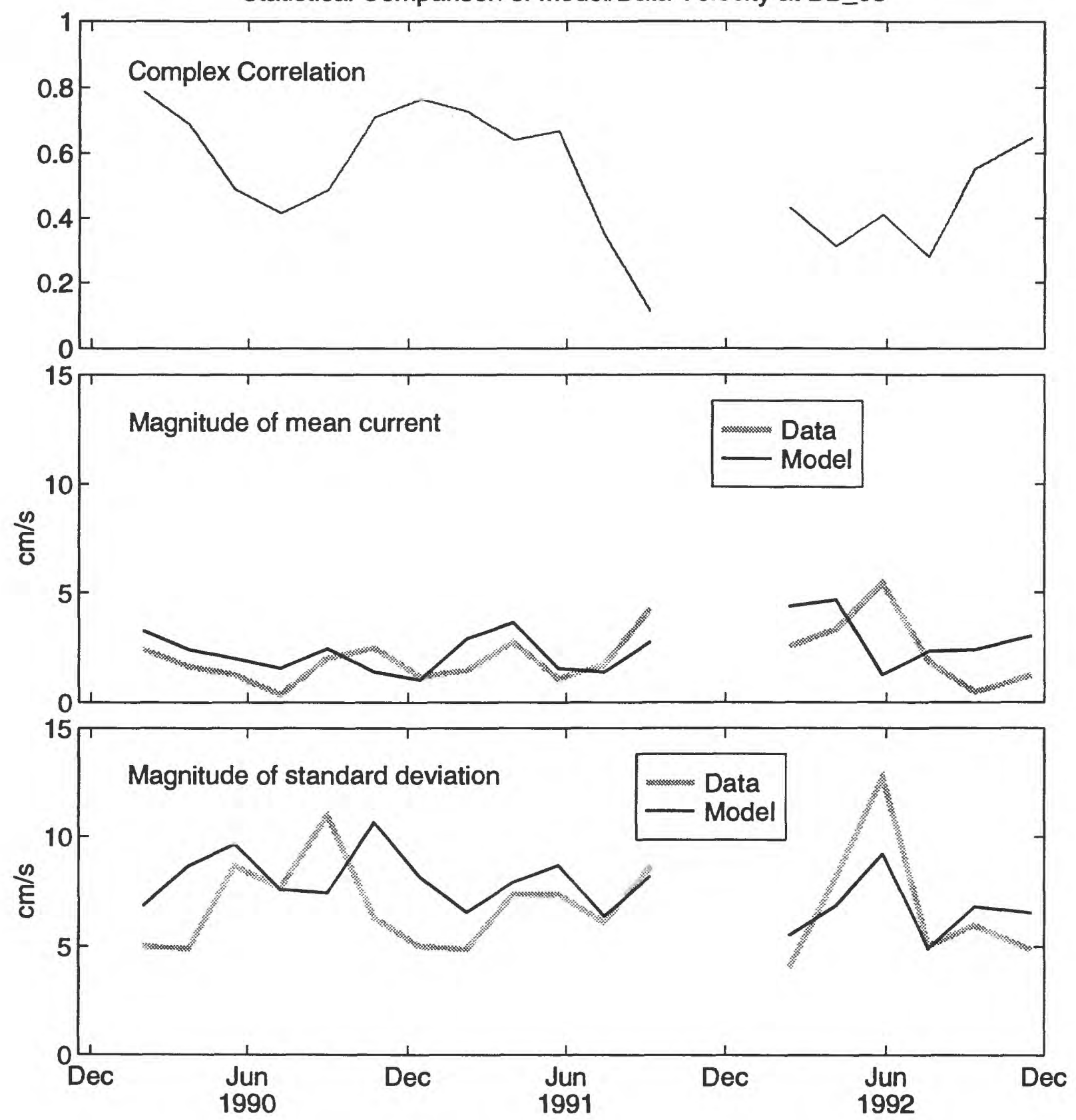

Figure 3.13: Boston Buoy Model/Data velocity statistics at $5 \mathrm{~m}$ depth. 
Statistical Comparison of Model/Data Velocity at BB_23
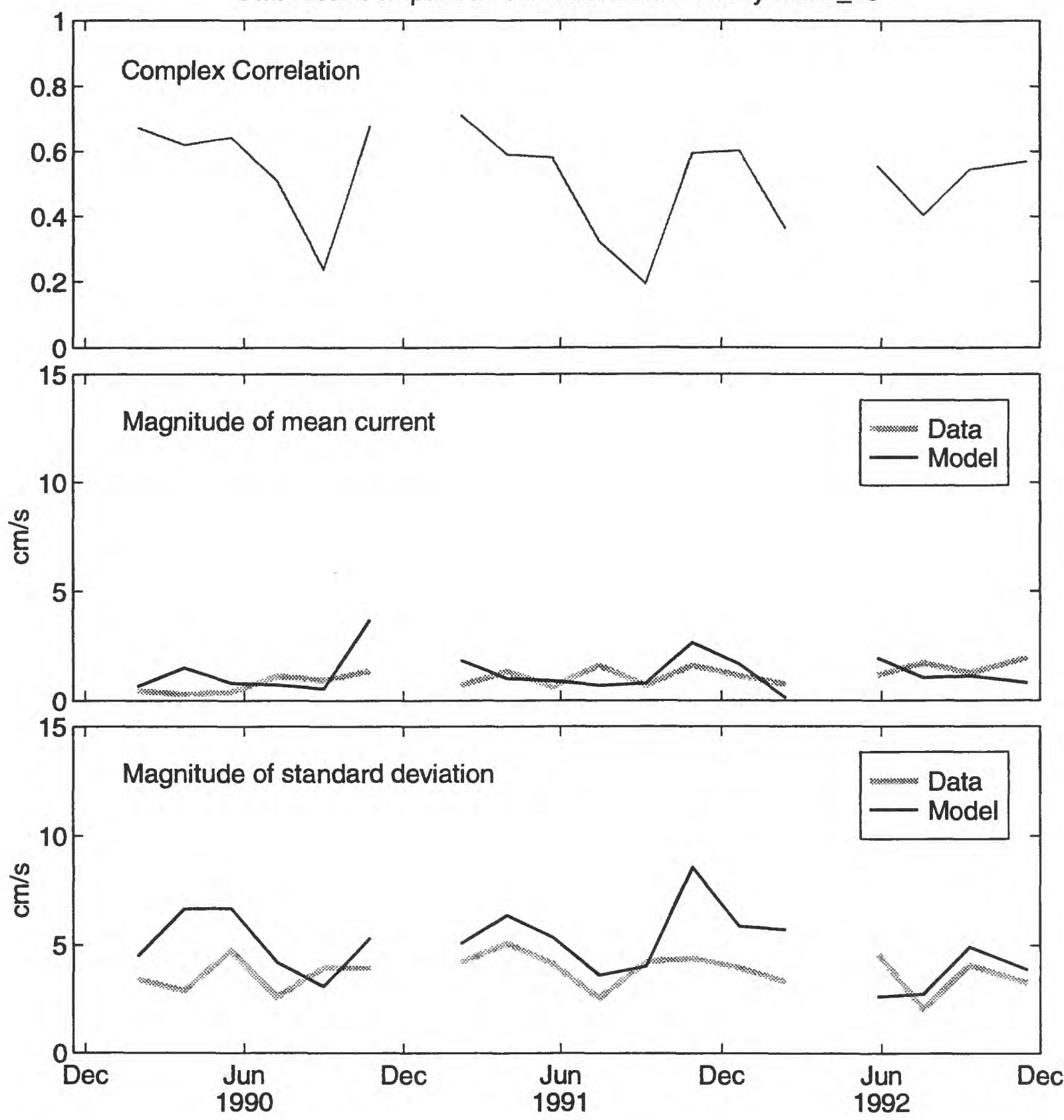

Figure 3.14: Boston Buoy Model/Data velocity statistics at $23 \mathrm{~m}$ depth. 
correlations are considerably lower in the summer, the modeled mean and standard deviation of the low-frequency currents are comparable to observed values and do not show any clear bias.

The relatively good correlation between observed and modeled currents at the Boston Buoy is also seen at the other western Massachusetts Bay stations Scituate and Manomet (Figure 3.15). The correlations are significantly lower in Cape Cod Bay and eastern Massachusetts Bay.

Another way of assessing the degree to which the model compares with data is to look at the empirical orthogonal functions (EOF's) of the model and data. At mooring locations where at least $60 \%$ of the time period May 1990 - June 1991 contained good data, time domain EOF's were computed from the east/west and north/south components of the sub-tidal velocity time series. The first modes of the observed and modeled velocities explain $50 \%$ and $69 \%$ of the variance, respectively, and have reassuringly similar structure (Figure 3.16). This indicates that surface currents in western Massachusetts Bay constitute the largest amount of the energy in both the model and the data.

\subsection{Statistical Comparison of Currents at the Mooring LOCATIONS}

Reproducing the day to day variations of ocean "weather" at specific locations may be required to warrant the use of the model to address some issues, but for other issues it may only be necessary to correctly reproduce the statistics or "climate" of the currents over a few weeks or months. To assess the capability of the model to represent the climate, the mean current and low-frequency ellipses from the data and model were compared at the moored locations for each season. The seasons are defined by distinct dynamical regimes instead of the conventional dates: Winter (November 1 to March 1) represents a wind-dominated, well-mixed regime; Spring (March 1 to June 1) represents a runoff-influenced, transitional stratification regime; Summer (June 1 to September 1) represent an upwelling, strongly stratified regime; and Fall (Sepember 1 to November 1) represents a transitional overturning regime.

During the winter, as expected from the relatively high correlations at the moorings, the mean and low-frequency ellipses compare quite well (Figure 3.17). The ellipses are shown centered around the tip of the mean flow, 

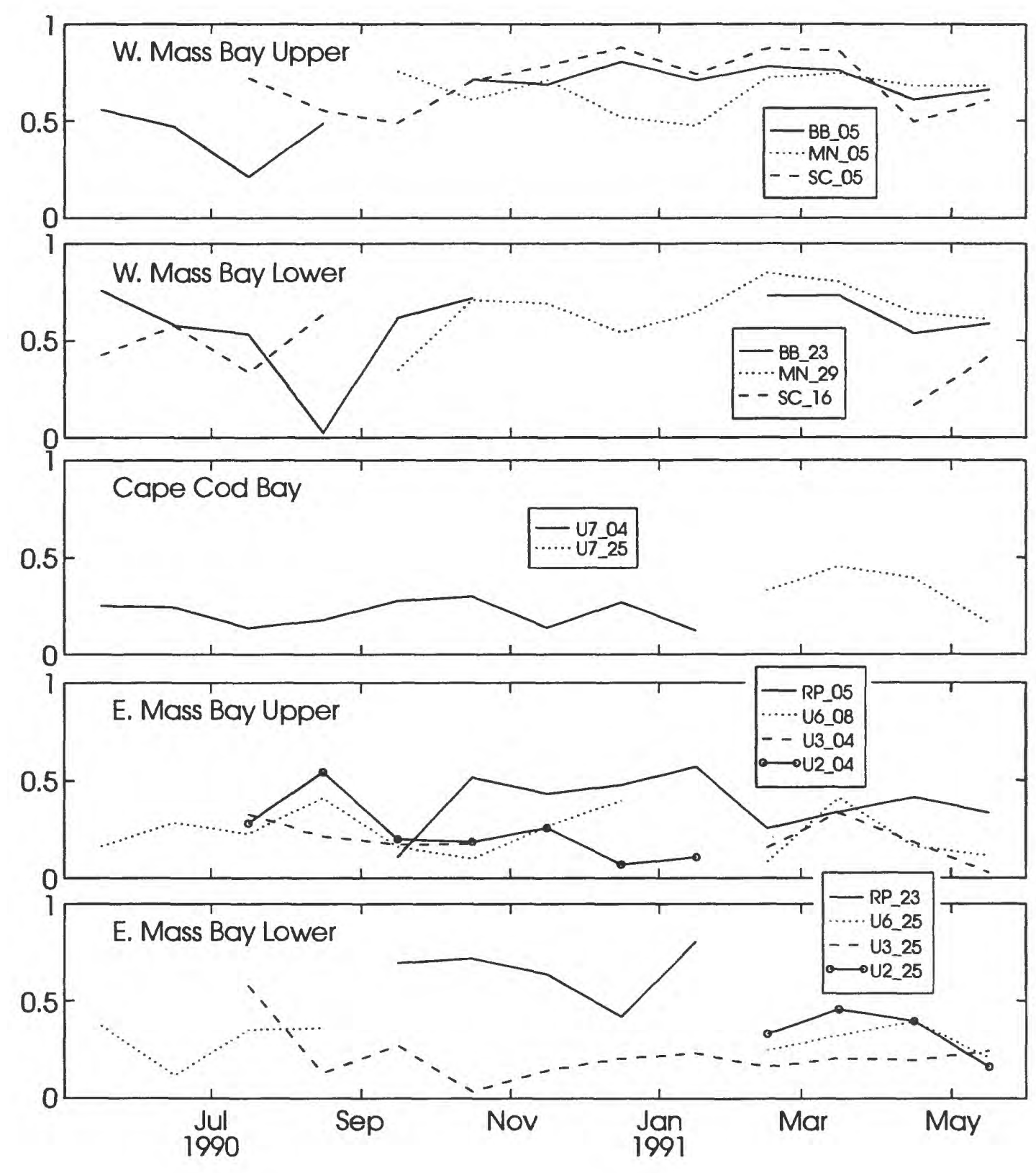

Figure 3.15: Model/Data velocity correlations at selected regional stations. 

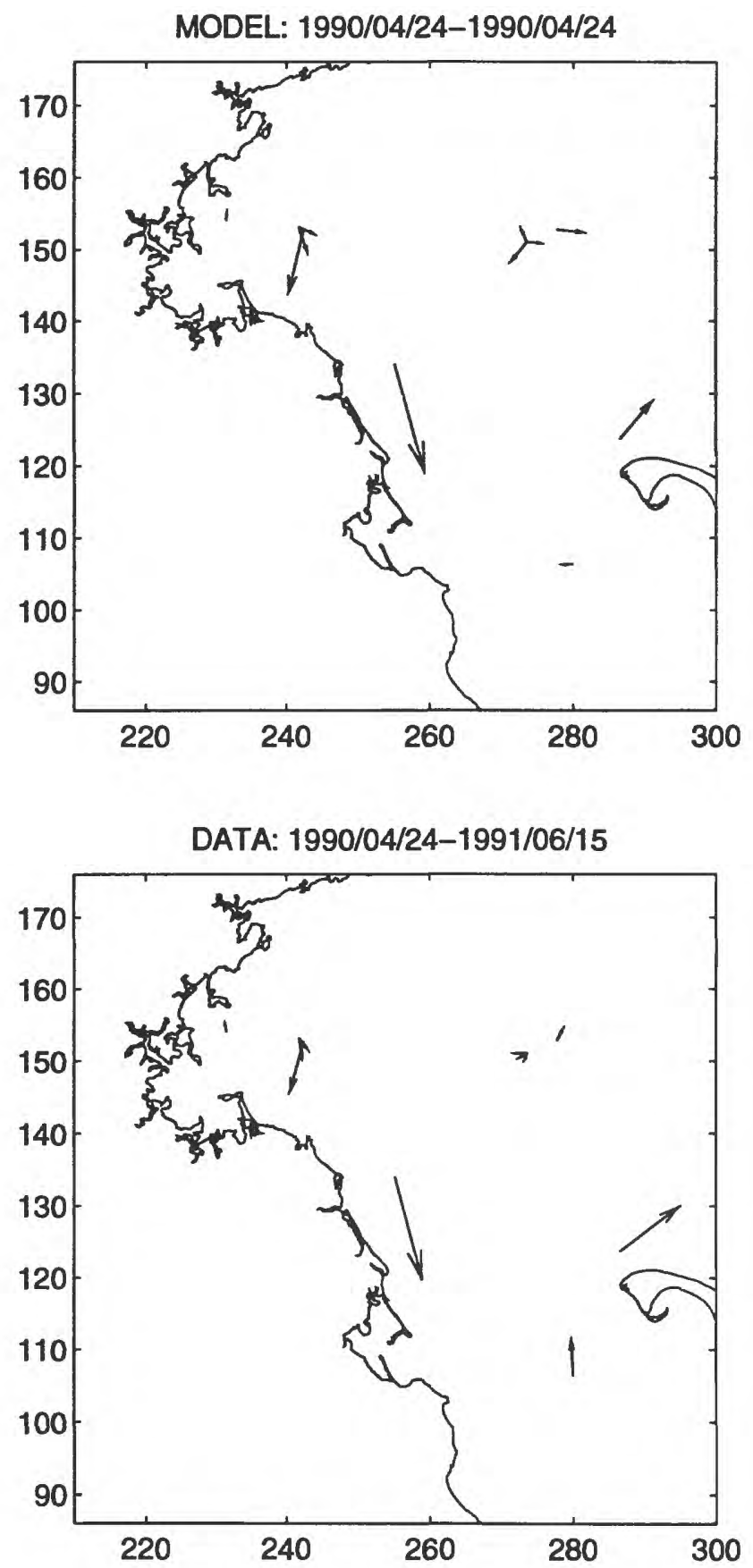

Figure 3.16: Model/Data comparison of the 1st EOF structure of the velocity time series 


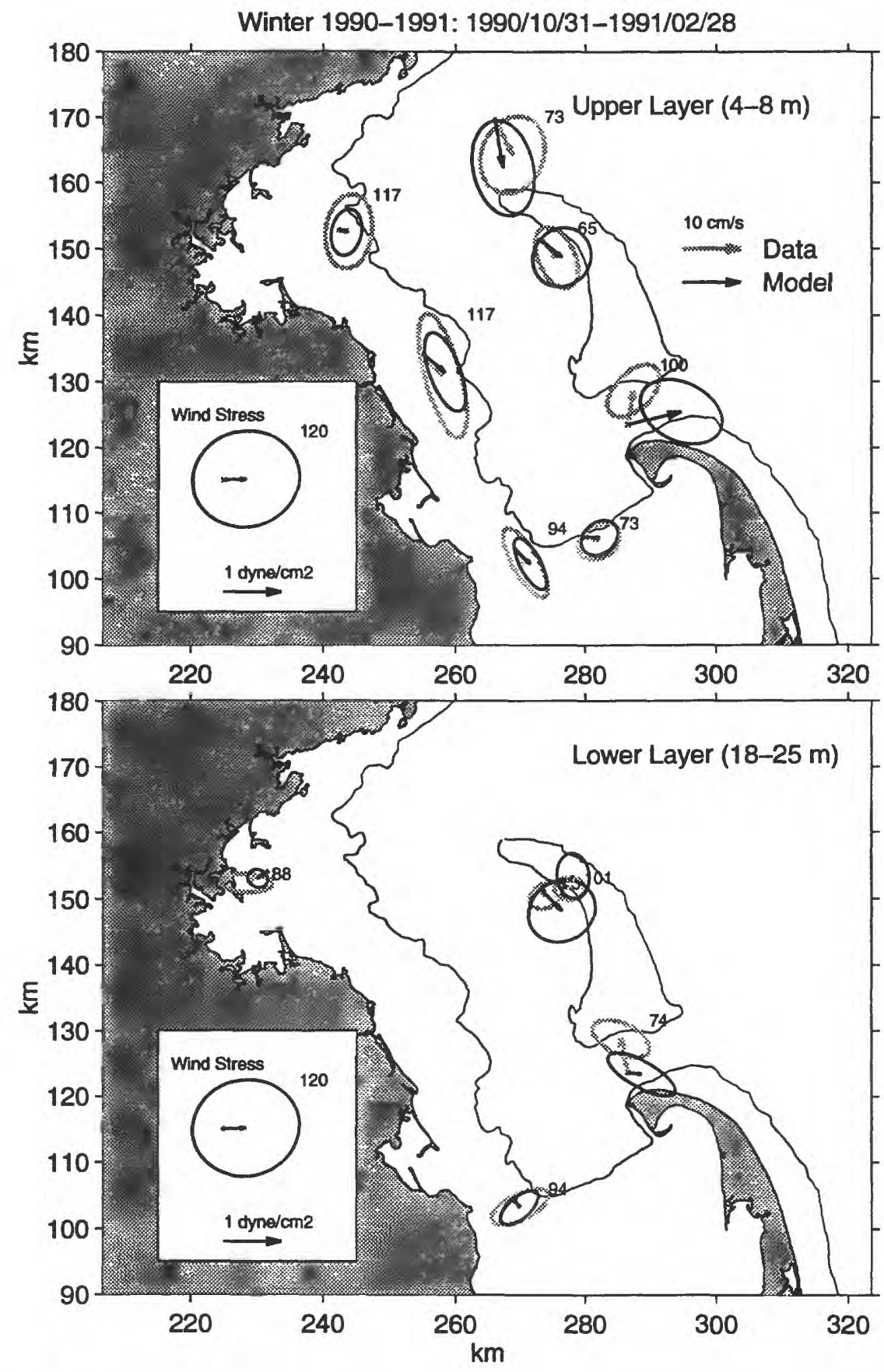

Figure 3.17: Mean flow and low-frequency variability ellipses for Winter 19901991 
and the arrows and ellipses are scaled to correspond to the distance that particles traveling at the observed velocity would move in 1 day. This means that about two-thirds of the time (the percentage of time particles move less than one standard deviation), particles released at the moored locations would be found somewhere inside the ellipse after 1 day. Modeled displacements are very close to predicted displacements with the exception of Race Point, where the observed mean flow is close to northward while the modeled flow is close to eastward. Analysis indicates that this discrepancy is most likely due to a shift in the modeled pattern of tide-induced residual currents rather than a major error in representing flow out of Massachusetts Bay. There is strong $\left(10 \mathrm{~cm} \mathrm{~s}^{-1}\right)$ northward mean flow in the model just $2 \mathrm{~km}$ to the southwest, the result of a small $(5 \mathrm{~km})$ tide-induced residual eddy off the tip of the Cape.

During the spring the surface current variability increases due to intrusions of low salinity water from Gulf of Maine rivers and weaker frictional resistance to wind driving since the surface layer becomes somewhat decoupled from the lower layer. The model reflects the increased intensity of surface currents and the general pattern of the current "climate," doing particularly well at the future outfall site (Figure 3.18). The modeled surface currents are slightly stronger than the observations near Stellwagen Bank and slightly weaker than the observations at Scituate and Manomet, however. At Race Point there is a discrepancy between the modeled and observed mean flows very similar to winter, consistent with the interpretation that this is due to slight spatial error in representation of the tidal residual eddy off the tip of the Cape. As with the surface currents, the lower layer currents are also stronger than observed near Stellwagen Bank, but are close to the observed currents at the other locations (except Scituate, where the modeled currents are extremely weak).

In the summer, strong stratification results in much stronger currents in the upper layer than in the bottom layer. The model represents this behavior quite well, and again is a close match to the current "climate" at the future outfall site (Figure 3.19). The model currents are again stronger than observed near Stellwagen Bank, and Cape Cod Bay surface currents are also stronger than observed.

In the fall the surface mean flow reverses and flows northward at Scituate and Manomet in both the observations and the model while the mean flow near Stellwagen Bank still flows to the south (Figure 3.20). The ellipses are 


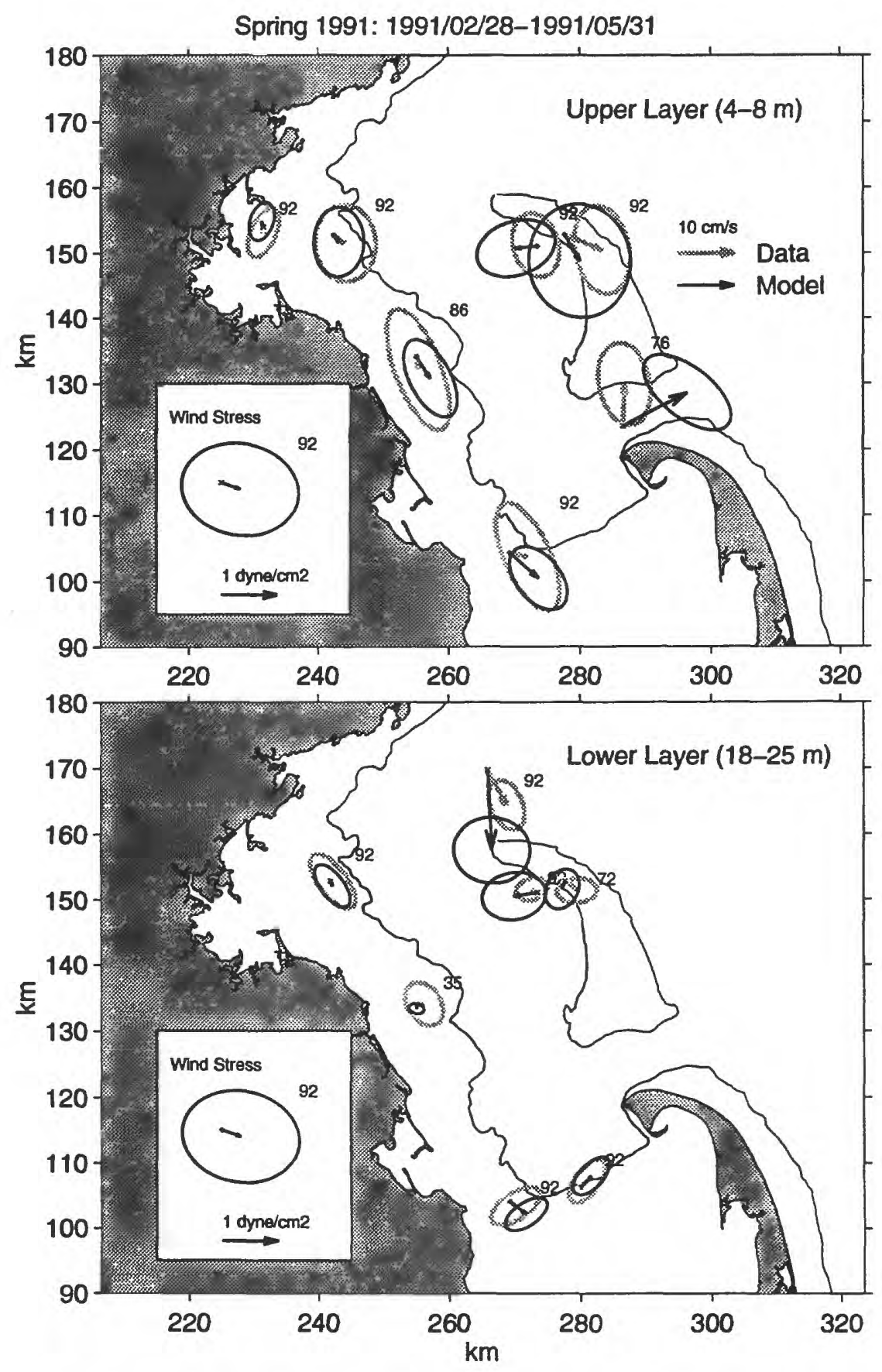

Figure 3.18: Mean flow and low-frequency variability ellipses for Spring 1991 


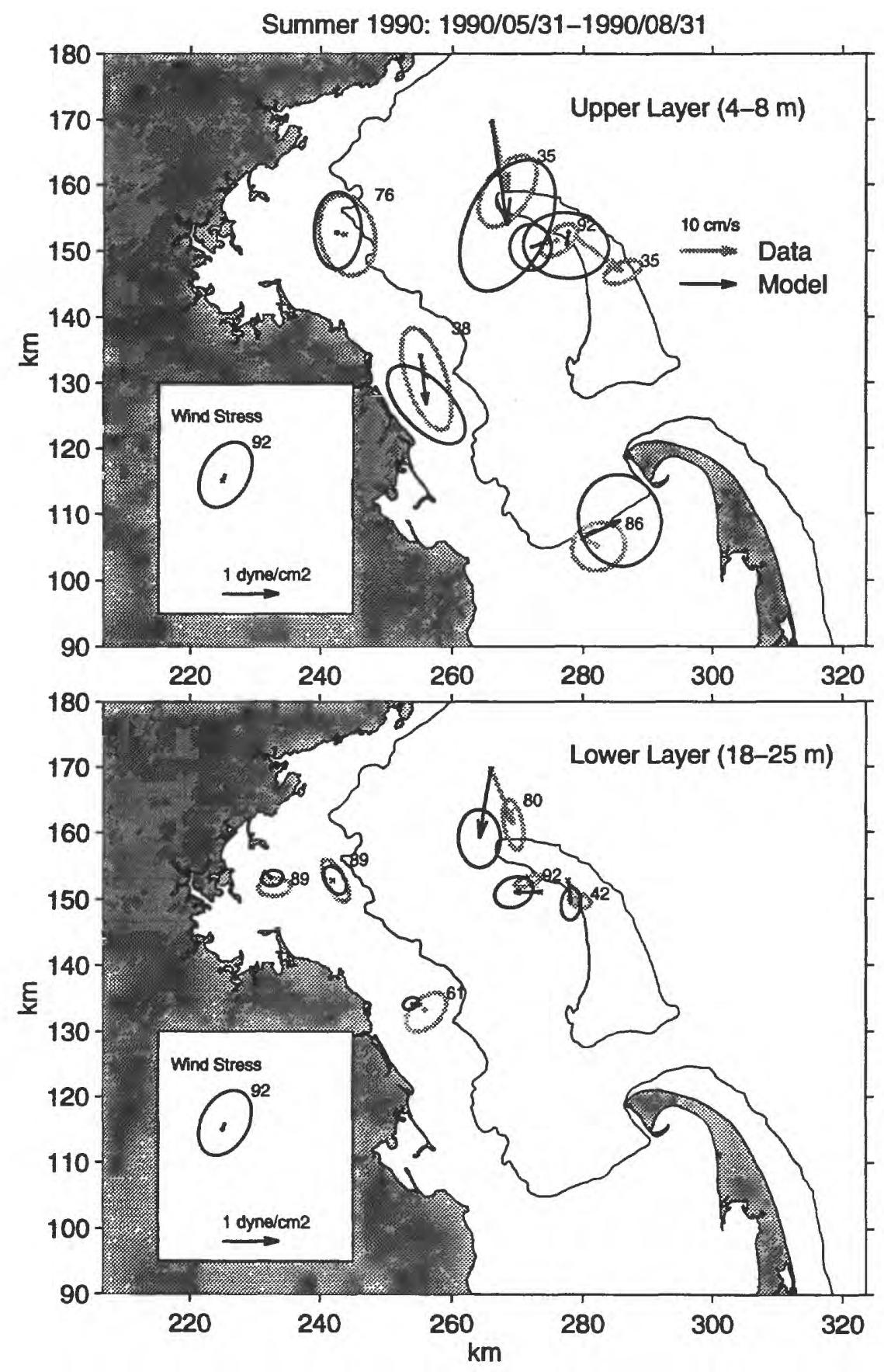

Figure 3.19: Mean flow and low-frequency variability ellipses for Summer 1990 
Fall 1990: 1990/08/31-1990/10/31

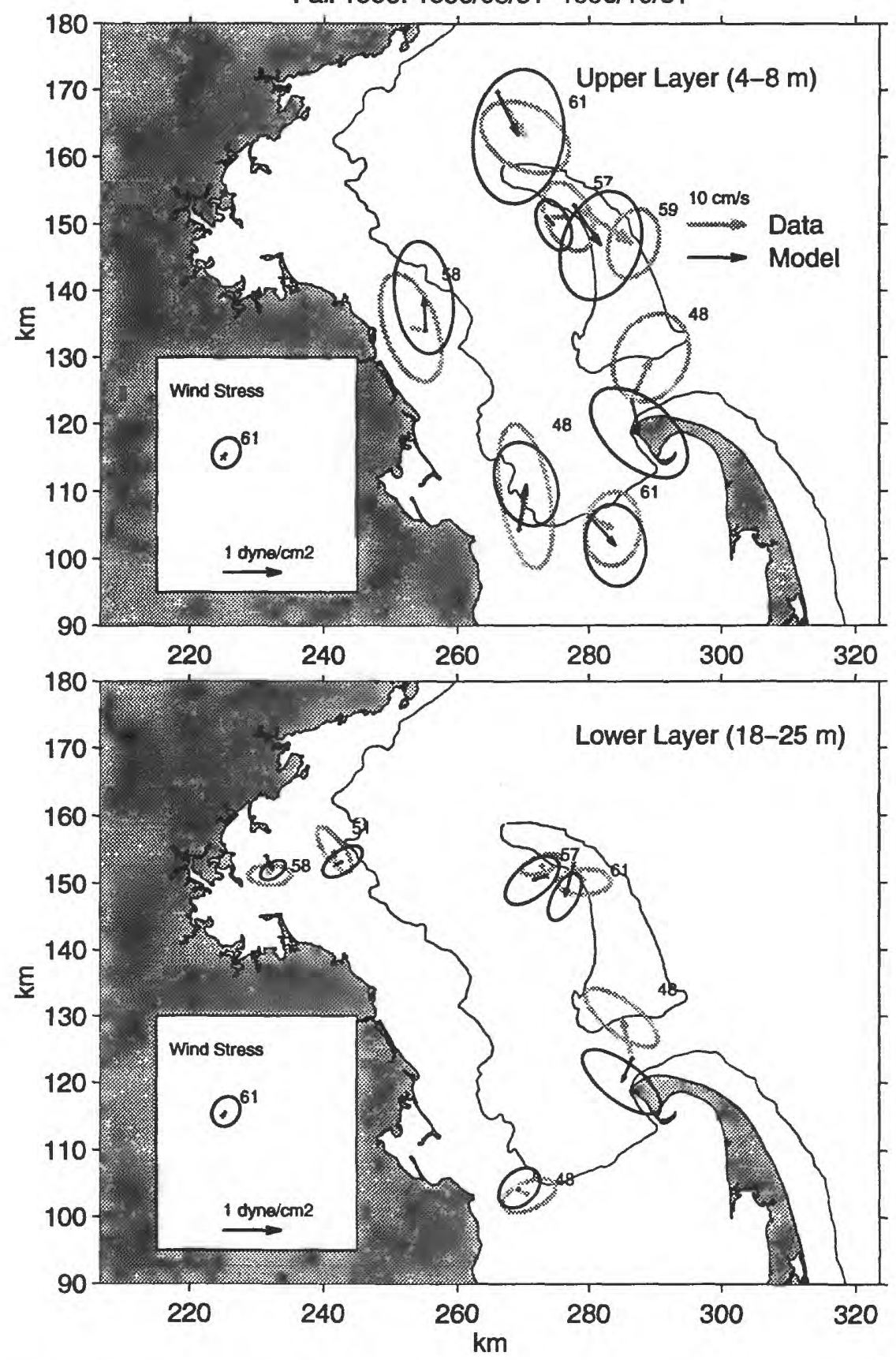

Figure 3.20: Mean flow and low-frequency variability ellipses for Fall 1990 
generally quite similar except at Race Point, where there appears to be some flow into Massachusetts Bay that is not apparent in the data.

The degree to which the model compares with data can be used to identify appropriate uses of the modeled hydrodynamics. For example, since the current "climate" is well represented in western Massachusetts Bay throughout the years, it is appropriate to use the model to study the near-continuous release of effluent in this region by the existing and future outfalls. Likewise, since individual events are well-represented in western Massachusetts Bay during unstratified conditions, the model is well suited to studying the transport of suspended material from this region during individual winter storms. On the other hand, predicting the detailed evolution of a low-salinity plume from a spring runoff event is not possible, at least partially due to inadequate information about the large scale forcing from the Gulf of Maine. 


\section{Chapter 4}

\section{Effluent Modeling}

Since the hydrodynamic model represents the stratification and statistics of low-frequency currents in the western part of Massachusetts Bay rather well, it is appropriate to use the model to investigate the transport of effluent from the existing and future outfalls over timescales of weeks to months. To model the effluent, a conservative tracer was added to the code, modeled the same as temperature and salinity, but with no dynamical effect. The effluent concentration was set to 100 at the Nut and Deer Island diffusers for the existing outfall run. For the future outfall run, the discharge from Nut and Deer Islands was added together and introduced at the future outfall, again with a concentration of 100 . Along the open boundary, far from the sources, the effluent concentration was set to zero. Since the loading concentration is arbitrary, the effluent concentrations were converted to effluent dilutions for the purposes of presentation.

Since ECOM-si is a hydrostatic model with grid spacing of about $1 \mathrm{~km}$ in the vicinity of the future outfall, it cannot represent the physics of the turbulent entrainment process that occurs when the effluent is discharged from the diffusers. By designing the grid so that the size of the diffuser grid cell is comparable to the area of zone of initial dilution, however, it is possible to dilute the effluent by approximately the same amount as predicted by nearfield models such as EPA's ULINE. This allows ECOM-si to effectively model the height to which the plume rises (Blumberg et al., 1994). Ph.D work by Xue-Yong Zhang (in preparation) at MIT has shown that with the relatively strong pycnocline observed in Massachusetts Bay there is considerable latitude in choosing the size of the diffuser grid cell to produce approximately 
the right trap height.

Effluent was discharged and tracked from the existing and future outfalls from October 1989 to September 1991, and the results have been presented in a variety of forms. Some animation clips comparing the two outfall locations during winter and summer periods can be seen on the World Wide Web at http://crusty.er.usgs.gov. The 200:1 dilution level is about the level at which the nutrient signal from the outfall should become lost in background variability, and thus is highlighted in presentations.

During the winter, highest effluent concentrations from both the existing and future outfalls occur at the surface, since the initially diluted effluent is lighter than the well-mixed, dense seawater (Figure 4.1). The existing outfall, due to the shallow depth and confines of Boston Harbor, results in a much larger region of poorly diluted effluent. There is very little difference in the size of the 200:1 dilution region between 1990 and 1991, although the size of the 800:1 dilution region changes considerably (Figures 4.1 and 4.2).

During the summer, the highest effluent concentrations from the existing outfall are again found at the surface, since the effluent is effectively discharge directly into the surface layer due to strong tidal mixing in Boston Harbor. The 200:1 dilution region is very similar to the winter region (Figure 4.3). At the future outfall, however, the effluent plume becomes trapped below the pynocline since the seawater near the surface has warmed and freshened to the point where it is lighter than the initially diluted effluent. At $16 \mathrm{~m}$, the depth of maximum areal extent of the 200:1 effluent surface, the region affected by the future outfall is still considerably smaller than the surface extent of the 200:1 region from the existing outfall (Figure 4.4). Average dilution comparisons for other seasons are presented in Appendix C.

While the dispersion of effluent can be characterized by the plots of the average effluent dilution, a residence time for effluent in Massachusetts Bay and Boston Harbor can be determined by dividing the total amount of effluent in the bay or harbor by the rate of loading. This calculation of residence time assumes that both the input effluent and export from the system are relatively steady. The boundary of Massachusetts Bay was specified as a straight line between Cape Ann and Provincetown, and the boundary of Boston Harbor was specified as a straight line across the harbor mouth. The residence times for Massachusetts Bay are very similar for the existing and future outfall scenarios, and show a distinct seasonal cycle (Figure 4.5).

Overall, the residence time for effluent in Massachusetts Bay is from 40- 

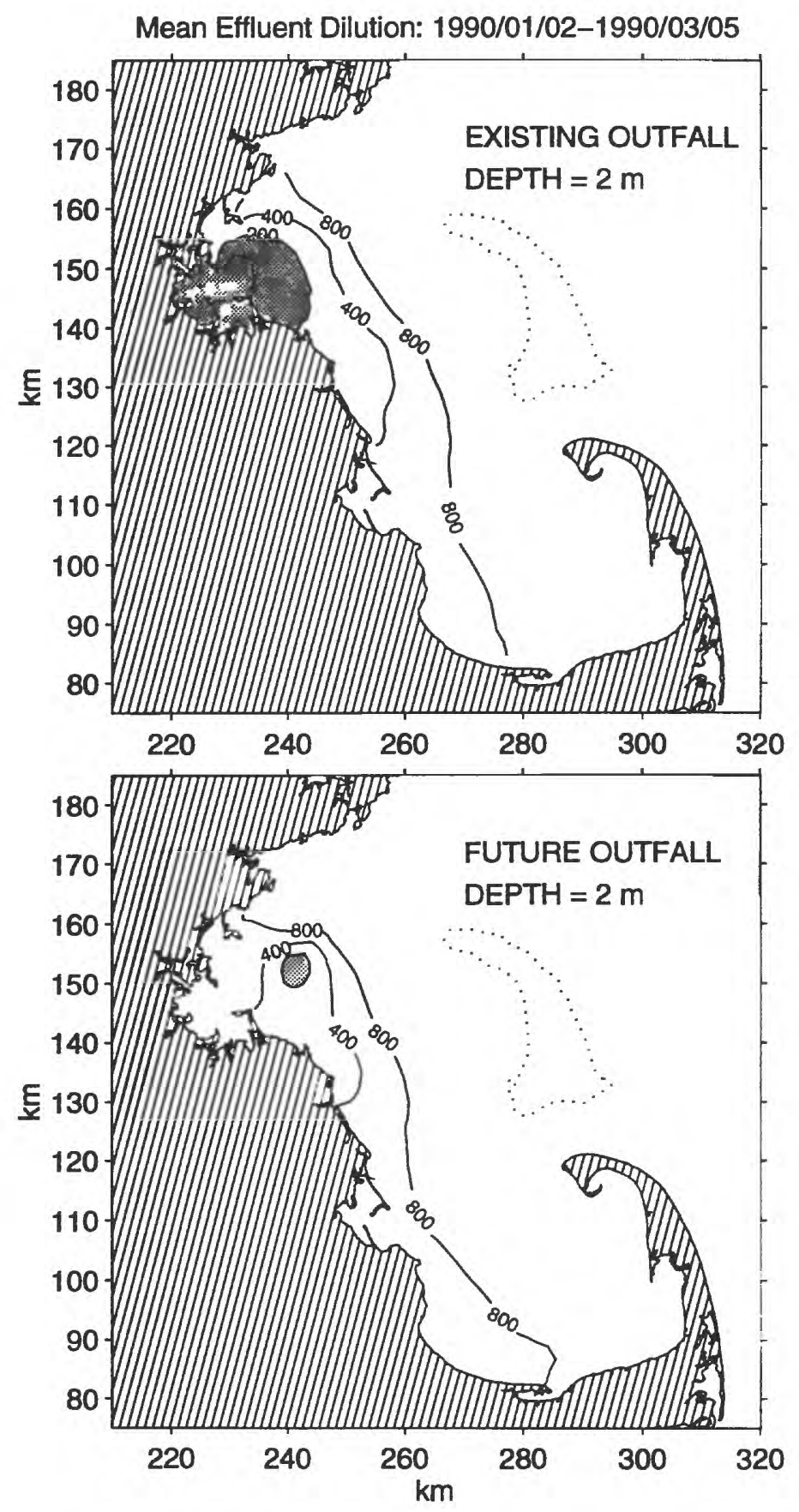

Figure 4.1: Effluent comparison at $2 \mathrm{~m}$ depth during Winter 1990. 

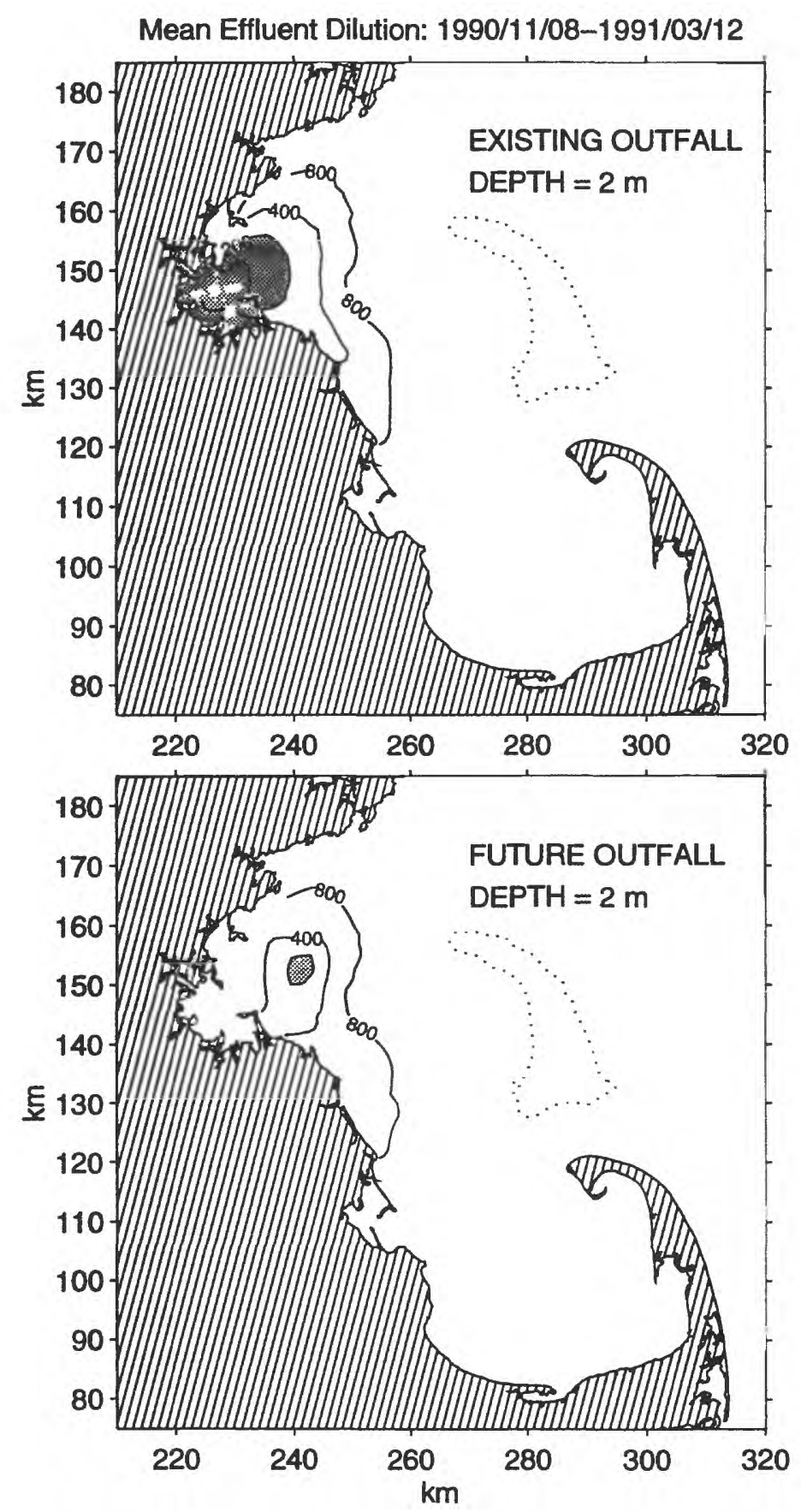

Figure 4.2: Effluent comparison at $2 \mathrm{~m}$ depth during Winter 1991. 


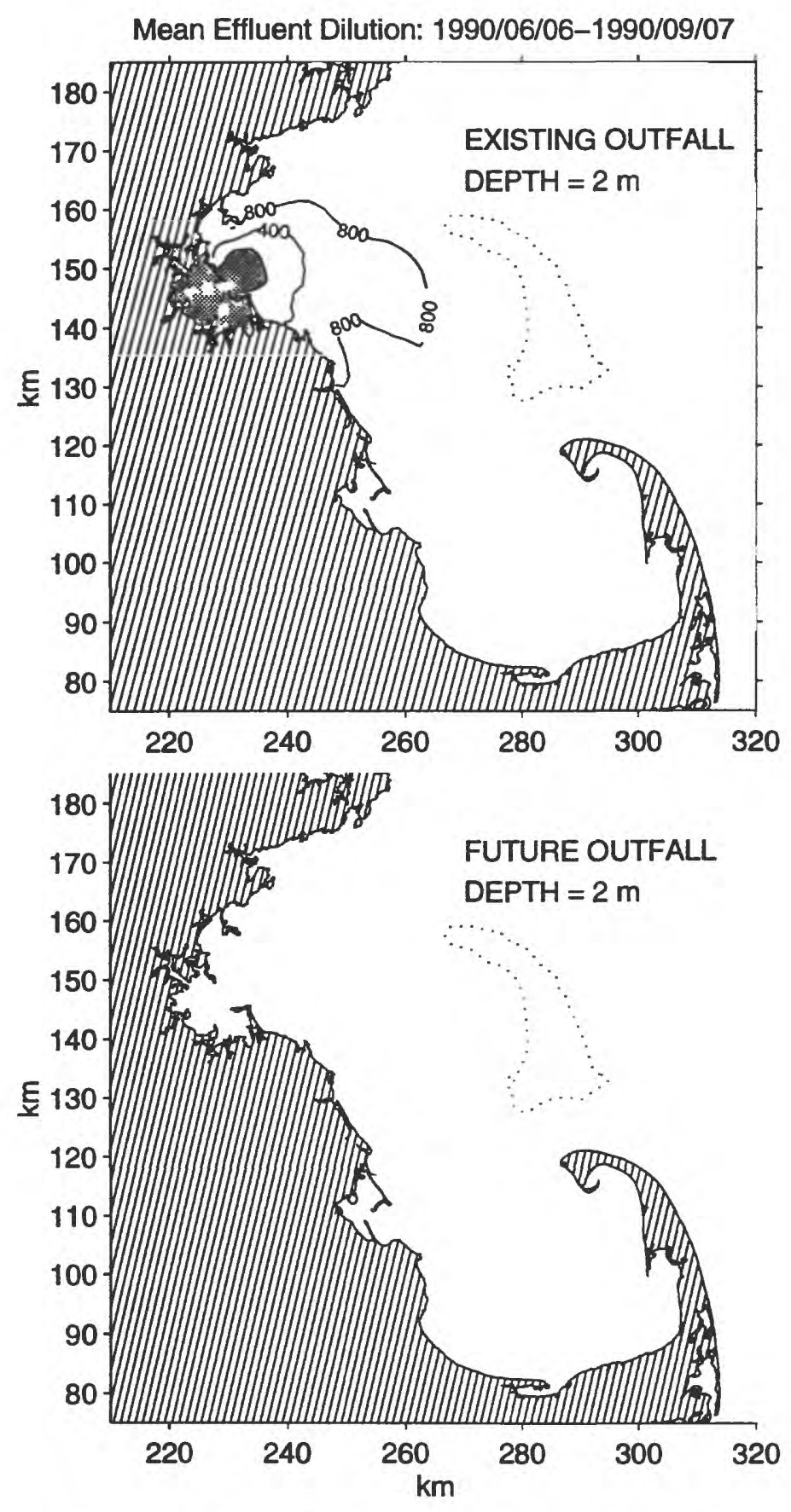

Figure 4.3: Effluent comparison at $2 \mathrm{~m}$ depth during Summer 1990. 


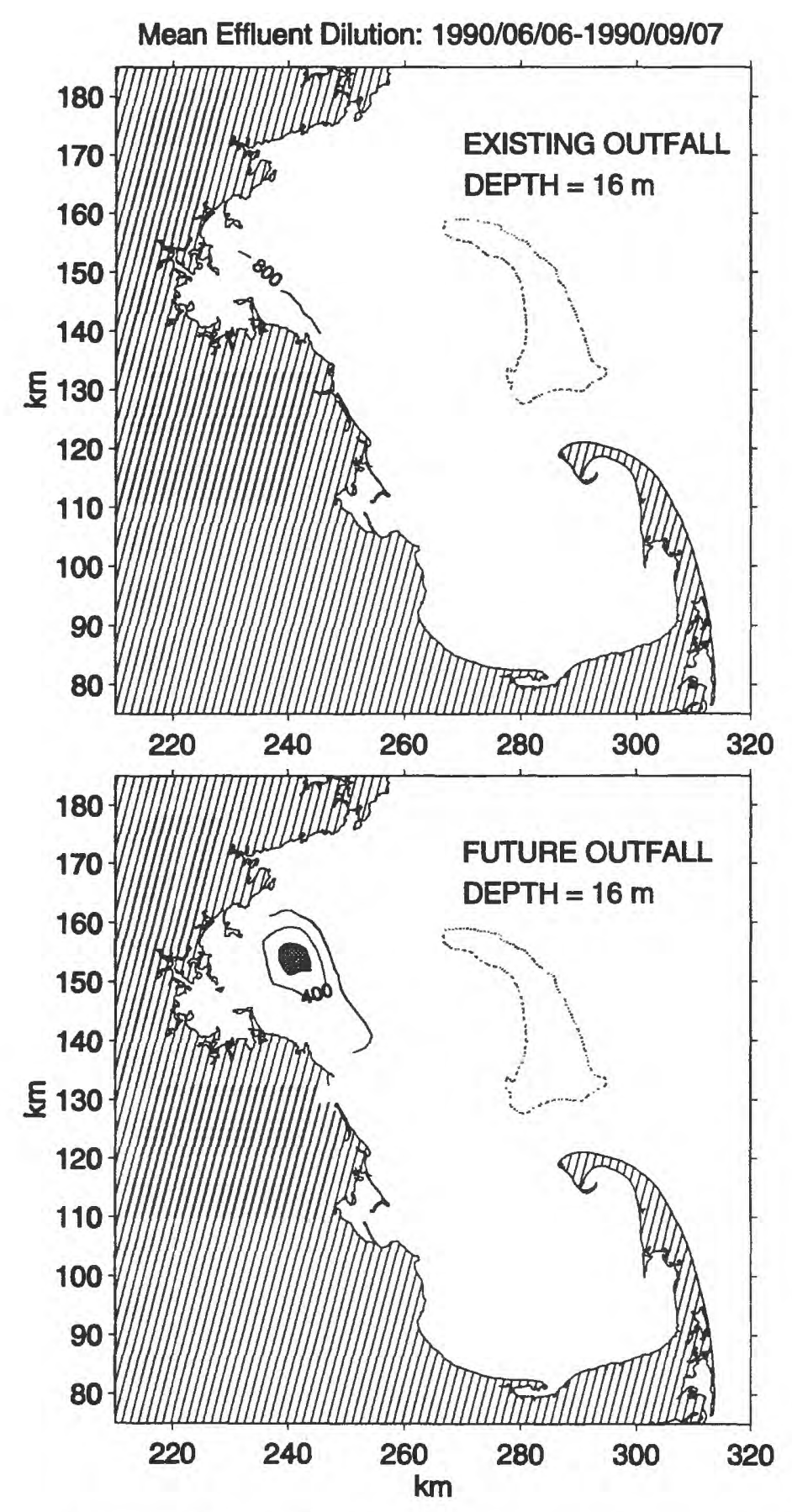

Figure 4.4: Effluent comparison at $16 \mathrm{~m}$ depth during Summer 1990. 

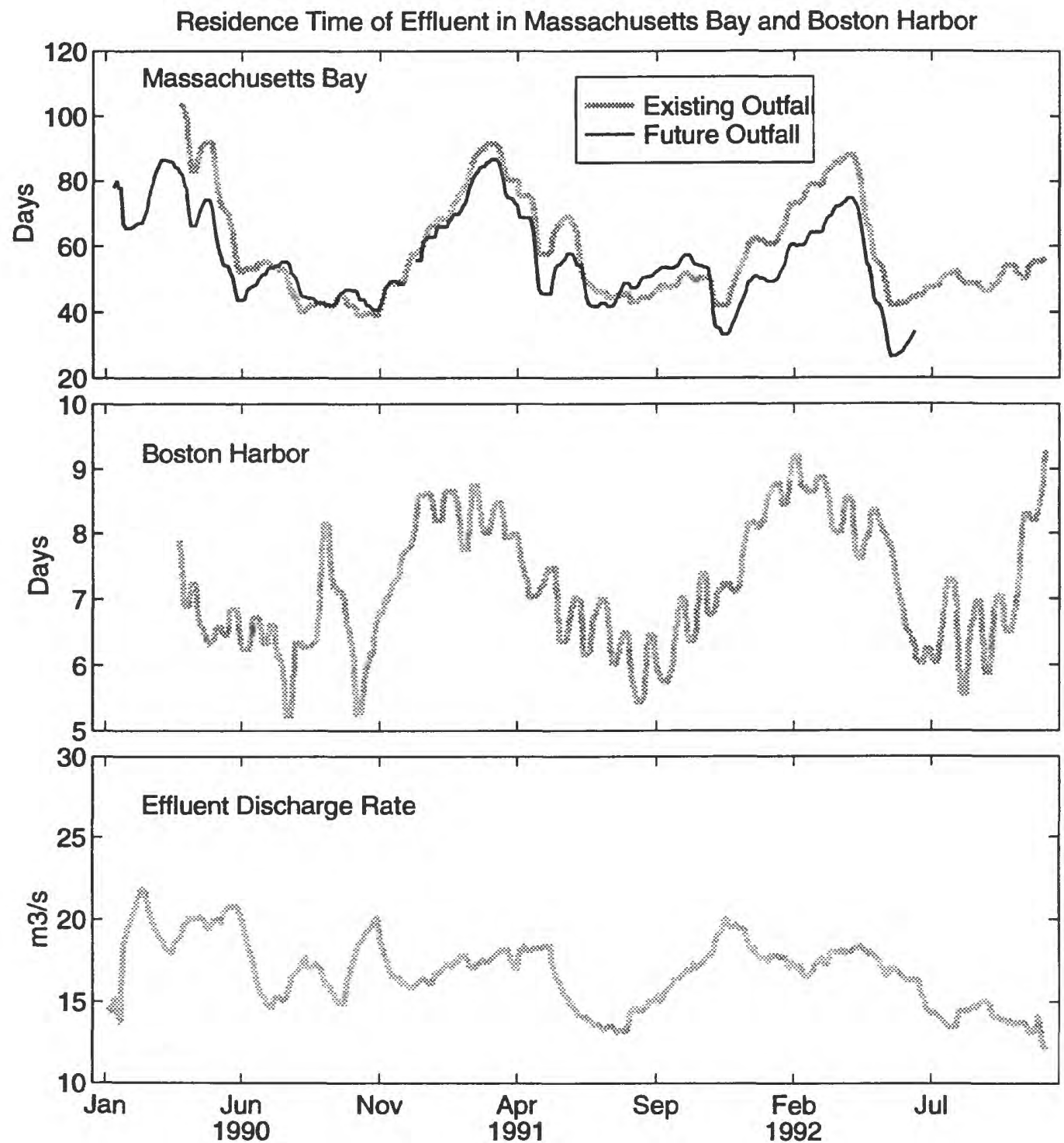

Figure 4.5: Residence time for effluent determined by dividing the total amount of effluent in a the bay or harbor by the effluent loading rate. 
100 days, while the residence time in Boston Harbor is 5-9 days. The effluent has longer residence times in the winter and shorter residence times in the summer in both the harbor and the bay. Since the effluent discharge does not have a clear seasonal cycle, the change in residence time is presumably due to increased flushing. For the bay, the residence time calculated via this method changes over time scales that are comparable to or less than the residence time itself, indicating that an interpretation as total amount of effluent in the bay is more appropriate (since the loading is relatively constant). Effluent levels in the bay build during the fall and winter, reach a peak in March, then fall precipitously in April as the bay is flushed by energetic springtime currents. The lowest amounts of total effluent are found in summer, and as the water column destratifies, the effluent levels begin to climb again. 


\section{Chapter 5}

\section{Simulation of chlorination breakdown at the existing and future outfall locations}

One of the design considerations for the future outfall site was that it should be more than one tidal excursion offshore so that in the event of a chlorination failure, untreated effluent would not be swept into Boston area beaches on the incoming tide. Signell et al. (1992) showed that even at spring tide, the future outfall location is well offshore of the region from which Boston Harbor draws water on flood tide. To quantify the expected benefit of the offshore locations, however, chlorination failures were simulated in ECOMsi and the bacteria concentrations were monitored at beaches throughout Massachusetts Bay. Chlorination failure was modeled as a breakdown that releases concentrations of $5,000,000$ cells $/ 100 \mathrm{ml}$ for a period of 1 day. A e-folding decay timescale of 12 hours was used to simulate die-off of the bacteria.

Since currents are variable, chlorination failures were simulated every 10 days over a one year period from October 1989 to October 1990, and the observed concentration levels were monitored at 15 different beaches and harbors along the coast (Table 5.1).

Two runs were conducted, one for the existing outfalls at Nut and Deer Islands, and one for the future outfall near the Boston Buoy. For each location, the number of events where the concentration (counts/100 ml) exceeded various values were calculated, and are shown in Tables 5.2 and 5.3. Events 


\begin{tabular}{rrrl} 
Number & Longitude & Latitude & Location \\
\hline 1 & -70.6667 & 42.5833 & Glouchester Harbor \\
2 & -70.8333 & 42.4917 & Marblehead Neck \\
3 & -70.9333 & 42.4333 & Nahant Beach \\
4 & -70.9667 & 42.3833 & Winthrop Beach \\
5 & -71.0000 & 42.2750 & Wollaston Beach \\
6 & -70.8833 & 42.3000 & Nantasket Beach \\
7 & -70.7500 & 42.2333 & N. Scituate Beach \\
8 & -70.7000 & 42.1333 & Humarock \\
9 & -70.6333 & 42.0167 & Duxbury Beach \\
10 & -70.6333 & 41.9500 & Plymouth Beach \\
11 & -70.5167 & 41.8000 & Sagamore Beach \\
12 & -70.3333 & 41.7417 & Sandy Neck \\
13 & -70.0667 & 41.9000 & Great Island \\
14 & -70.2333 & 42.0667 & Race Point
\end{tabular}

Table 5.1: Locations monitored in chlorination failure simulations.

were only counted if they occurred at least 5 days after the previous event.

The future outfall location obviously has a large beneficial effect, as the the total number of events with concentrations greater than 5 counts $/ 100 \mathrm{ml}$ dropping from 136 to 6 and the number of events greater than 10 counts/100 $\mathrm{ml}$ dropping from 130 to 0 . The existing outfall caused 12 events greater than 1000 counts $/ 100 \mathrm{ml}$, whereas the highest concentration for the future outfall was less than 10 counts $/ 100 \mathrm{ml}$. 


\begin{tabular}{lrrrrr} 
Counts $/ 100 \mathrm{ml}$ & Nahant & Winthrop & Wollaston & Nantasket & N. Scituate \\
\hline$>5$ & 19 & 35 & 37 & 33 & 7 \\
$>10$ & 15 & 33 & 37 & 31 & 4 \\
$>25$ & 7 & 24 & 37 & 28 & 2 \\
$>50$ & 4 & 20 & 37 & 19 & 1 \\
$>125$ & 0 & 11 & 37 & 9 & 0 \\
$>250$ & 0 & 6 & 30 & 7 & 0 \\
$>500$ & 0 & 2 & 23 & 3 & 0 \\
$>1000$ & 0 & 0 & 12 & 0 & 0 \\
$>2500$ & 0 & 0 & 2 & 0 & 0 \\
$>5000$ & 0 & 0 & 0 & 0 & 0
\end{tabular}

Table 5.2: Bacteria concentrations for breakdown of existing plant. Note: Glouchester Harbor, Marblehead Neck, Humarock, Duxbury Beach, Plymouth Beach, Sagamore Beach, Sandy Neck, Great Island, and Race Point had no events that exceeded 5 counts $/ 100 \mathrm{ml}$.

\begin{tabular}{llrrrr} 
Counts $/ 100 \mathrm{ml}$ & Nahant & Winthrop & Wollaston & Nantasket & N. Scituate \\
\hline$>5$ & 1 & 0 & 0 & 1 & 4 \\
$>10$ & 0 & 0 & 0 & 0 & 0 \\
$>25$ & 0 & 0 & 0 & 0 & 0 \\
$>50$ & 0 & 0 & 0 & 0 & 0 \\
$>125$ & 0 & 0 & 0 & 0 & 0 \\
$>250$ & 0 & 0 & 0 & 0 & 0 \\
$>500$ & 0 & 0 & 0 & 0 & 0 \\
$>1000$ & 0 & 0 & 0 & 0 & 0 \\
$>2500$ & 0 & 0 & 0 & 0 & 0 \\
$>5000$ & 0 & 0 & 0 & 0 & 0
\end{tabular}

Table 5.3: Bacteria concentrations for breakdown of future plant. 


\section{Chapter 6}

\section{Summary}

Comparison of model results with observations indicated that ECOM-si simulations are appropriate for studying the continuous release of effluent in western Massachusetts Bay, as they reproduce the most important features of the observed stratification and current regime in this region. The seasonal development and breakdown of the thermocline occur within a few weeks of the correct time, the vertical structure has the right top-to-bottom density difference and about the right vertical profile (though the modeled pycnocline is not quite as sharp as reality), and the currents responsible for transporting material have about the right mean flow and level of variability. The fact that the best comparisons are found on the western side of Massachusetts Bay reflects the strong effect of local wind driving in this region, an effect that can be directly modeled rather than parameterized by boundary conditions. Further offshore, near Stellwagen Bank for example, the currents and water properties are largely determined by Gulf of Maine conditions, and the model does not compare as well. Although significant improvements to salinity boundary conditions were obtained by including an adjunct model to model the western Gulf of Maine, boundary conditions remain one of the largest roadblocks to obtaining more realistic simulations. In the future, improvement of boundary condition information may be obtained from a time-varying coarser scale model of the entire Gulf of Maine or possibly from data collected from sensors at strategic locations and assimilated into model runs.

The effluent simulations show that with either the existing or future outfall, the region of Massachusetts Bay that experiences relatively high effluent 
concentration ( 1 part effluent: 200 parts sea water) is relatively small and confined to western Massachusetts Bay. The region of high concentration (1:50) that covers much of Boston Harbor with the existing outfall is completely eliminated with the future outfall scenario. This is consistent with the results of the two-dimensional modeling conducted as part of the outfall siting process (MWRA, 1988). The subsurface areal extent of the bottom trapped summertime plume is about the same size as the winter plume for the future outfall scenario. Although the initial vertical mixing of the effluent is confined to the lower half of column during the summer, this effect is offset by stronger currents and shears during the summer that act to increase dispersion. The total amount of effluent in the bay obtained from the future outfall is within $10 \%$ of that obtained from the existing outfall, and the time series track each other closely. Effluent levels build up over the winter, reaching their peak in March before being greatly reduced by the increased flushing of the system in April. 
Appendix A

Model/Data Comparison of Time Series Velocity at the Boston Buoy 

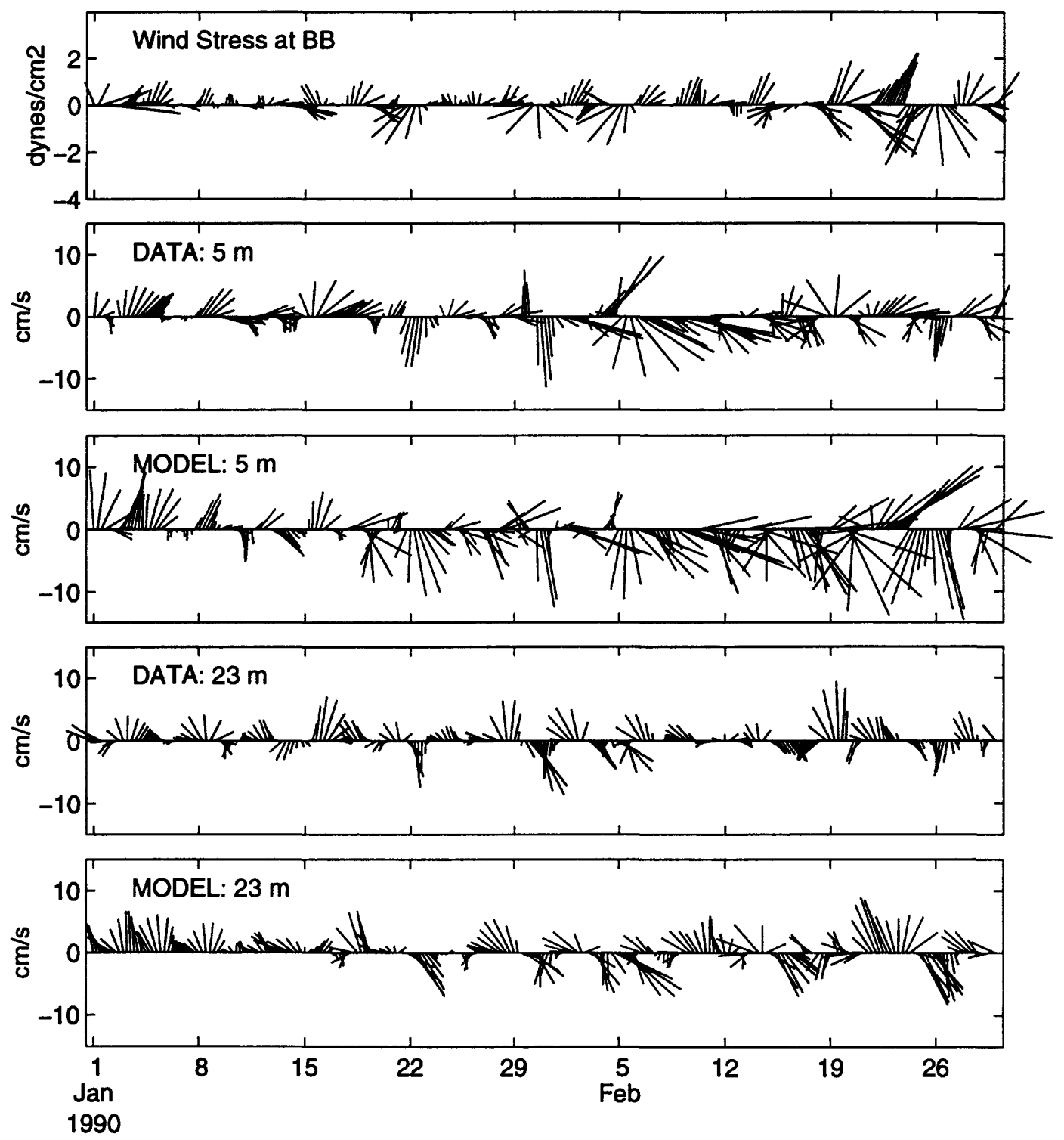

Figure A.1: Boston Buoy velocity comparison: Jan 1, 1990 - Feb 26, 1990. 

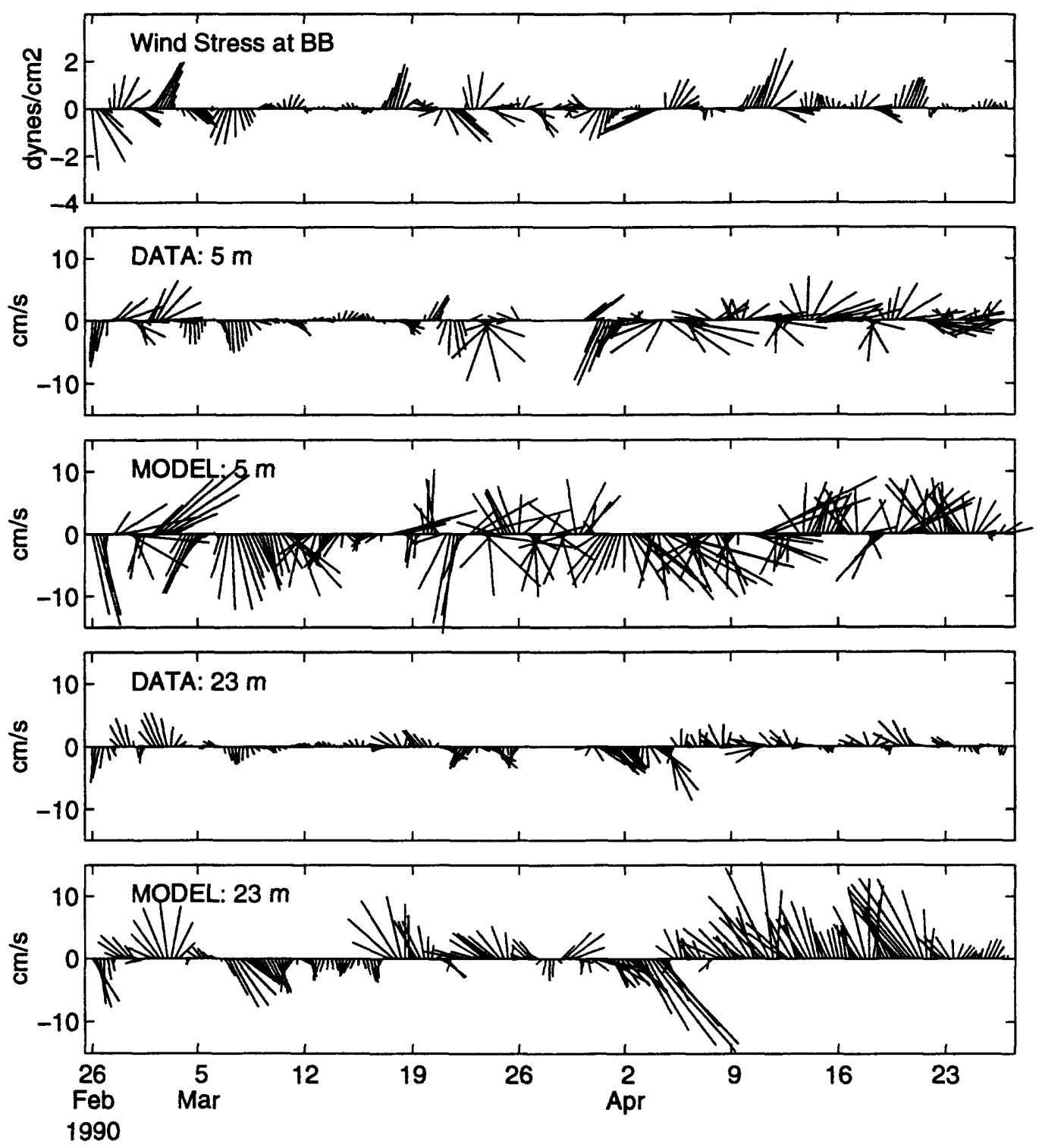

Figure A.2: Boston Buoy velocity comparison: Feb 26, 1990 - Apr 23, 1990. 

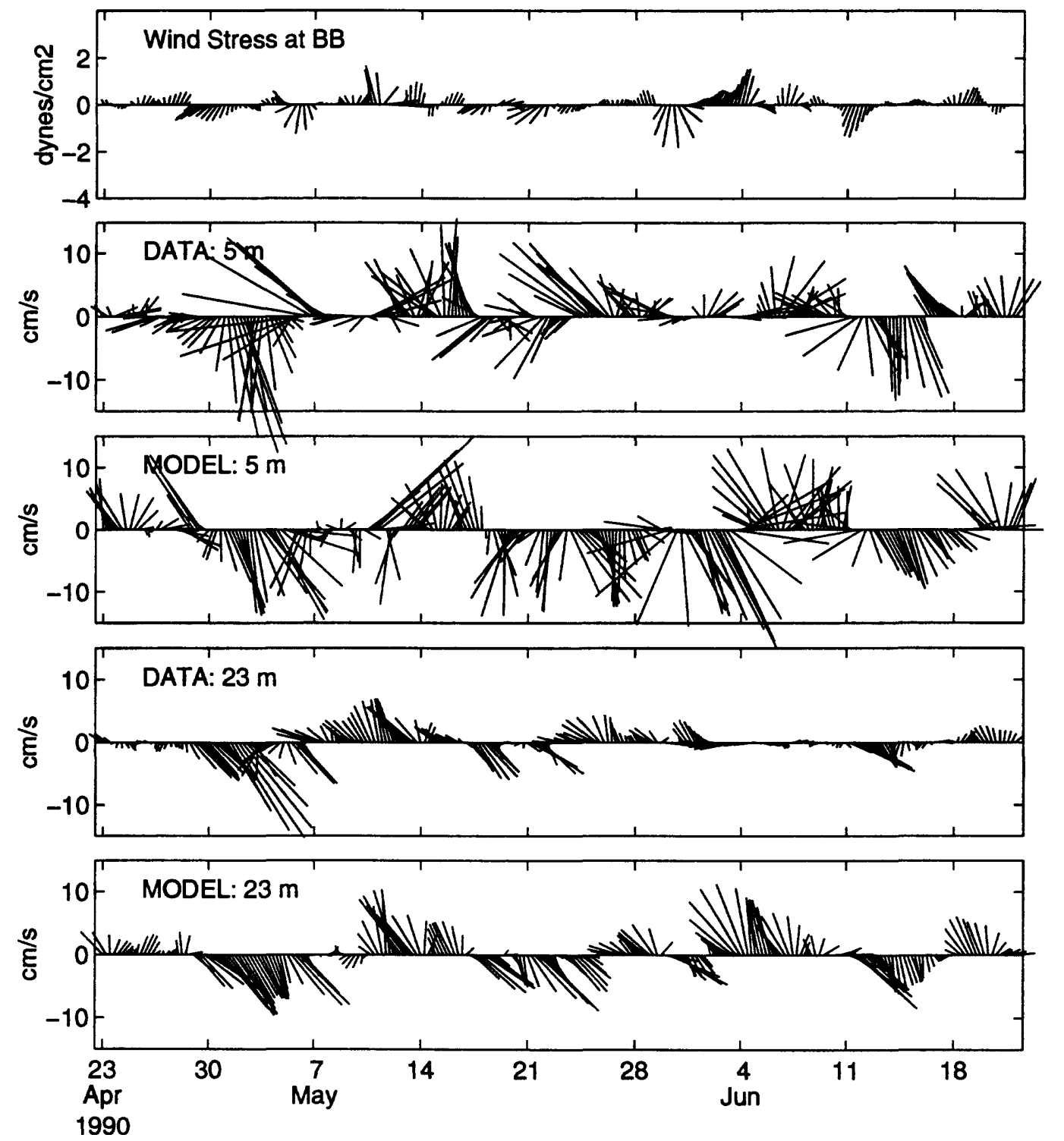

Figure A.3: Boston Buoy velocity comparison: Apr 23, 1990 - Jun 18, 1990. 

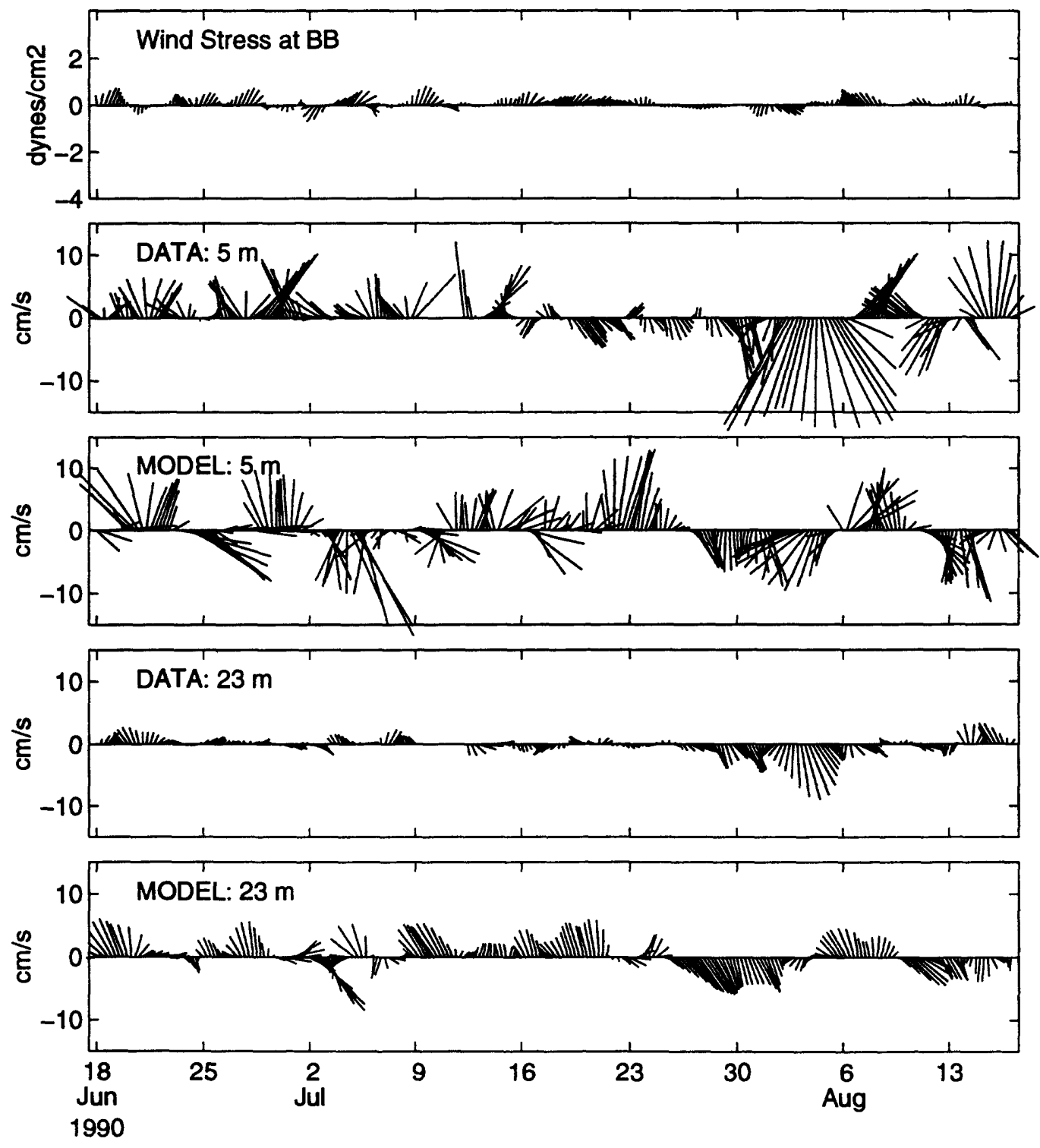

Figure A.4: Boston Buoy velocity comparison: Jun 18, 1990 - Aug 13, 1990. 

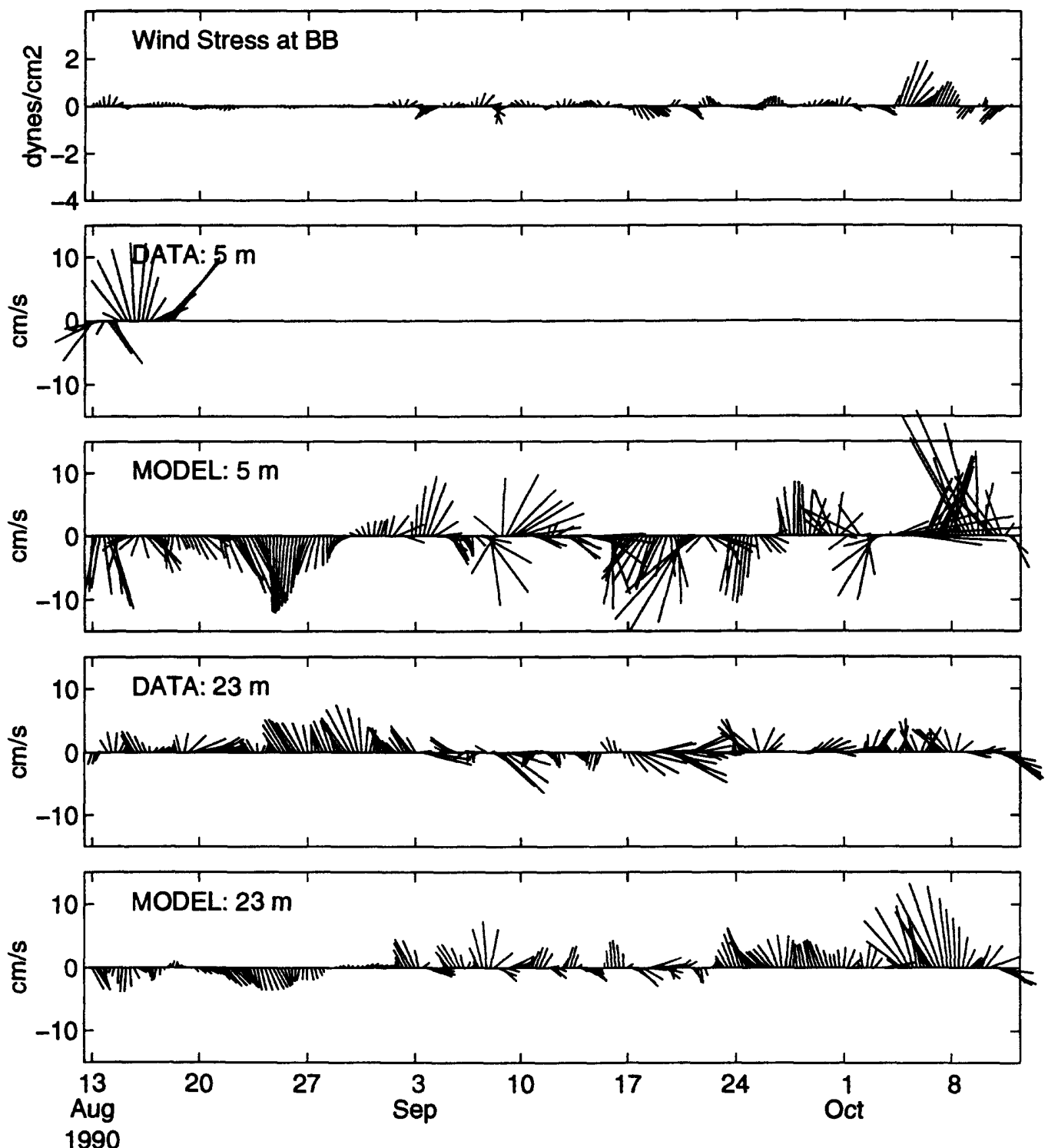

Figure A.5: Boston Buoy velocity comparison: Aug 13, 1990 - Oct 8, 1990. 

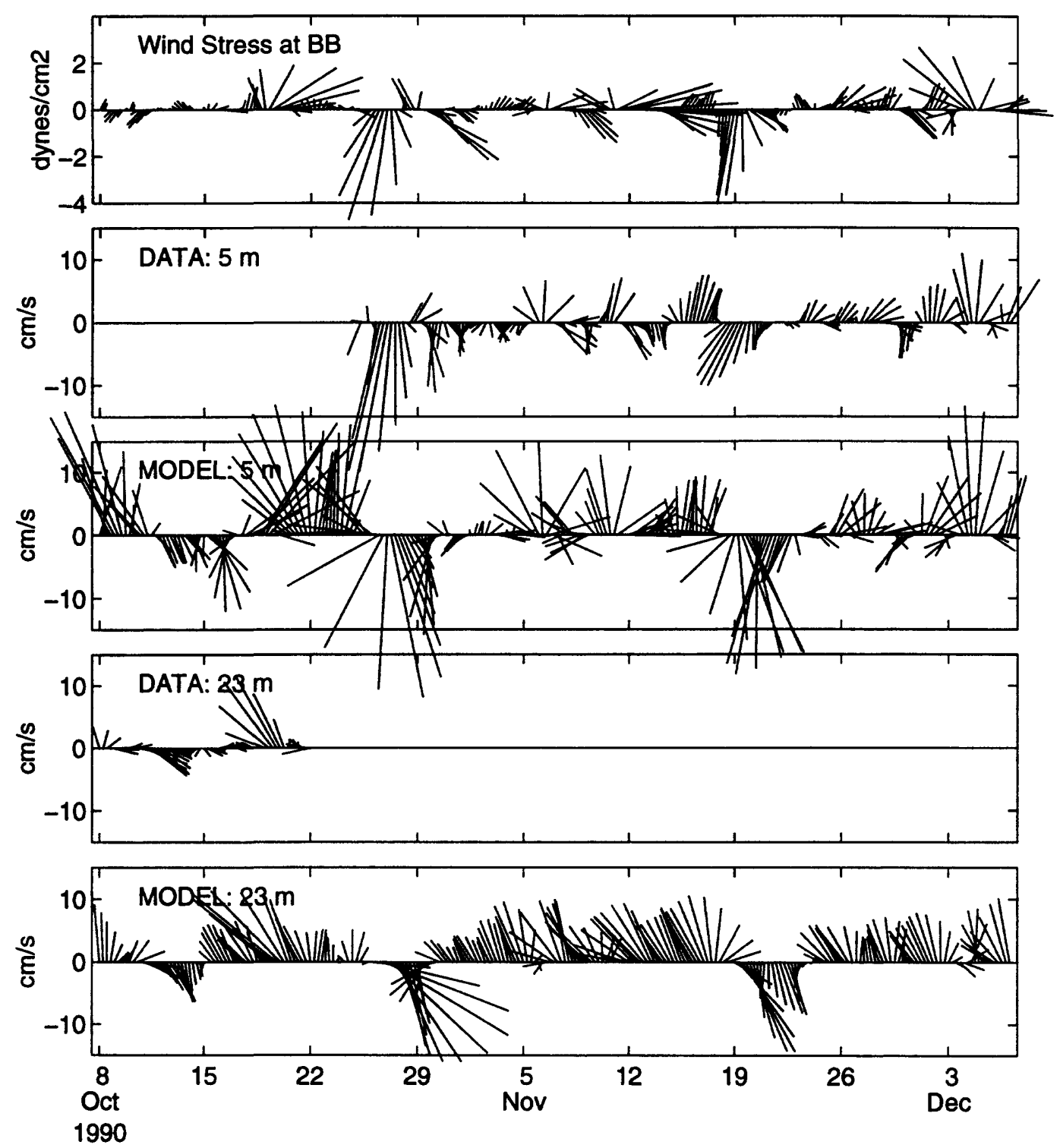

Figure A.6: Boston Buoy velocity comparison: Oct 8, 1990 - Dec 3, 1991. 

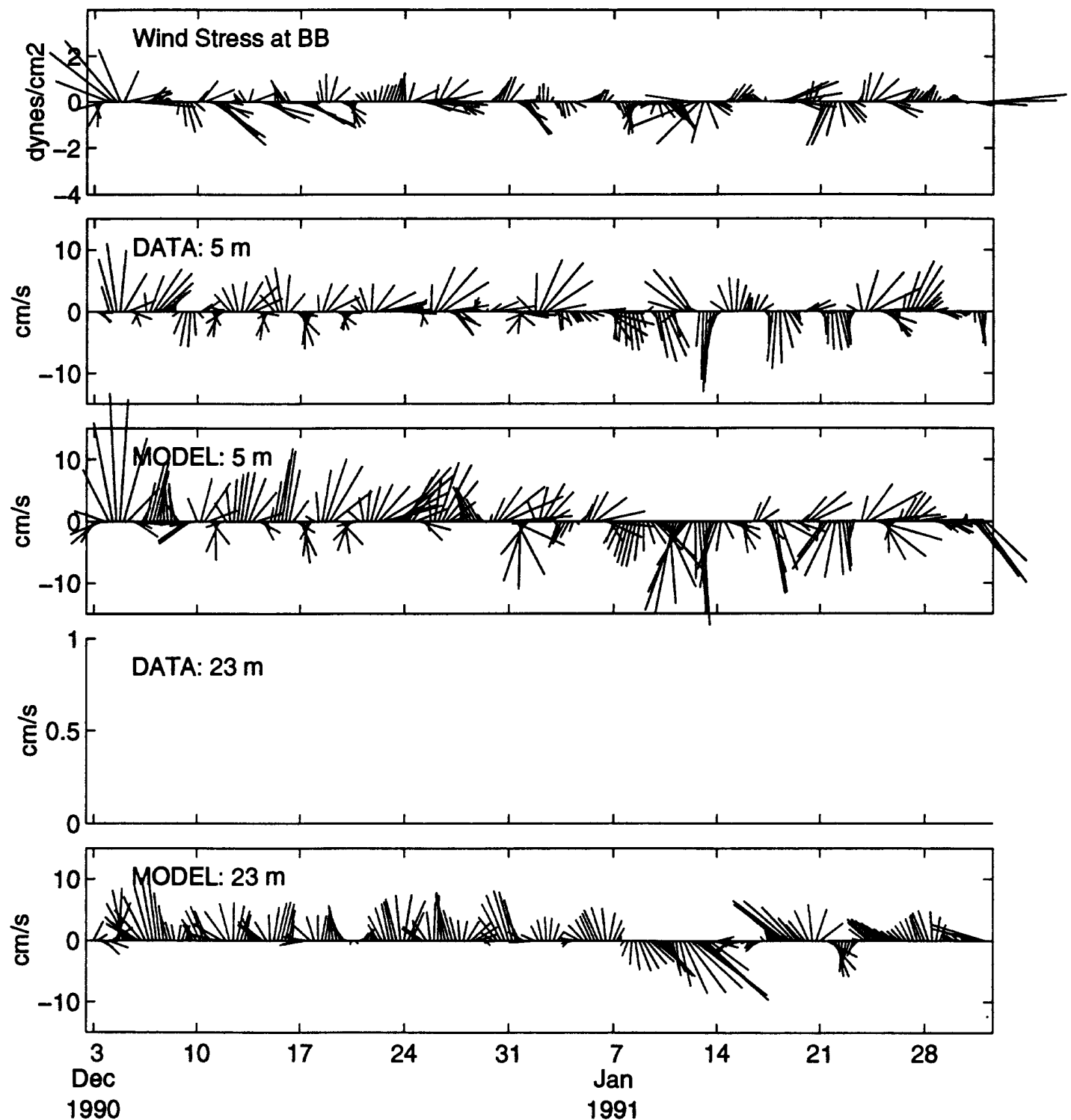

Figure A.7: Boston Buoy velocity comparison: Dec 3, 1990 - Jan 28, 1990. 

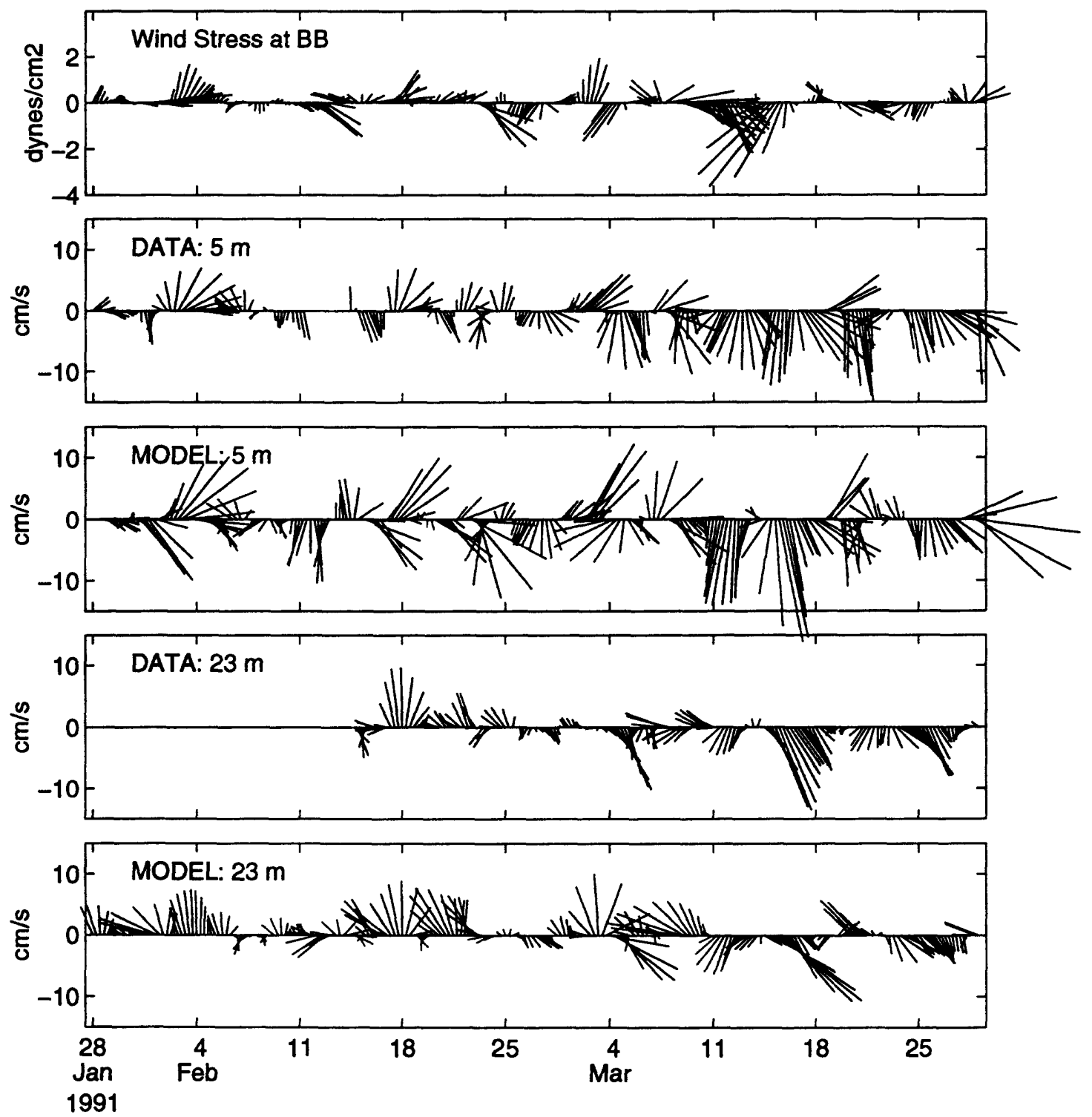

Figure A.8: Boston Buoy velocity comparison: Jan 28, 1991 - Mar 25, 1991. 

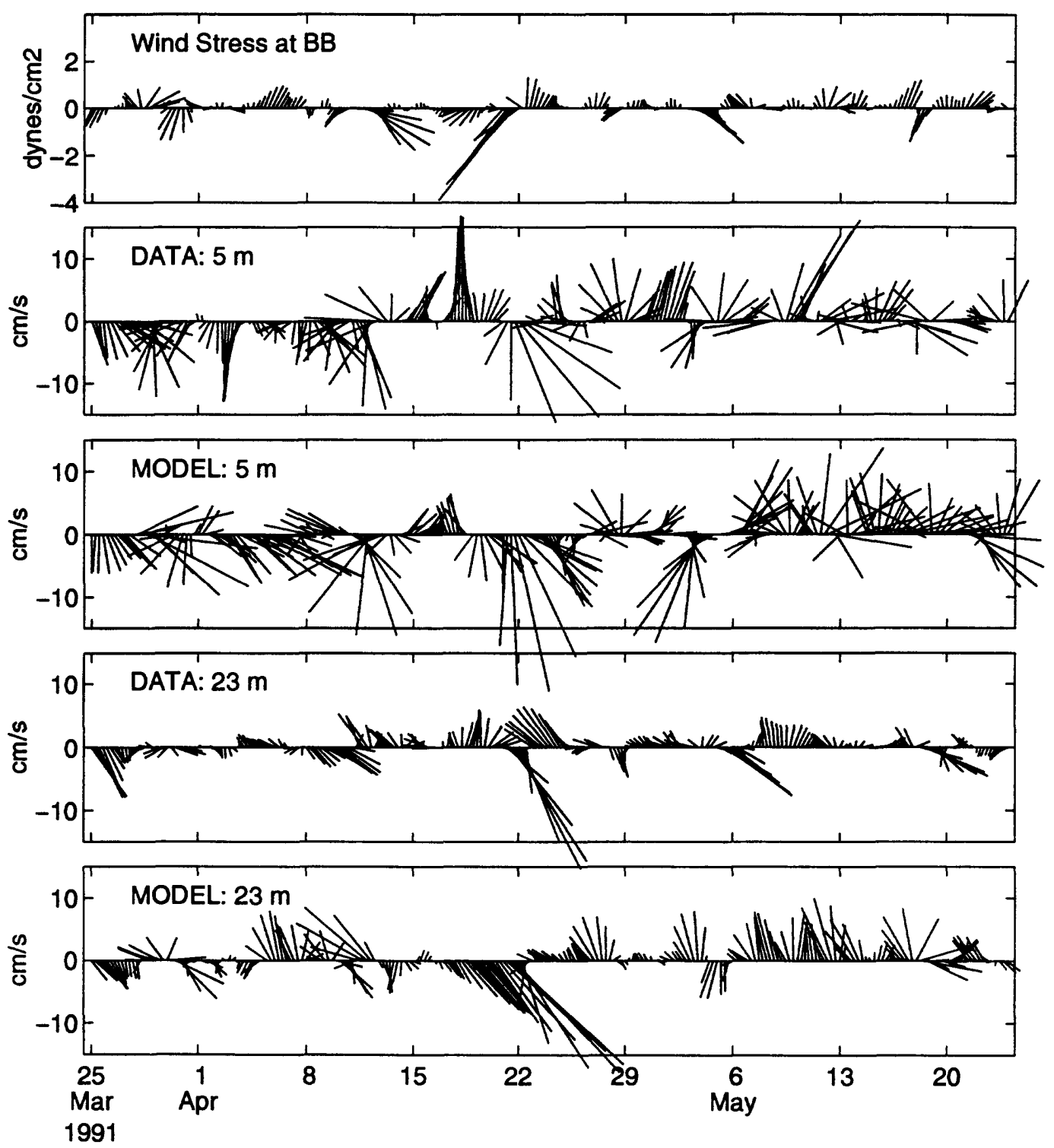

Figure A.9: Boston Buoy velocity comparison: Mar 25, 1991 - May 20, 1991. 

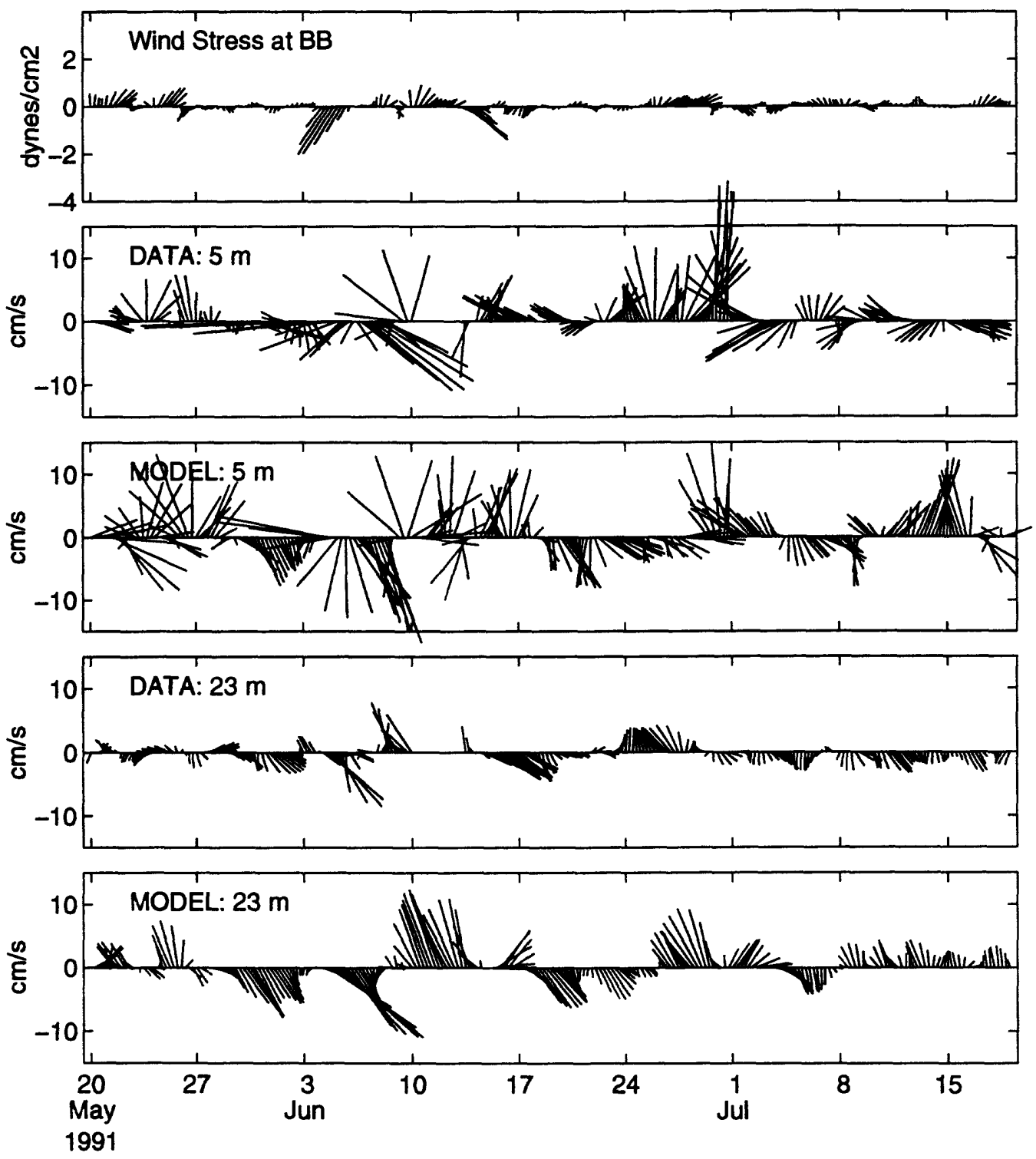

Figure A.10: Boston Buoy velocity comparison: May 20, 1991 - Jul 15, 1991. 

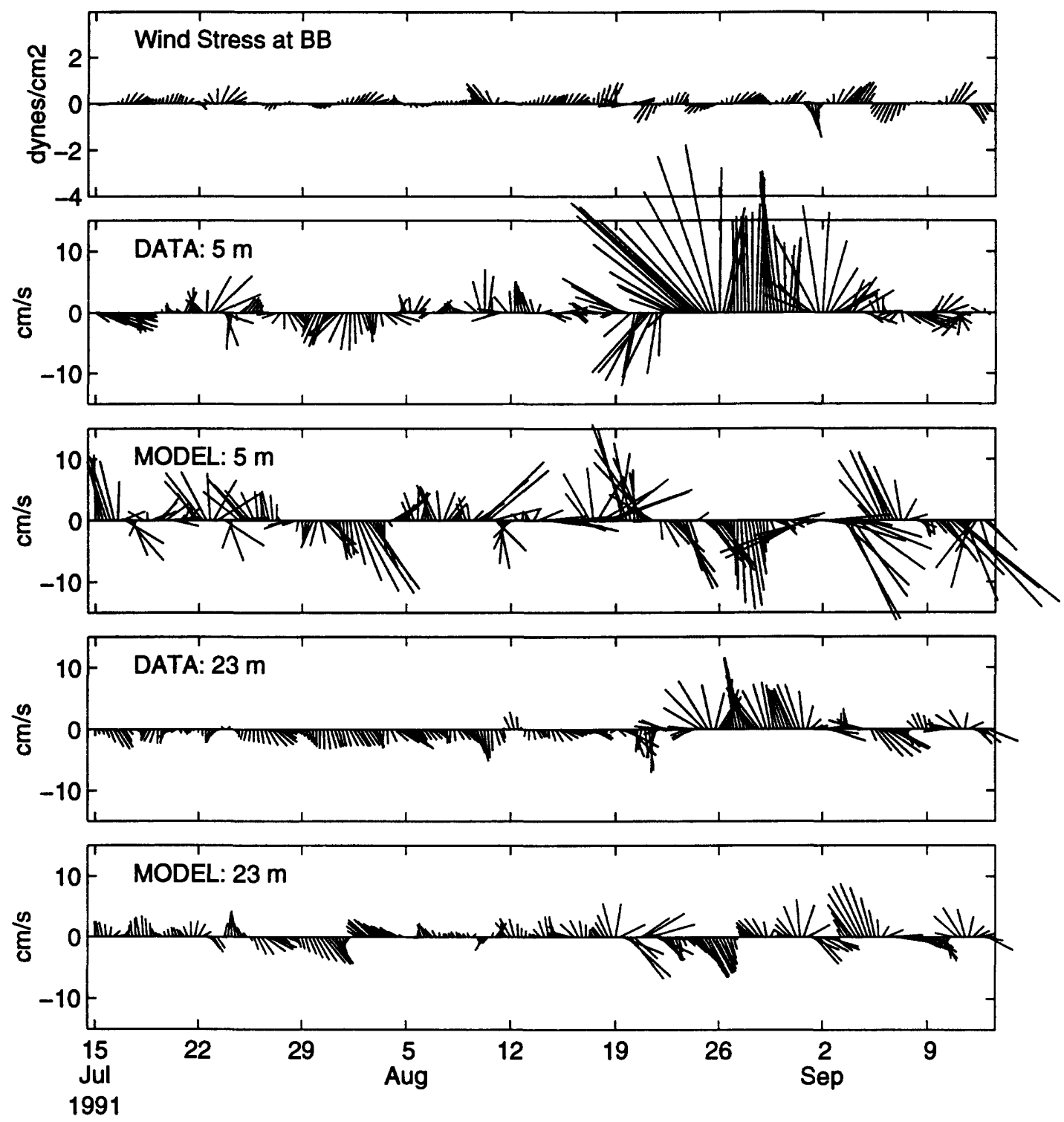

Figure A.11: Boston Buoy velocity comparison: Jul 15, 1991 - Sep 9, 1991. 

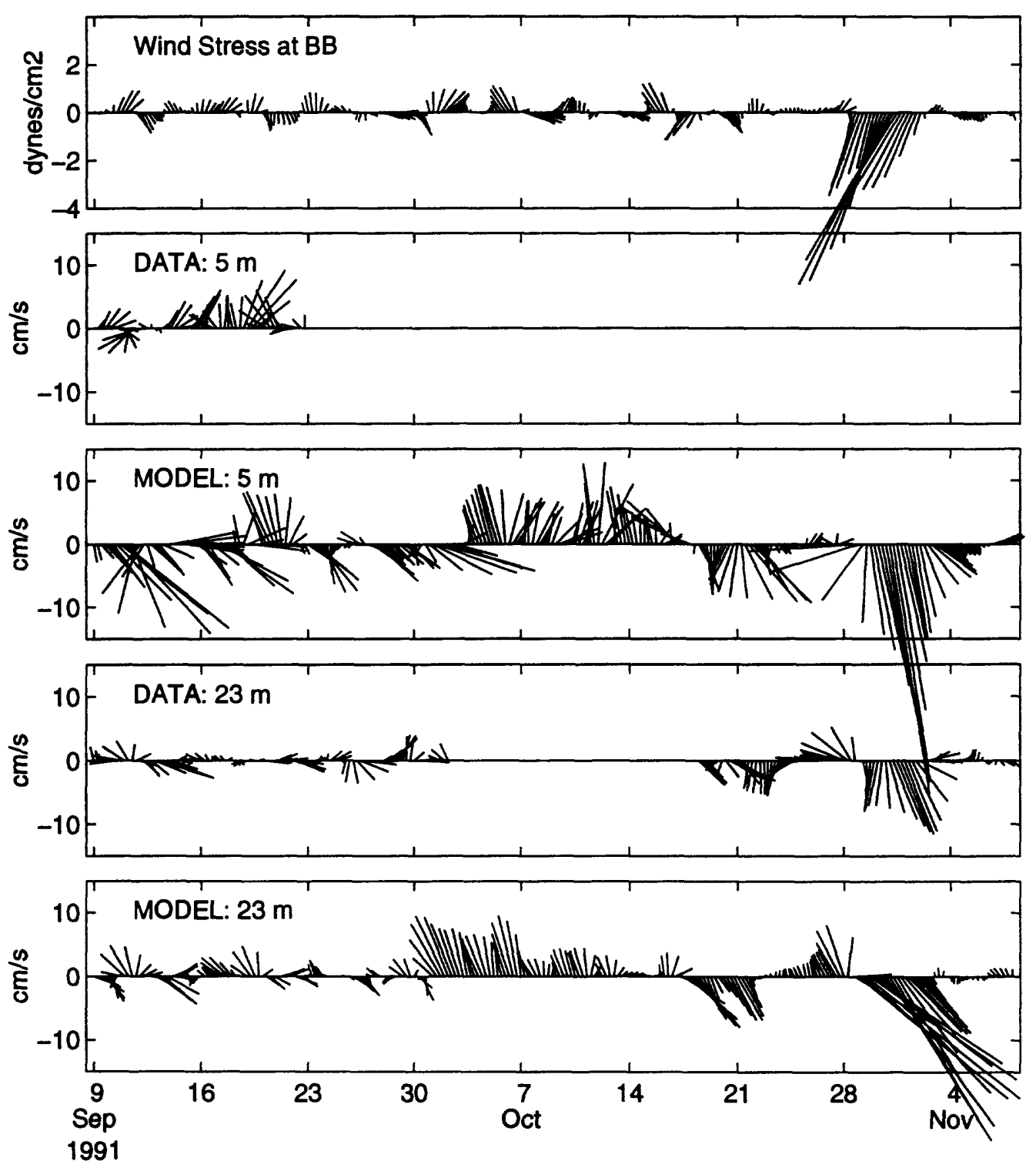

Figure A.12: Boston Buoy velocity comparison: Sep 9, 1991 - Nov 4, 1991. 

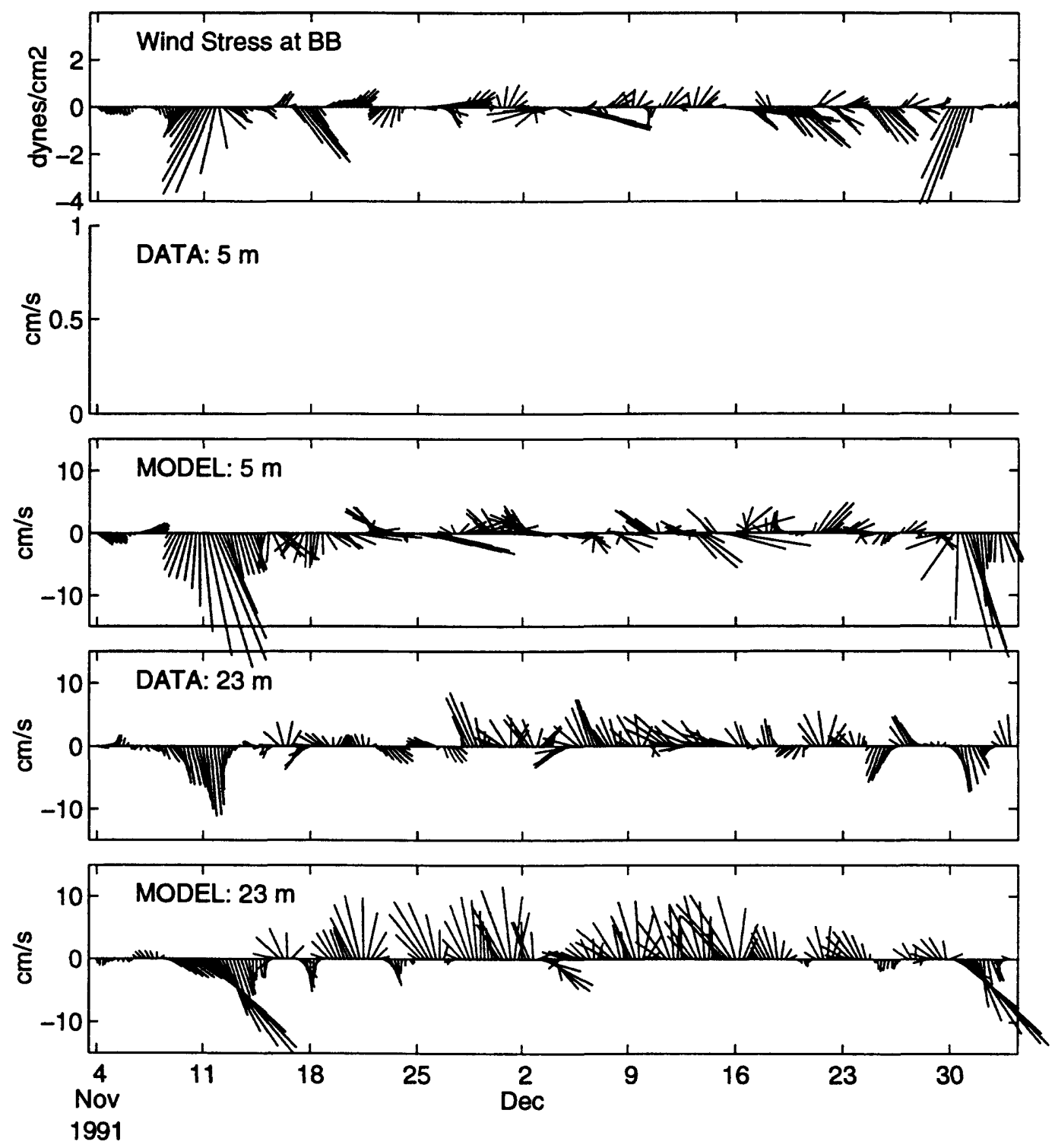

Figure A.13: Boston Buoy velocity comparison: Nov 4, 1991 - Dec 30, 1991. 

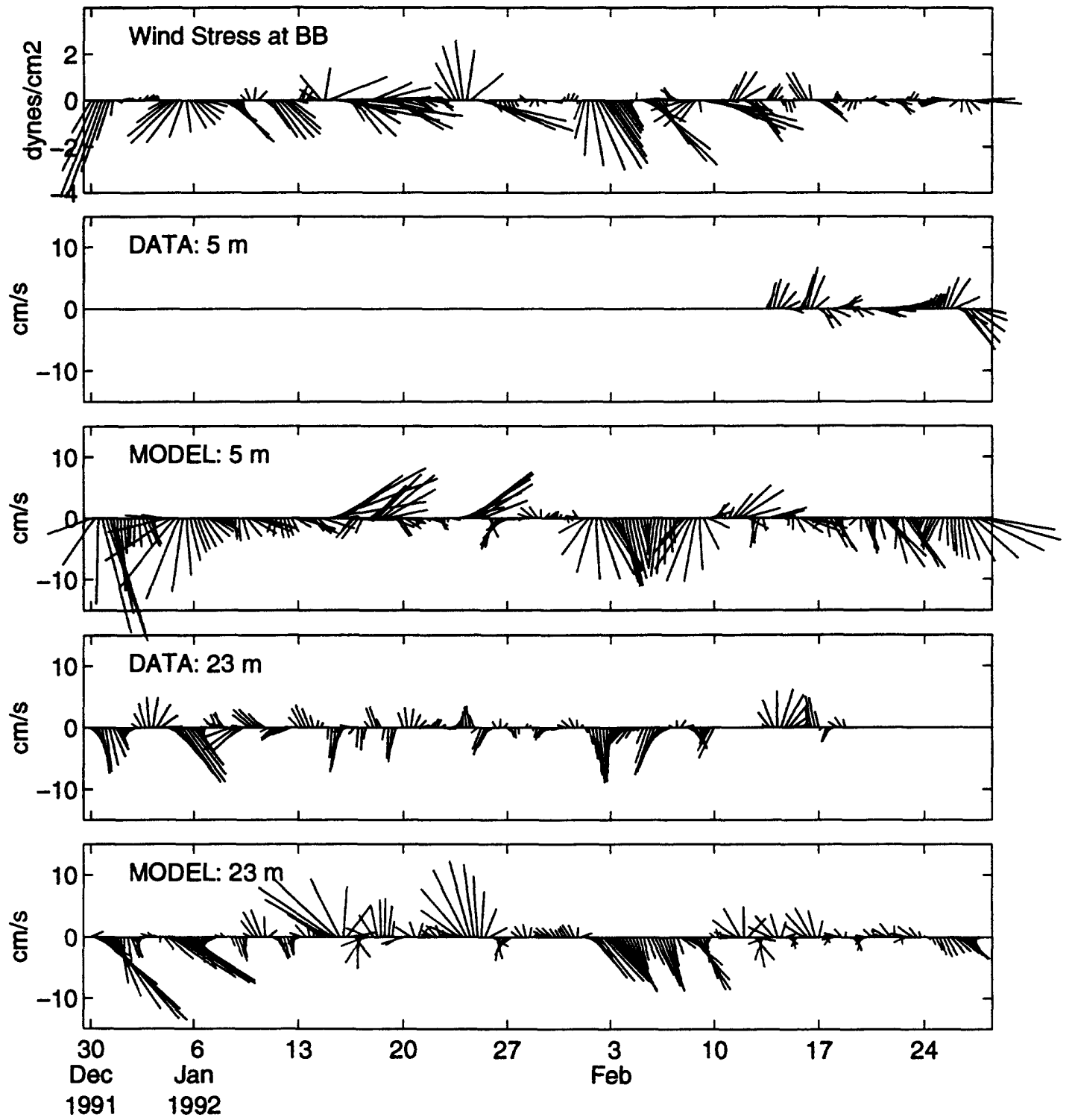

Figure A.14: Boston Buoy velocity comparison: Dec 30, 1991 - Feb 24, 1992. 

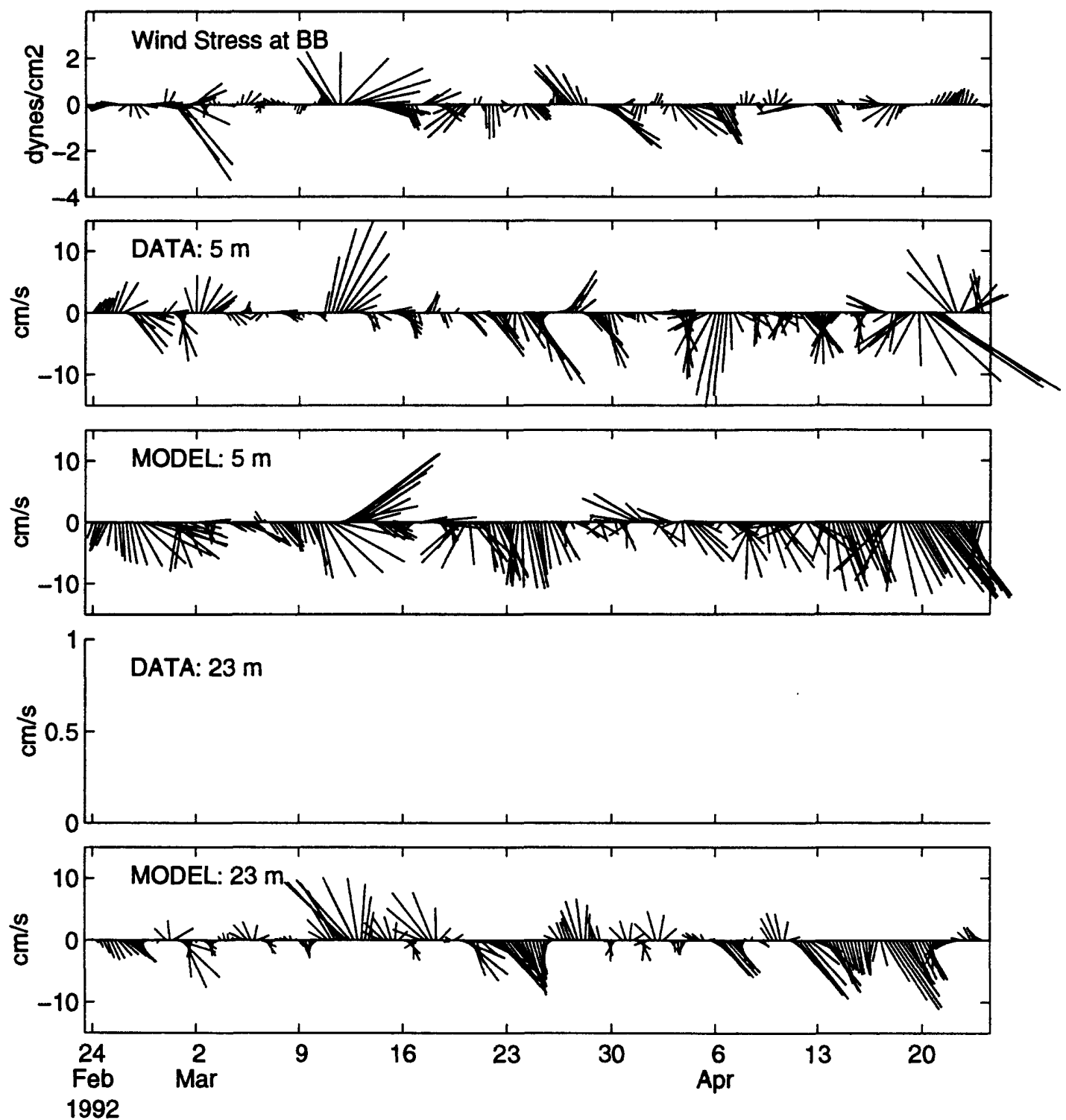

Figure A.15: Boston Buoy velocity comparison: Feb 24, 1992 - Apr 20, 1992. 

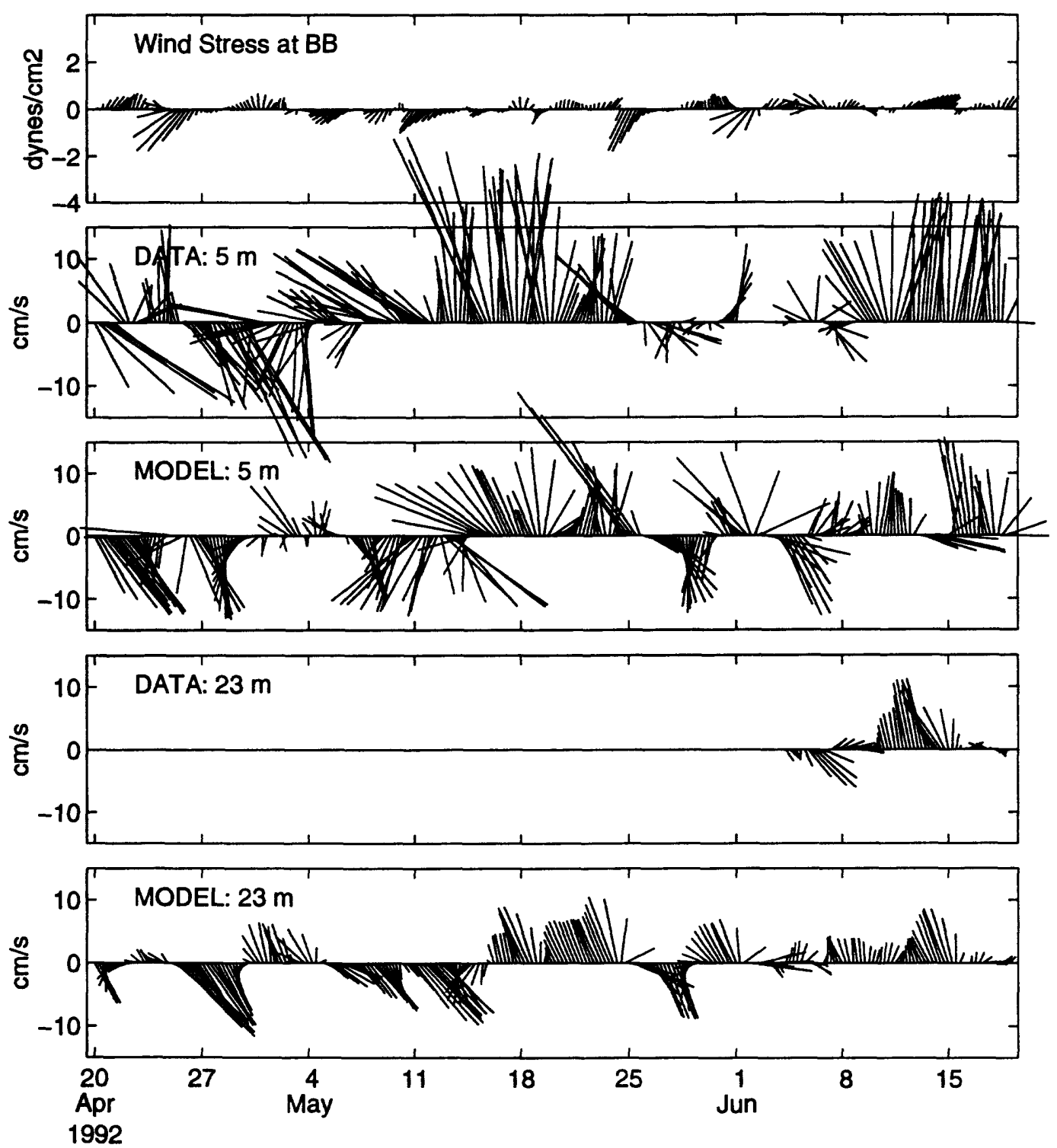

Figure A.16: Boston Buoy velocity comparison: Apr 20, 1992 - Jun 15, 1992. 

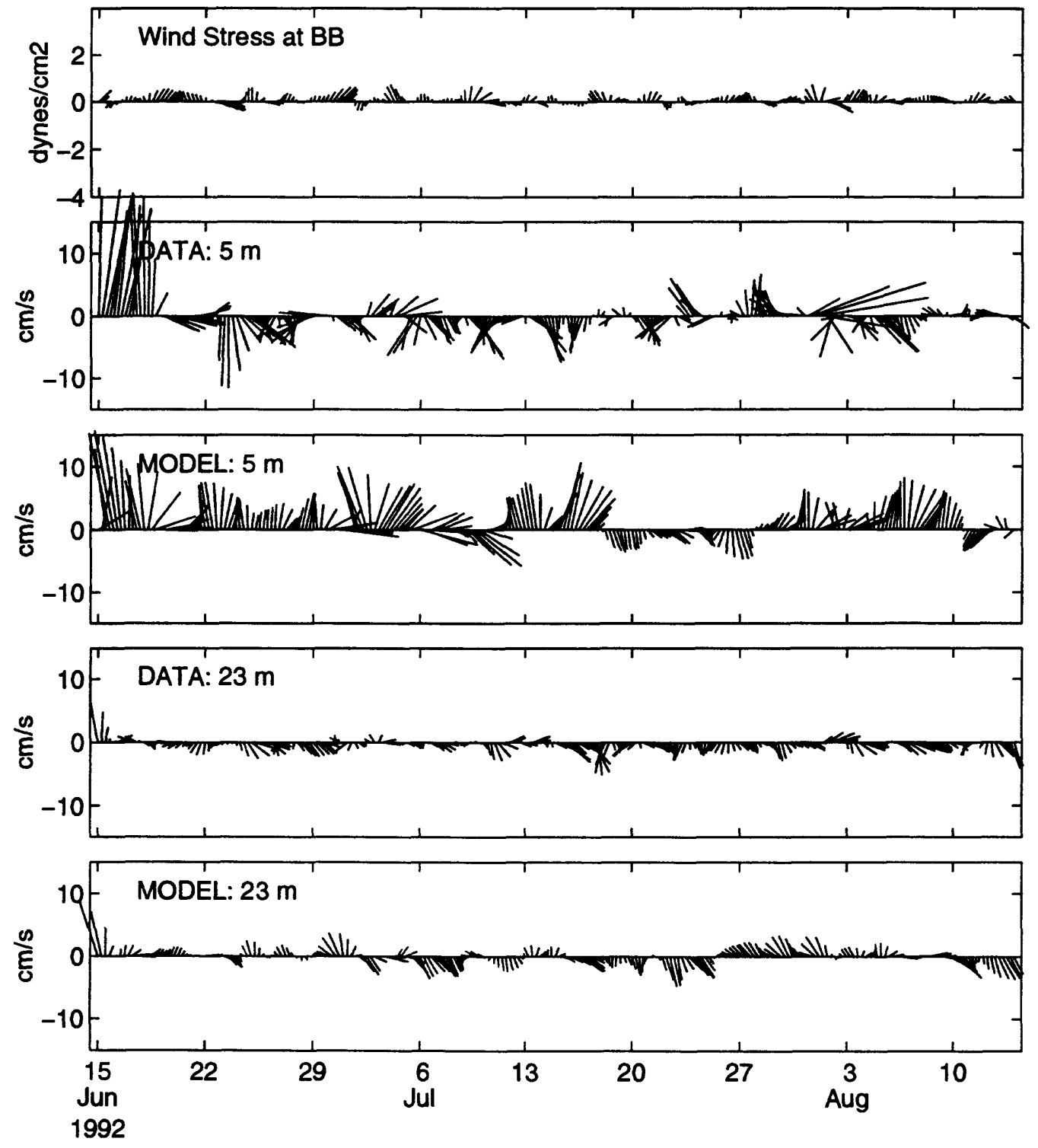

Figure A.17: Boston Buoy velocity comparison: Jun 15, 1992 - Aug 10, 1991. 

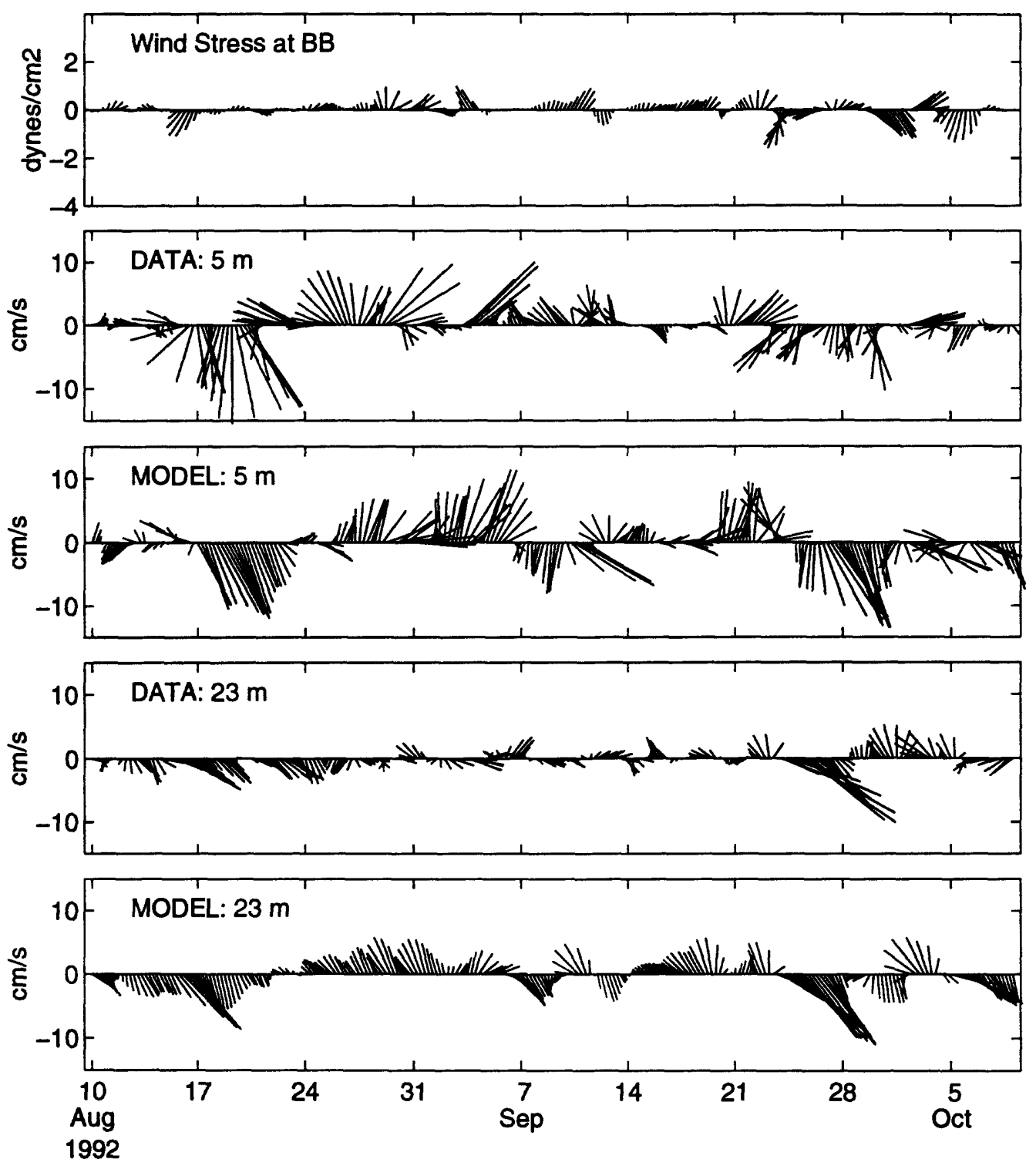

Figure A.18: Boston Buoy velocity comparison: Aug 10, 1992 - Oct 5, 1992. 

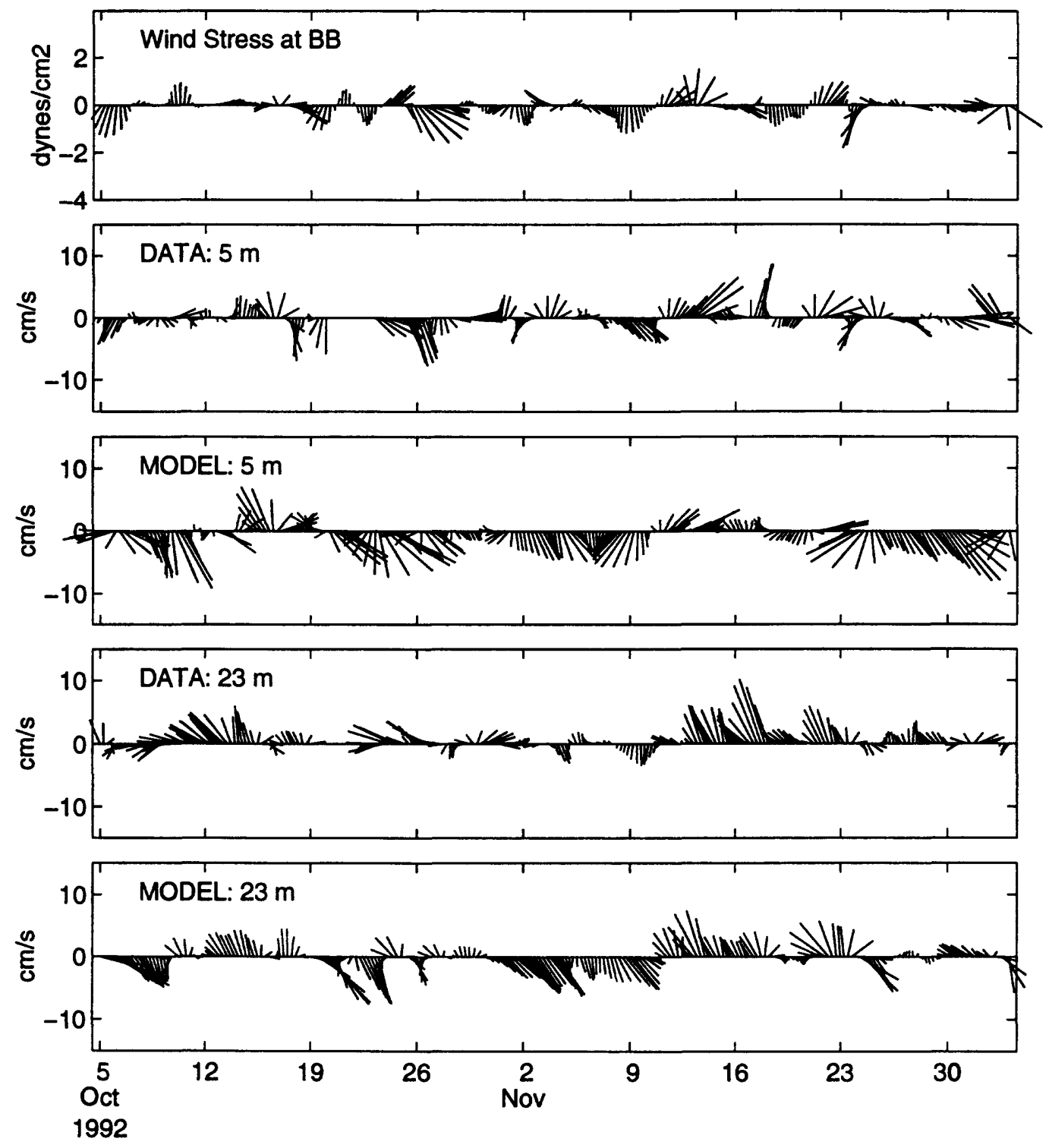

Figure A.19: Boston Buoy velocity comparison: Oct 5, 1992 - Nov 30, 1992. 
Appendix B

Mean Currents by Season 

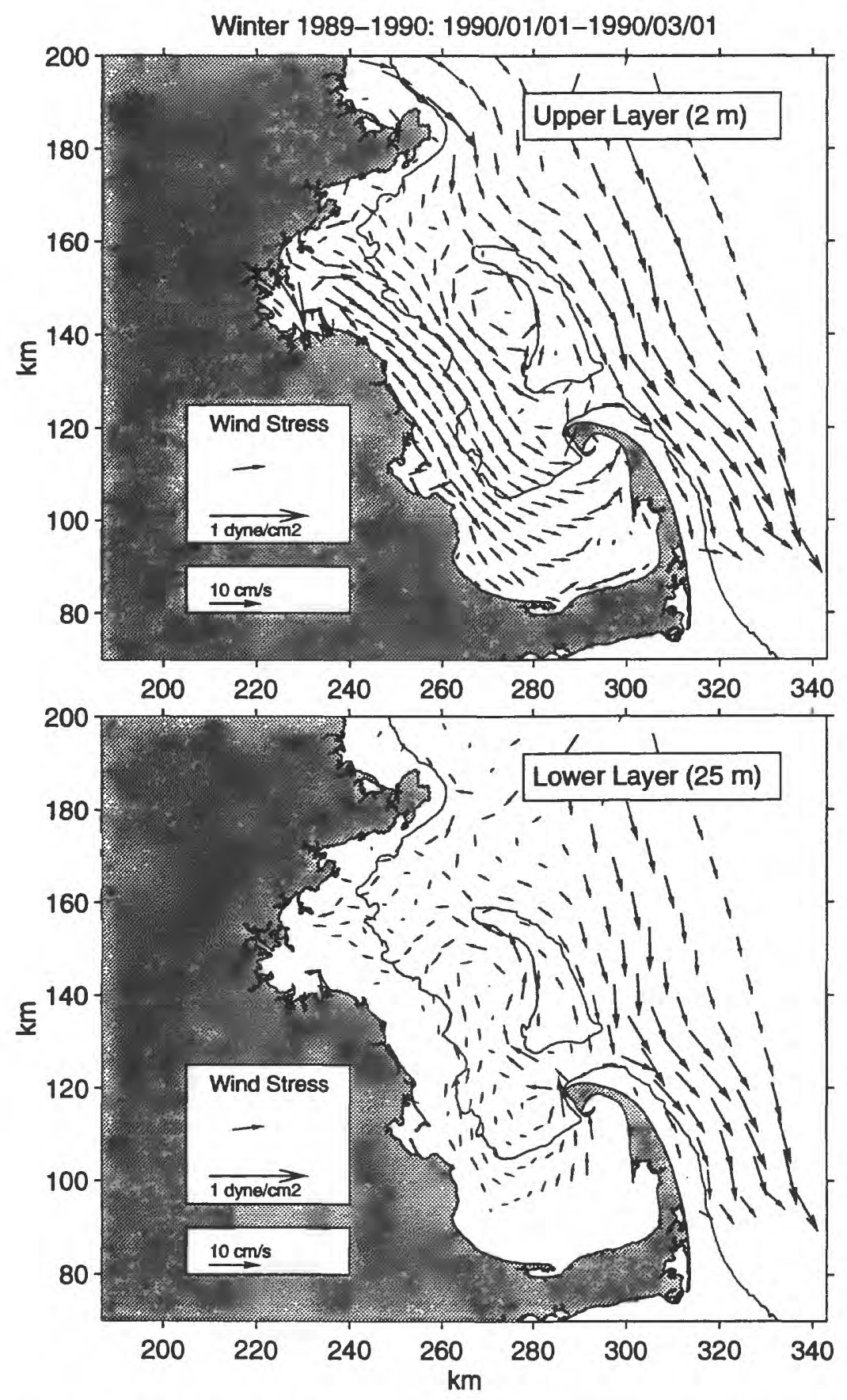

Figure B.1: Modeled mean flow at 2 and $20 \mathrm{~m}$ depth for Winter 1989-1990. 


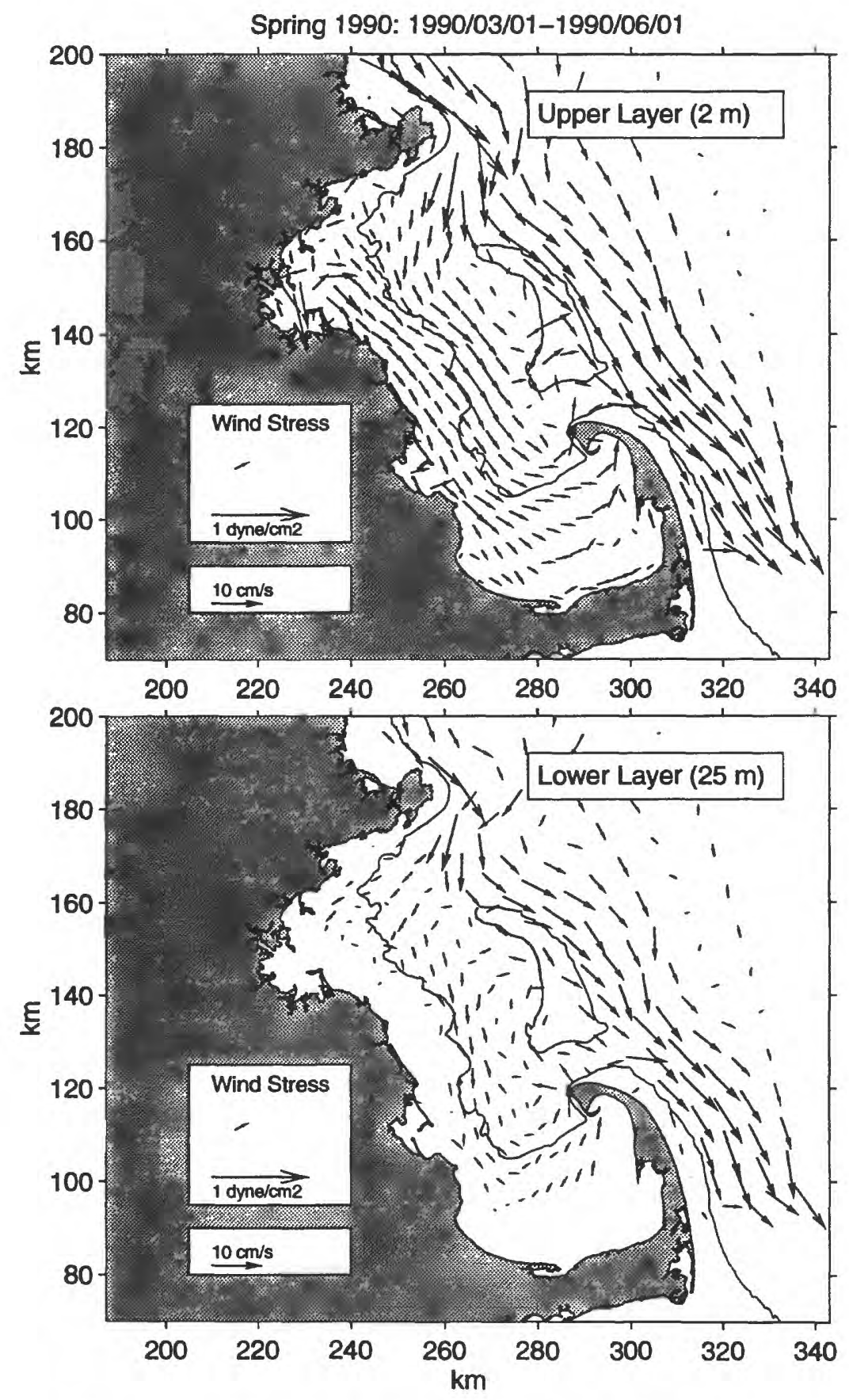

Figure B.2: Modeled mean flow at 2 and $20 \mathrm{~m}$ depth for Spring 1990. 


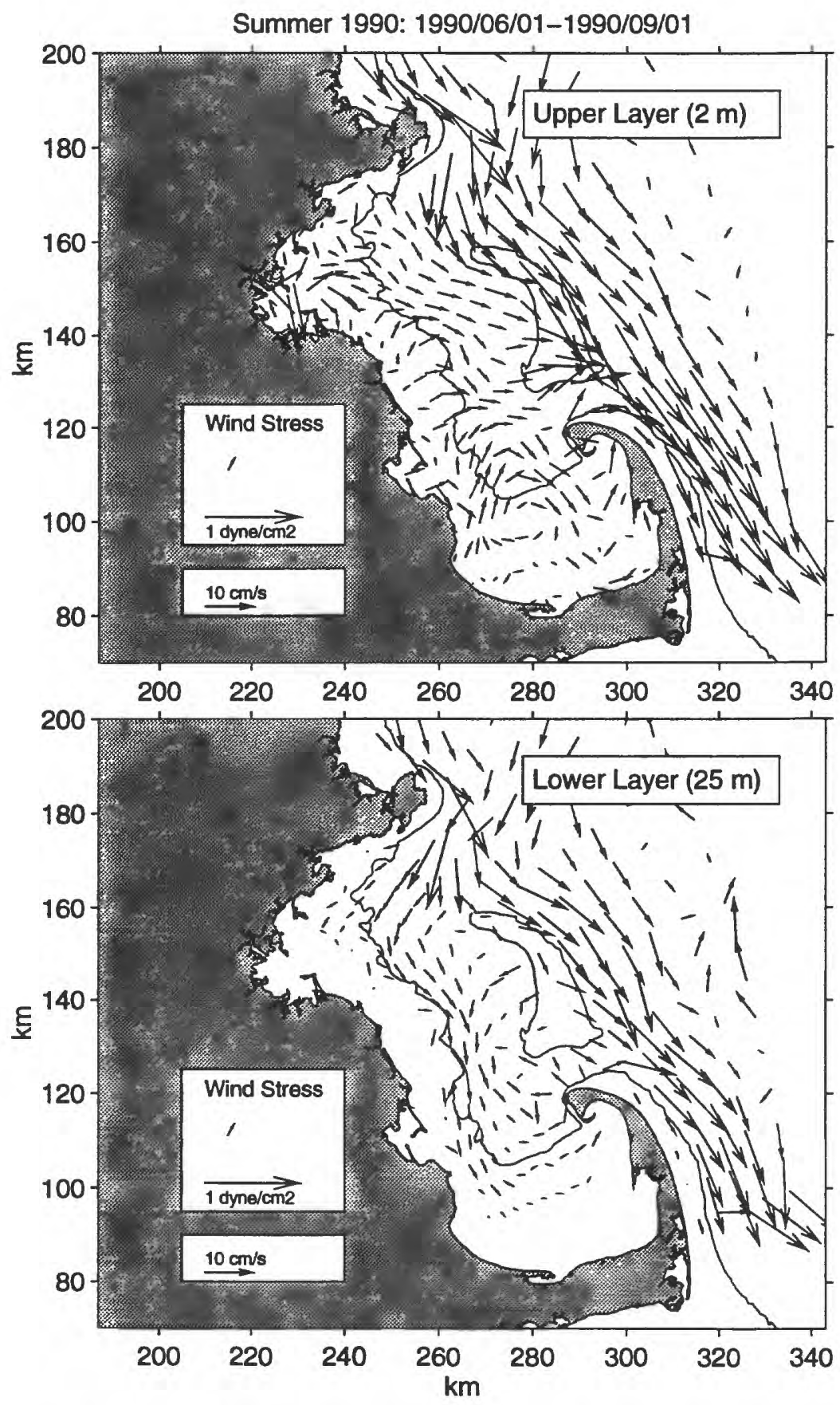

Figure B.3: Modeled mean flow at 2 and $20 \mathrm{~m}$ depth for Summer 1990. 


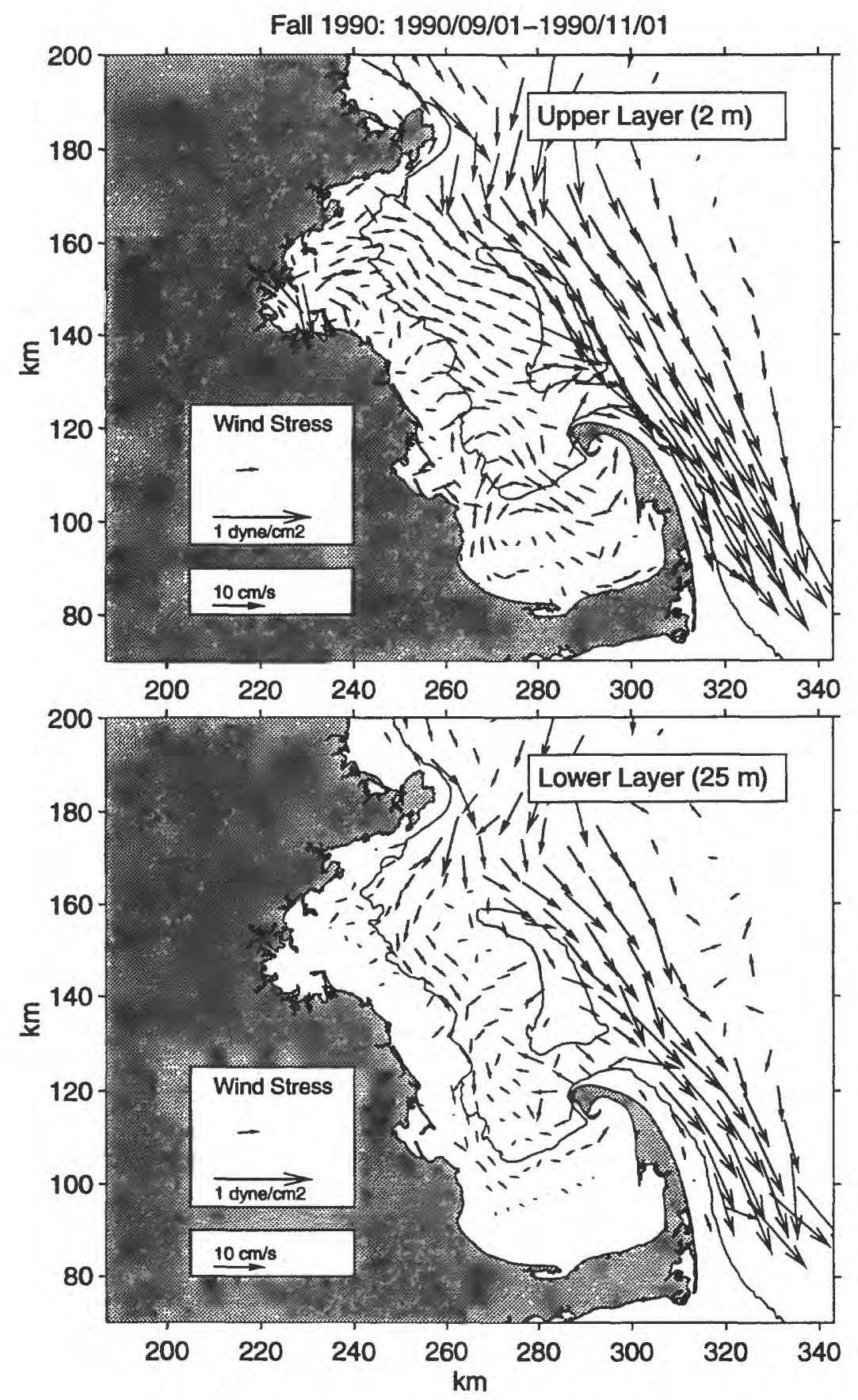

Figure B.4: Modeled mean flow at 2 and $20 \mathrm{~m}$ depth for Fall 1990. 


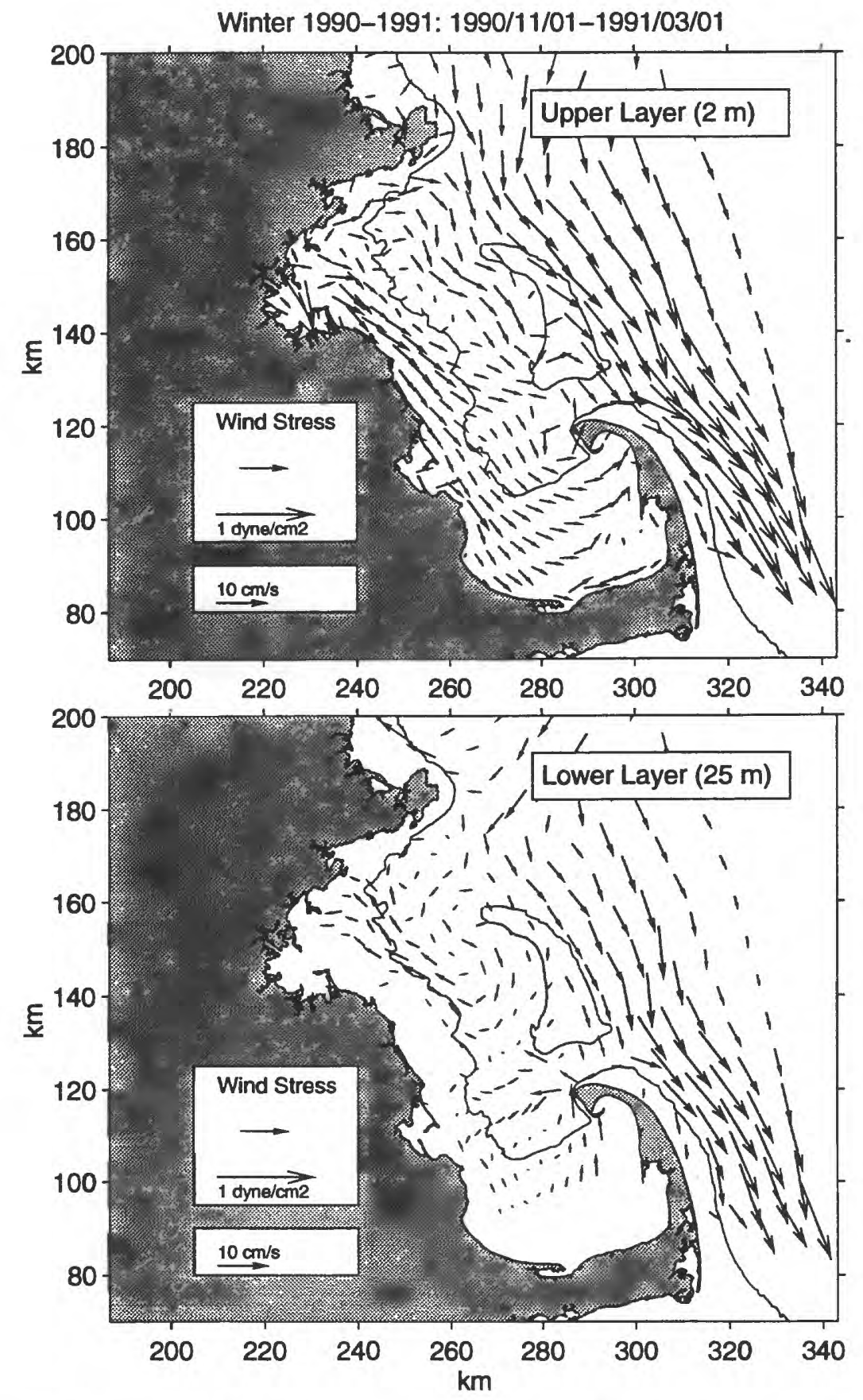

Figure B.5: Modeled mean flow at 2 and 20 m depth for Winter 1990-1991. 


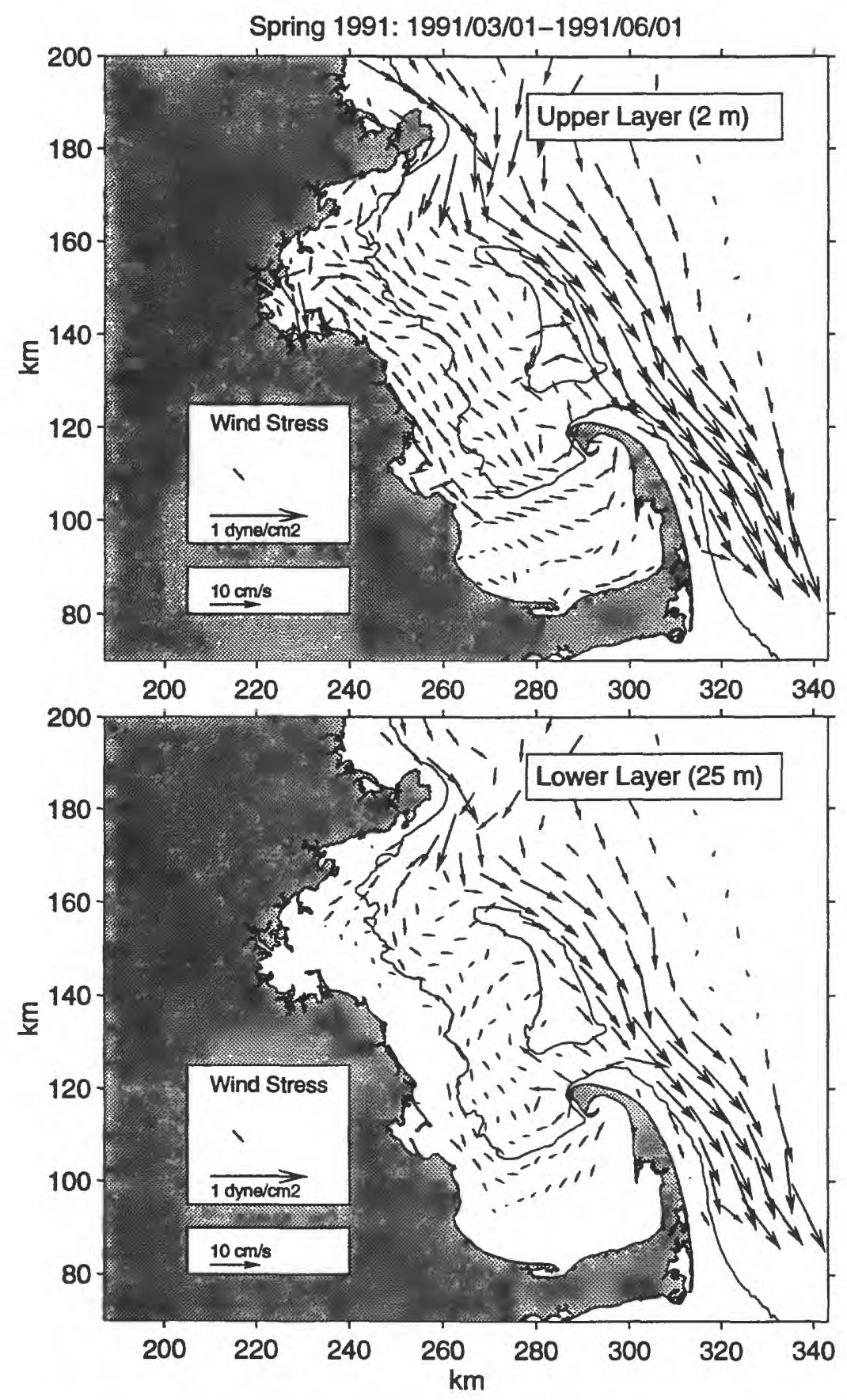

Figure B.6: Modeled mean flow at 2 and $20 \mathrm{~m}$ depth for Spring 1991. 


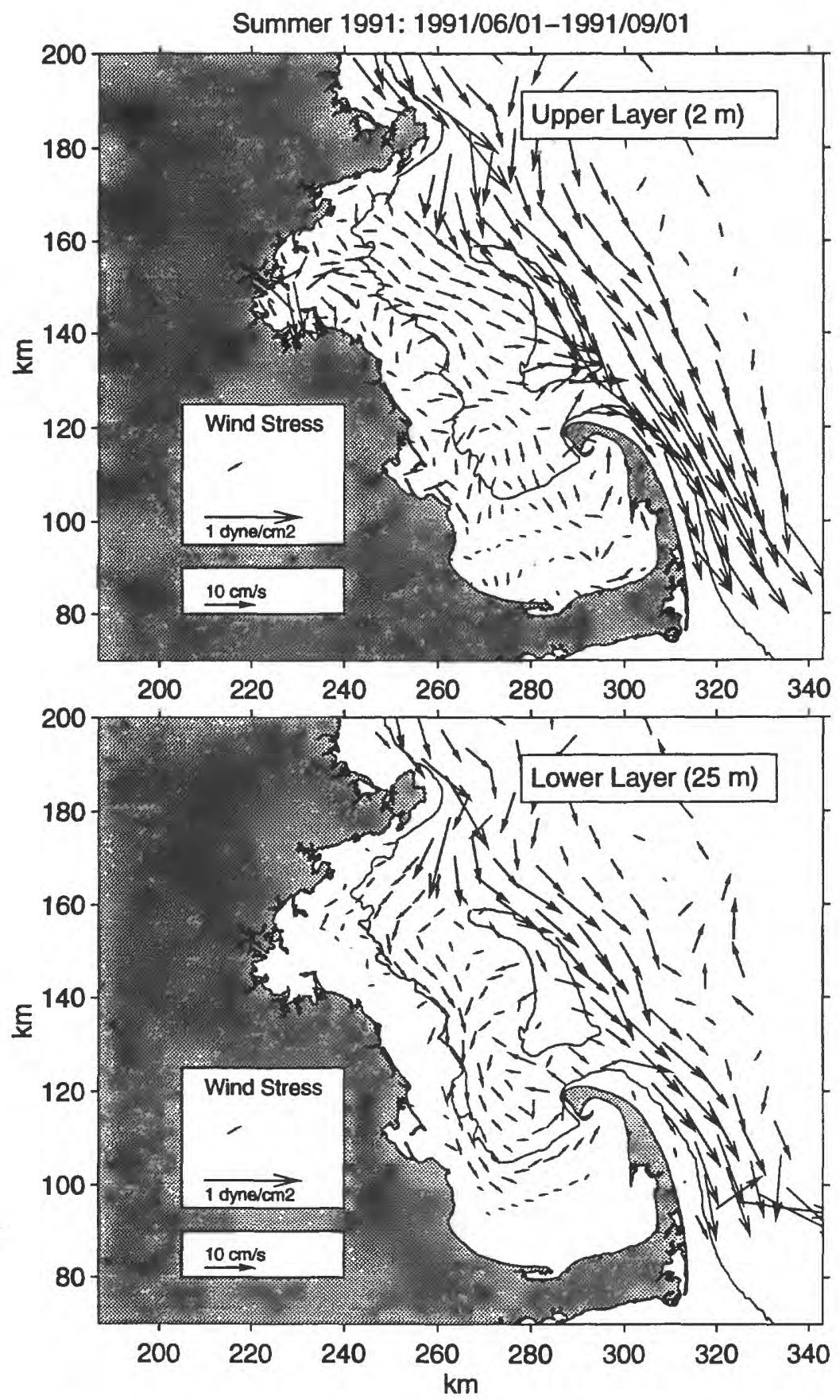

Figure B.7: Modeled mean flow at 2 and $20 \mathrm{~m}$ depth for Summer 1991. 


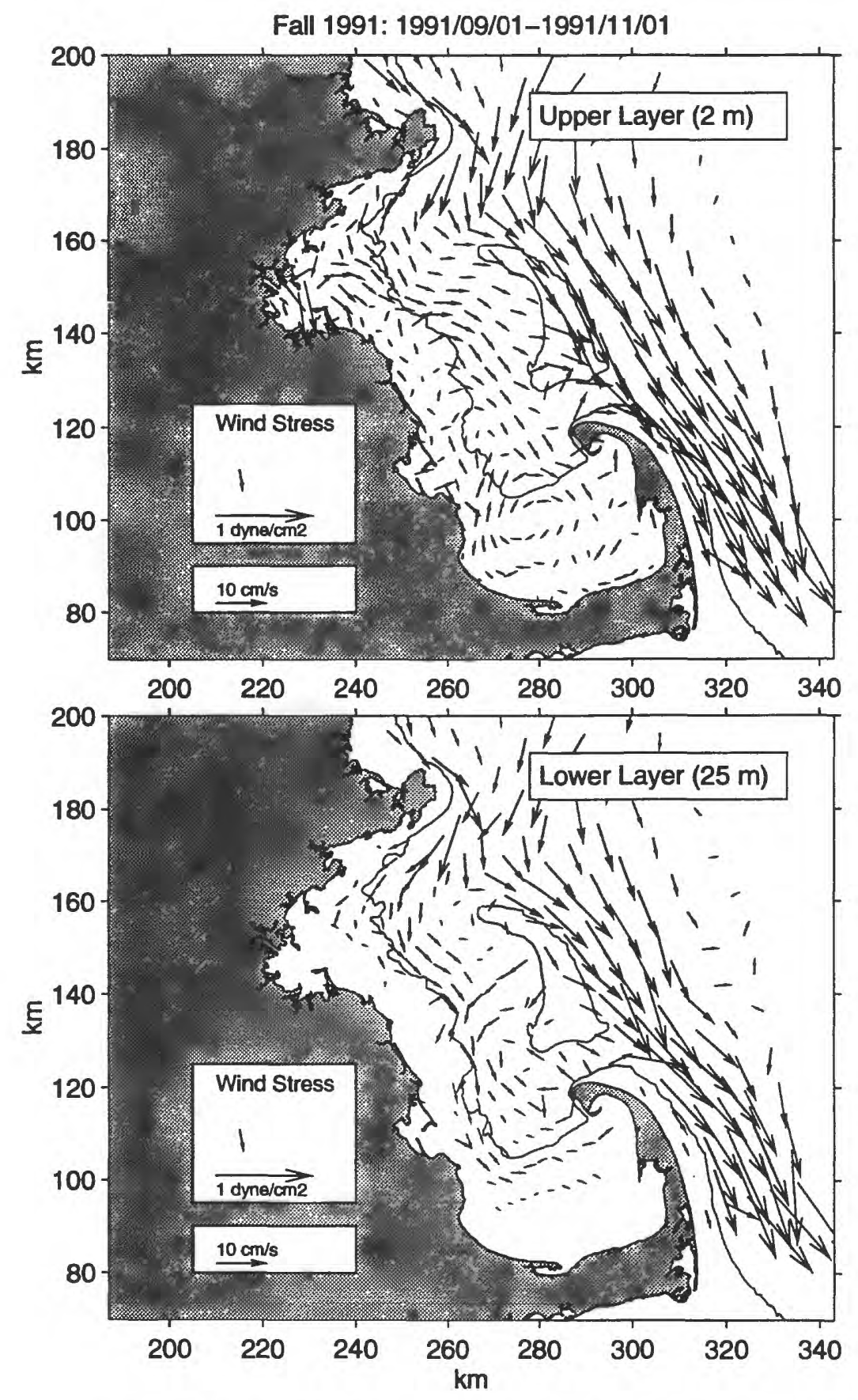

Figure B.8: Modeled mean flow at 2 and $20 \mathrm{~m}$ depth for Fall 1991. 


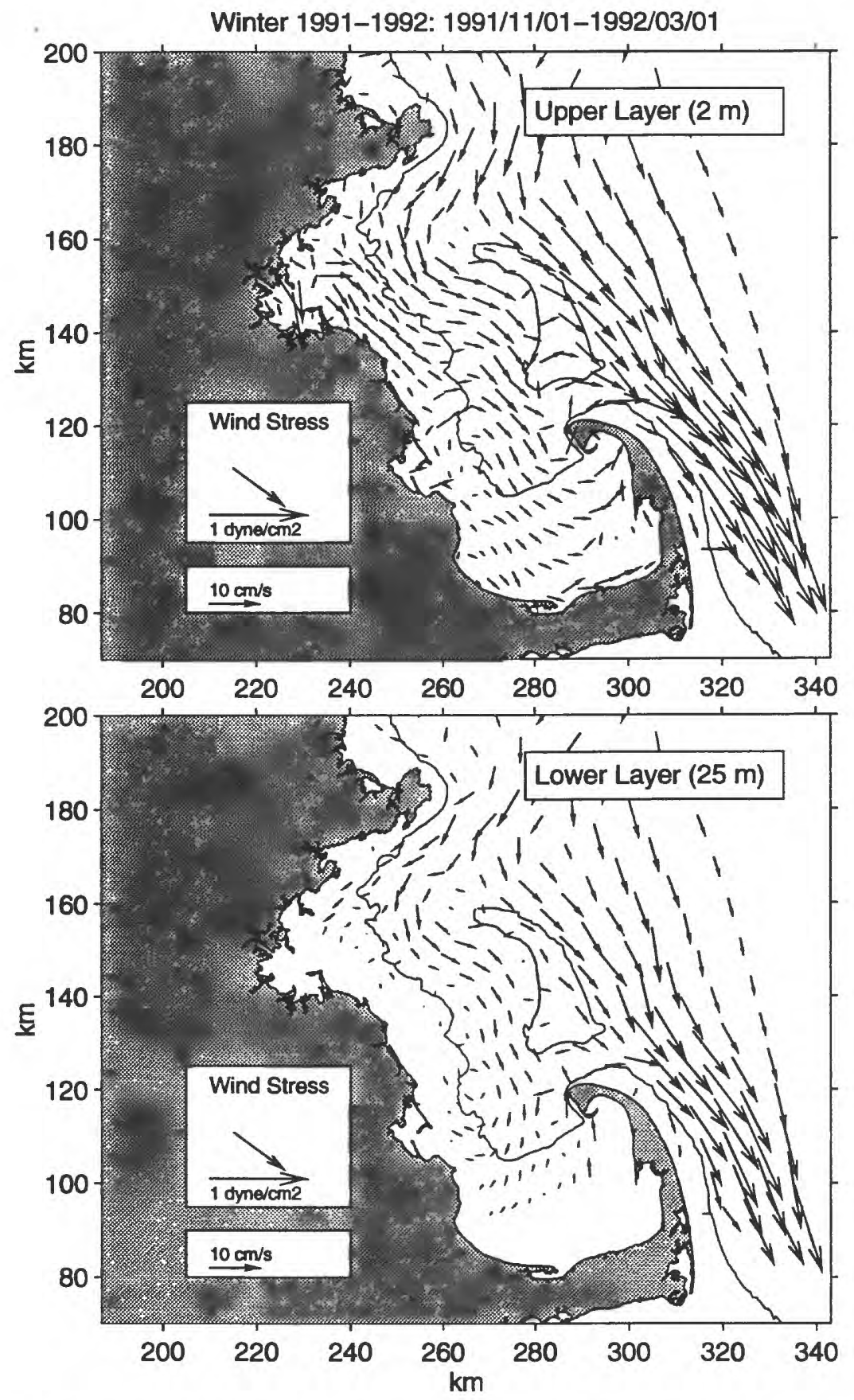

Figure B.9: Modeled mean flow at 2 and $20 \mathrm{~m}$ depth for Winter 1991-1992. 


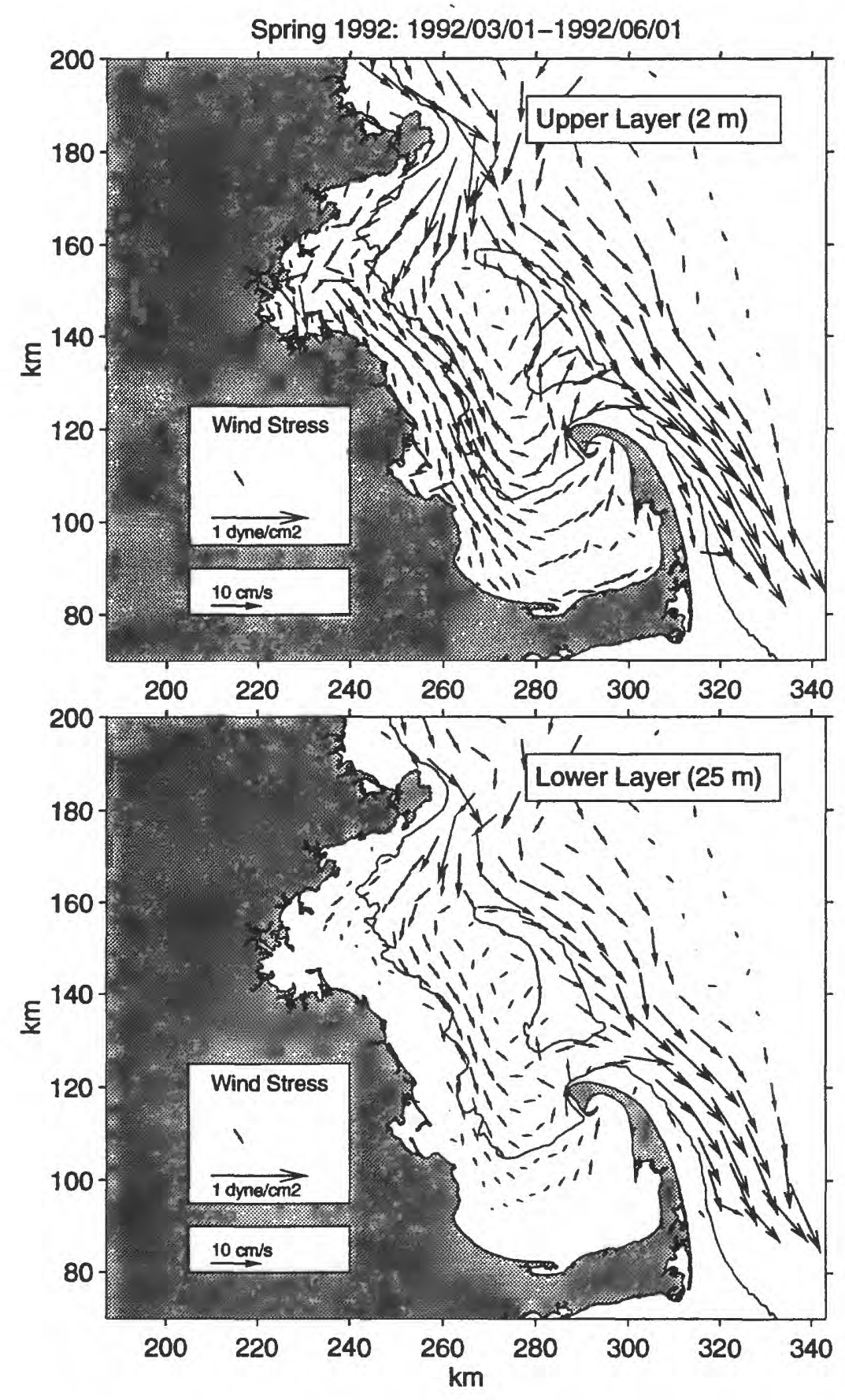

Figure B.10: Modeled mean flow at 2 and $20 \mathrm{~m}$ depth for Spring 1992. 


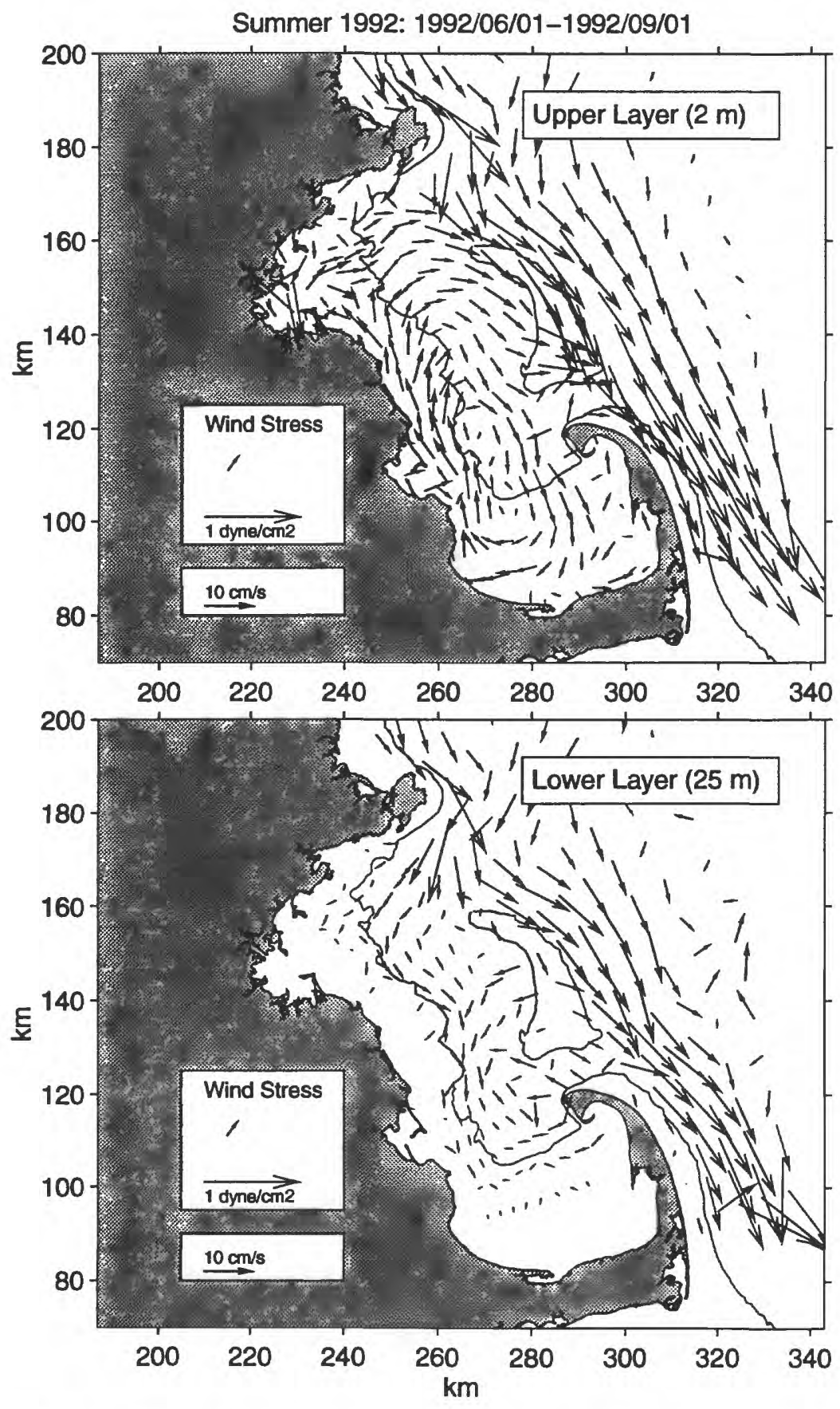

Figure B.11: Modeled mean flow at 2 and $20 \mathrm{~m}$ depth for Summer 1992. 
Fall 1992: 1992/09/01-1992/11/01

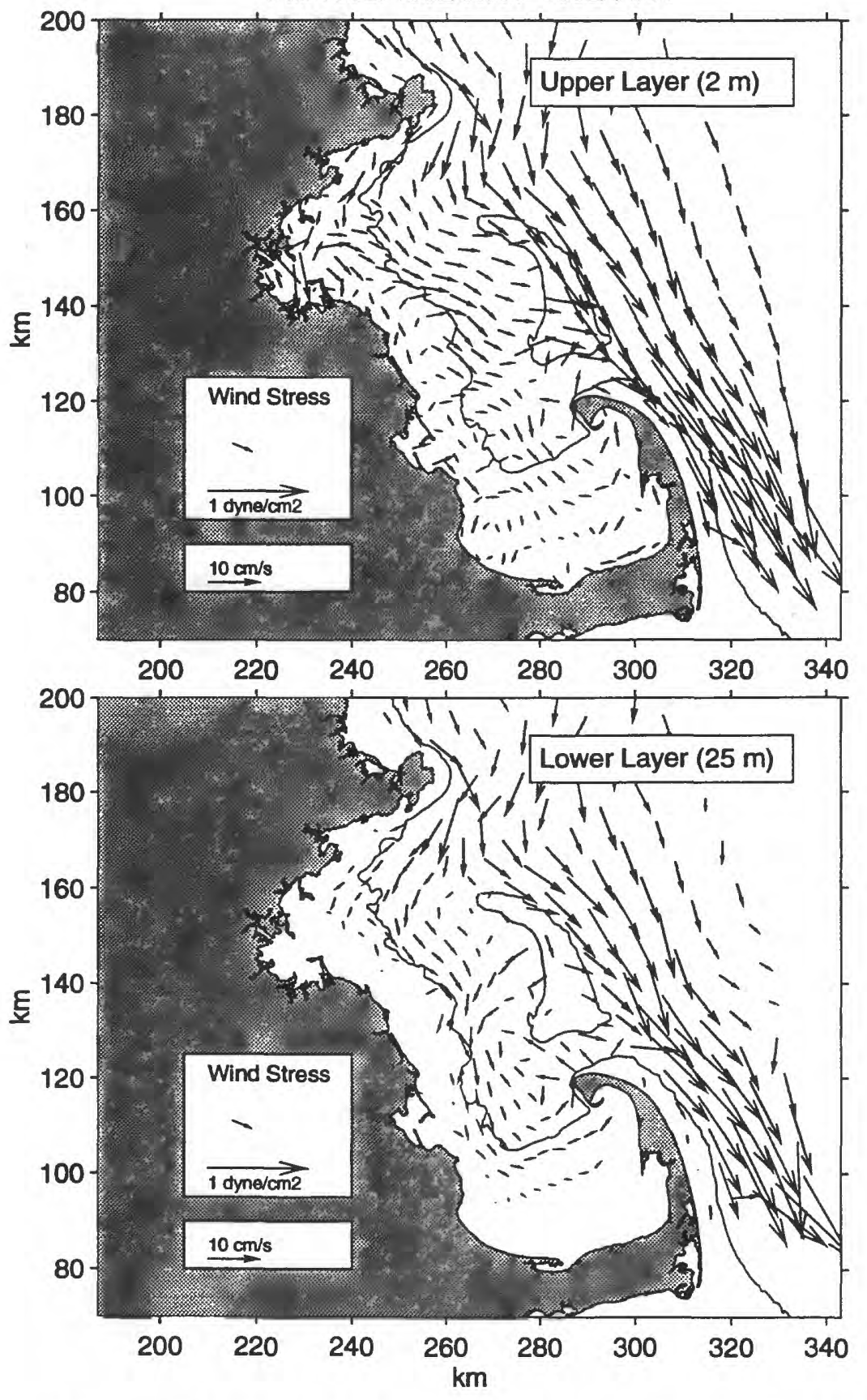

Figure B.12: Modeled mean flow at 2 and $20 \mathrm{~m}$ depth for Fall 1992. 


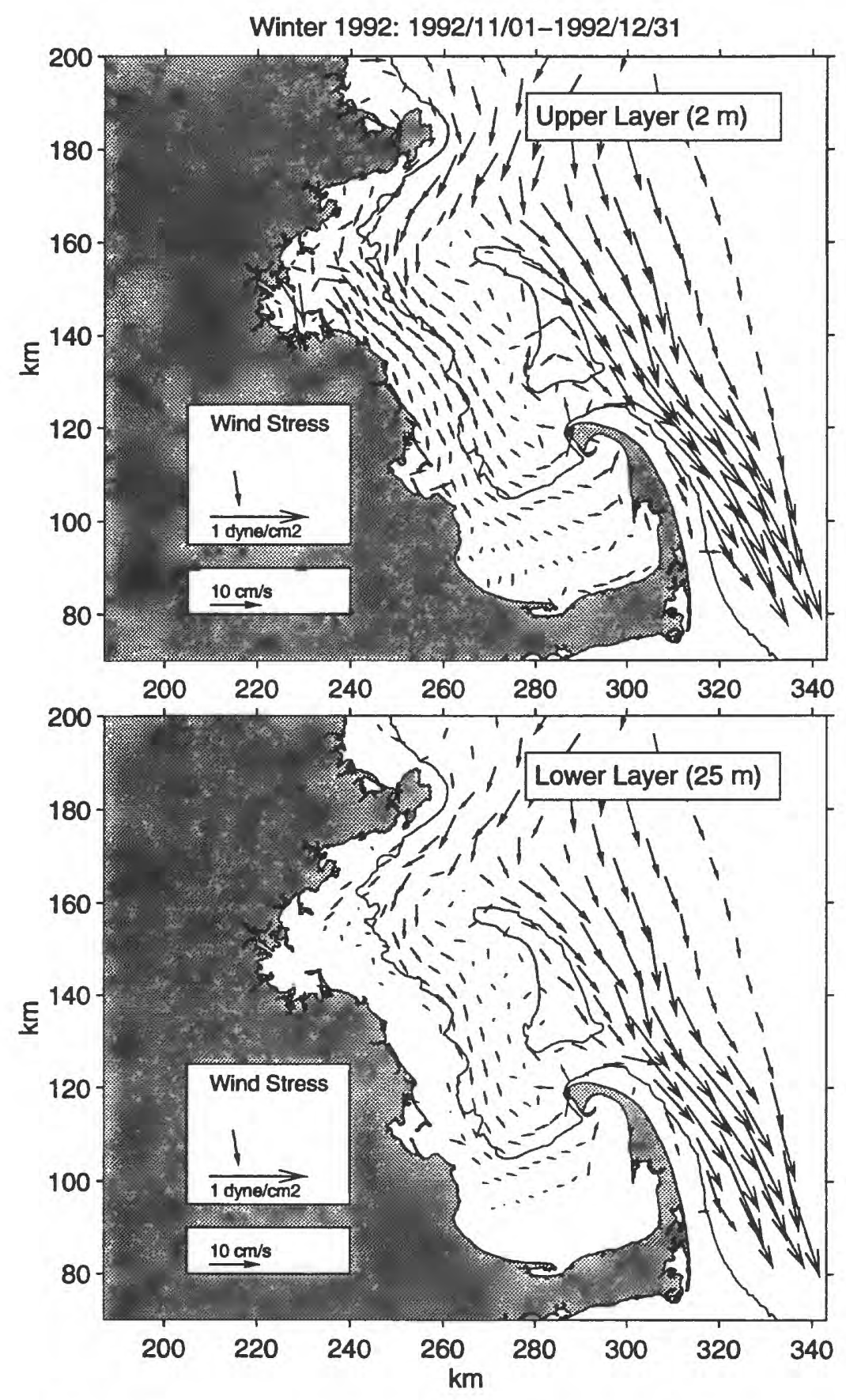

Figure B.13: Modeled mean flow at 2 and $20 \mathrm{~m}$ depth for Winter 1992. 
Appendix C

Comparative Effluent Dilution Simulations for the Existing and Future Outfalls 


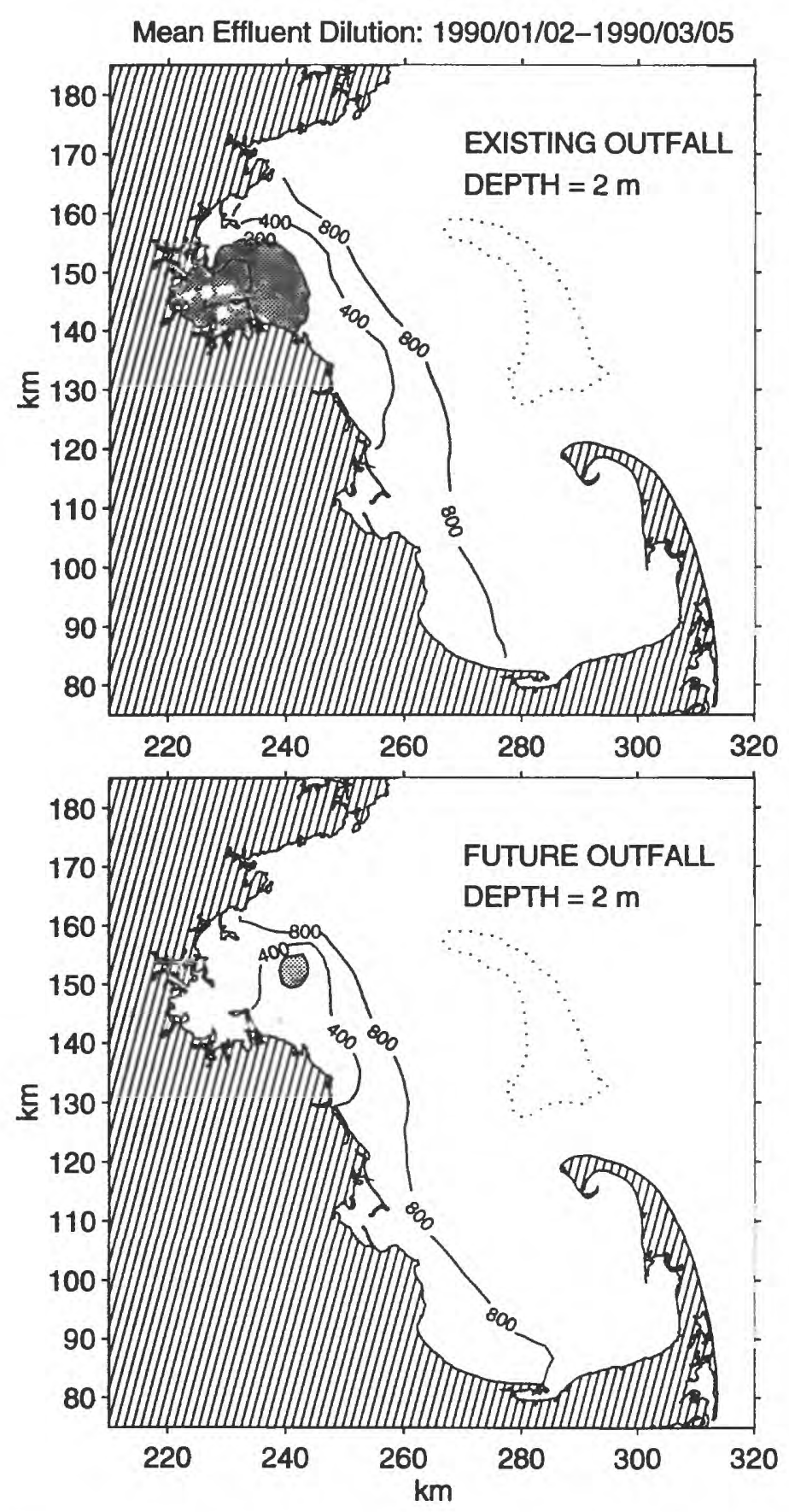

Figure C.1: Effluent comparison during Winter $1989-90$ at $2 \mathrm{~m}$ depth. Dilution contours of 200,400 and 800 are shown. Areas where the dilution is less than 200 are shaded in grey. The $40 \mathrm{~m}$ depth contour around Stellwagen Bank is indicated by the dotted line. 

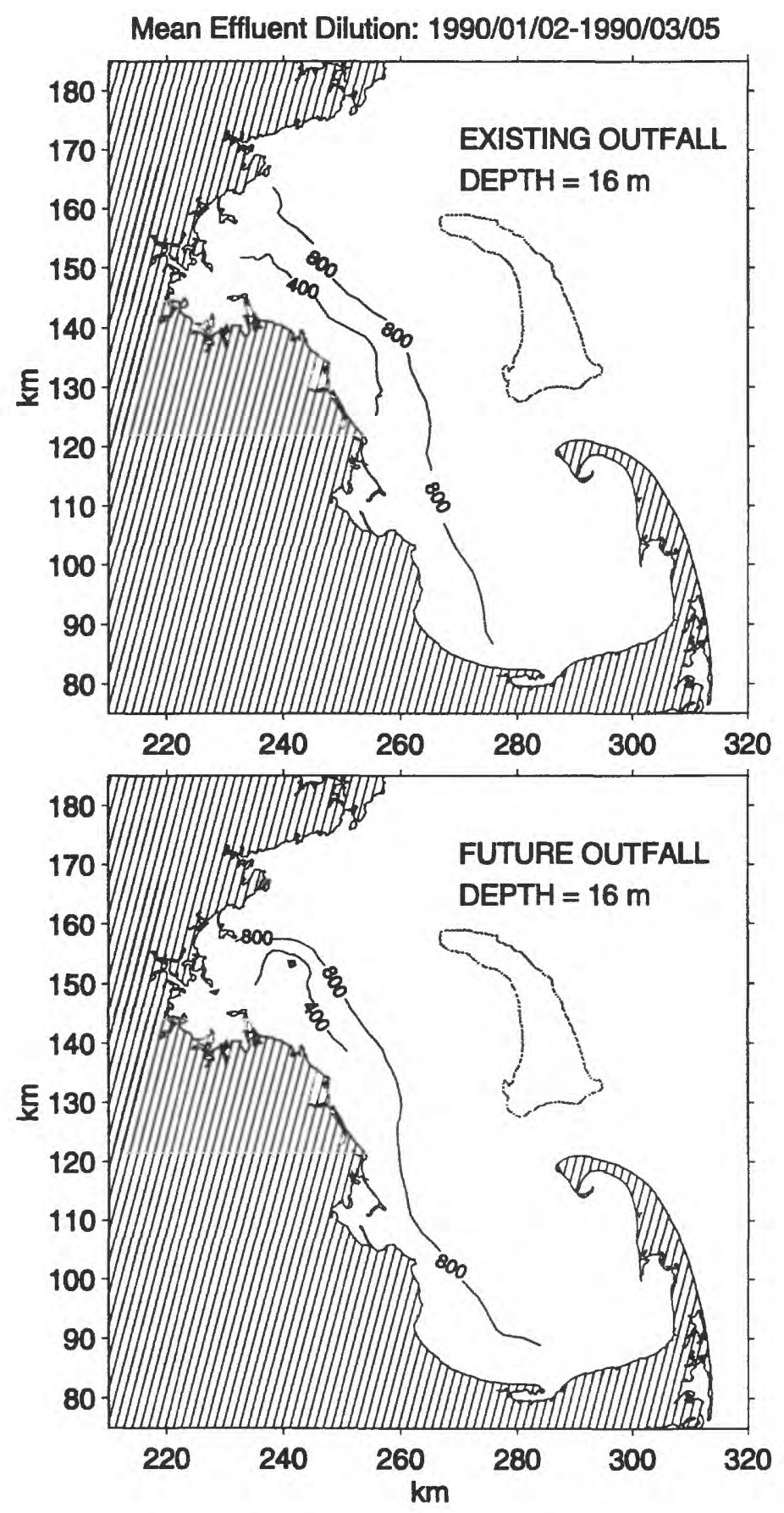

Figure C.2: Effluent comparison during Winter $1989-90$ at $16 \mathrm{~m}$ depth. 

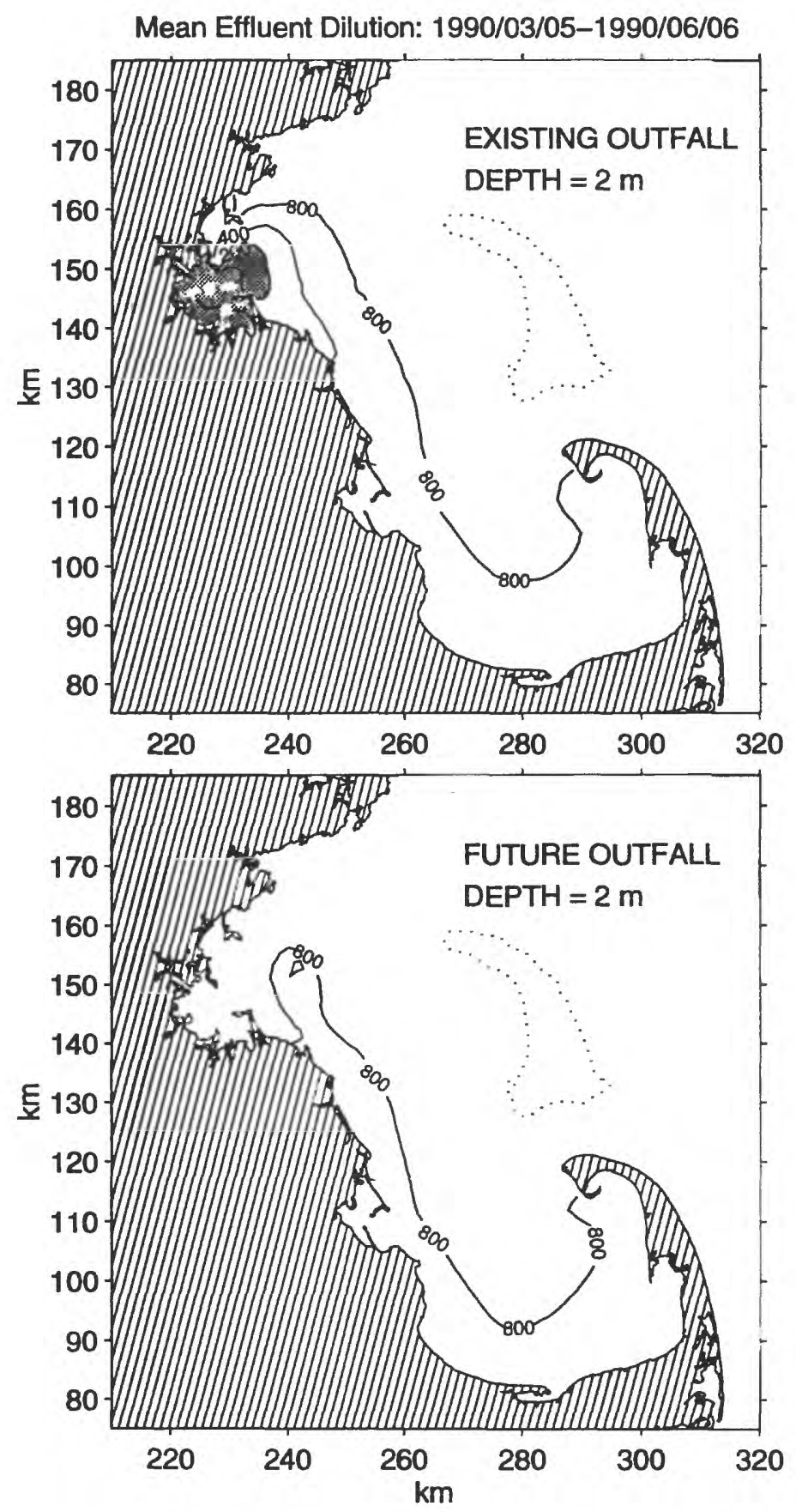

Figure C.3: Effluent comparison during Spring 1990 at $2 \mathrm{~m}$ depth. 

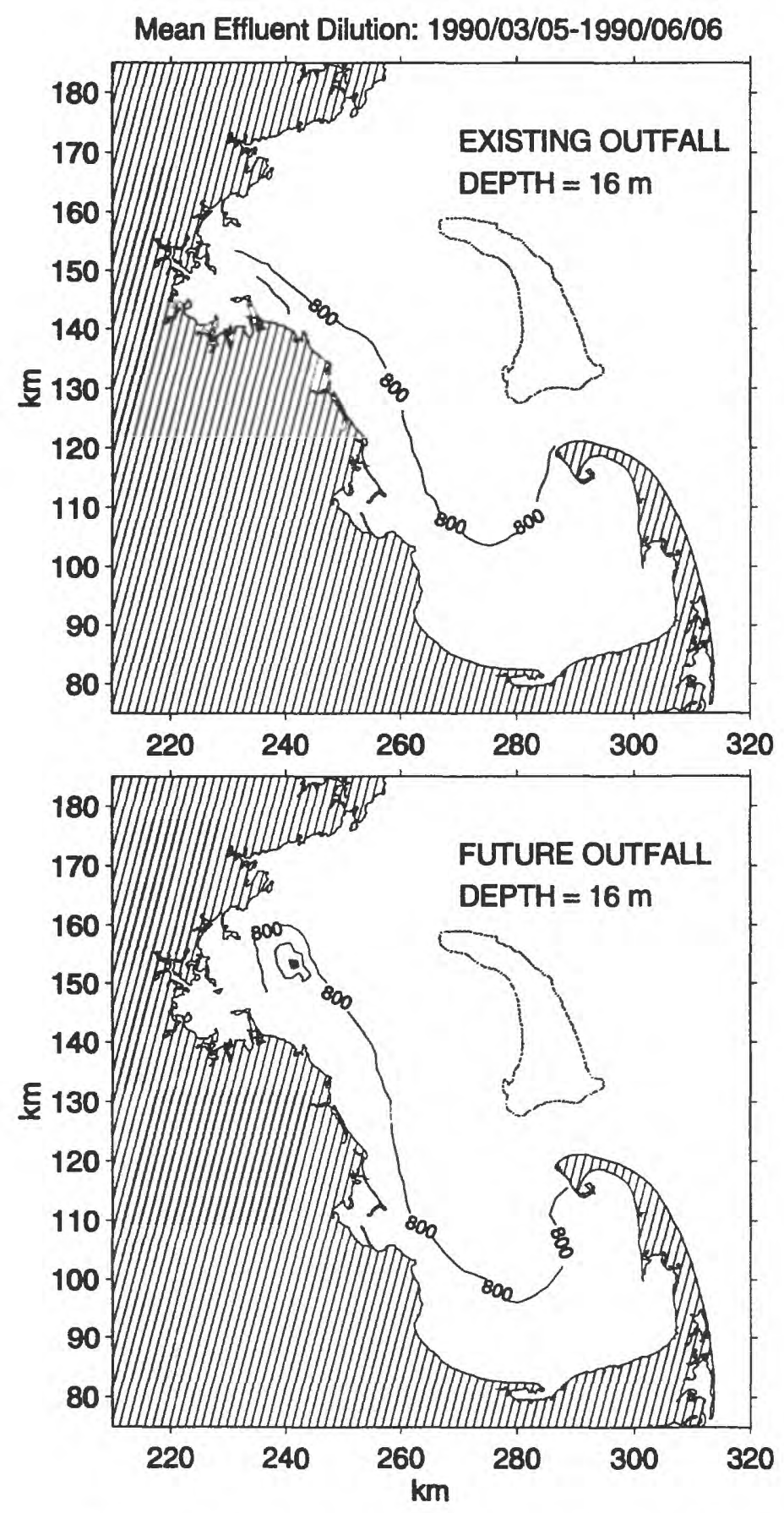

Figure C.4: Effluent comparison during Spring 1990 at $16 \mathrm{~m}$ depth. 


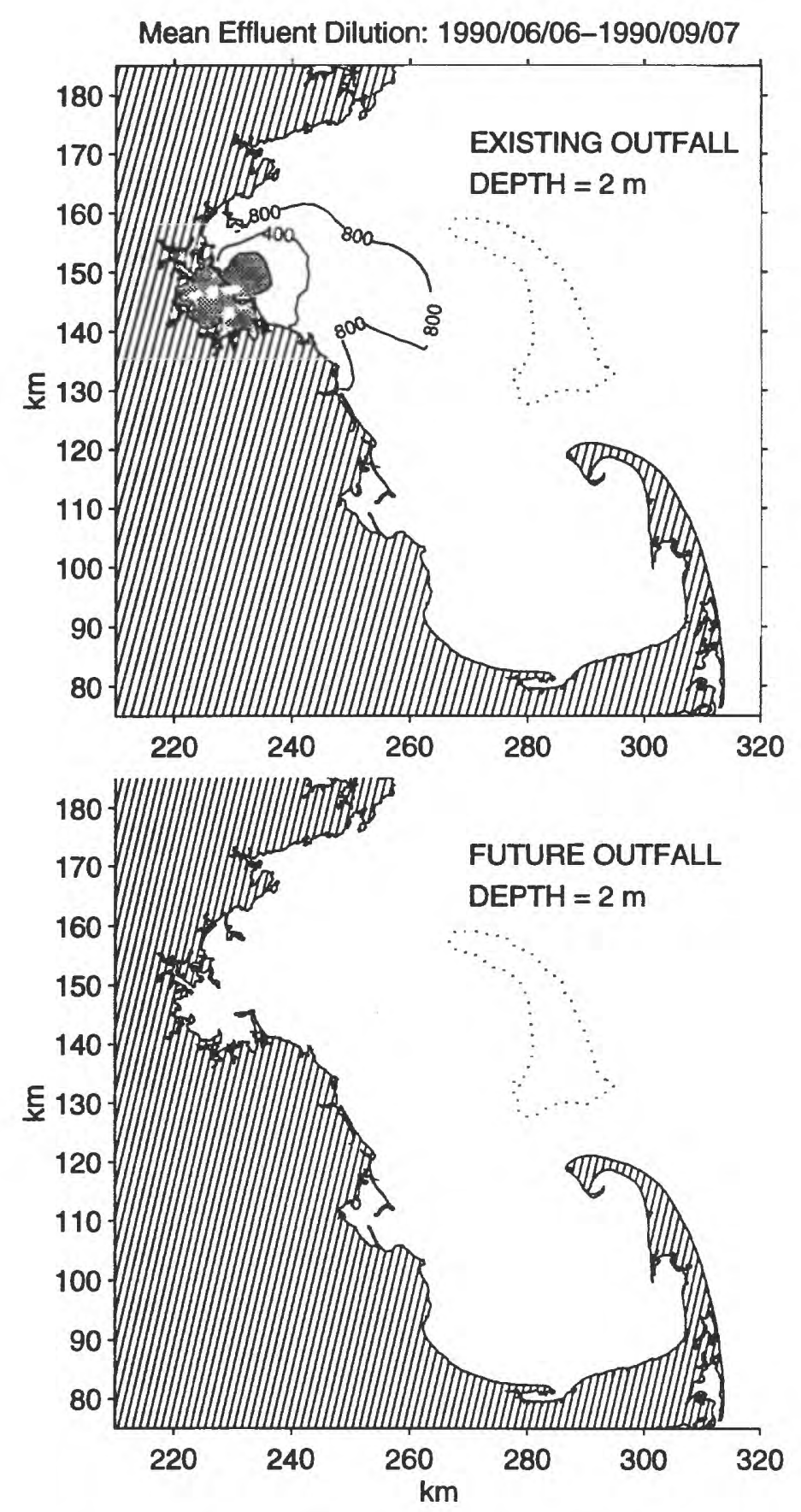

Figure C.5: Effluent comparison during Summer 1990 at $2 \mathrm{~m}$ depth. 

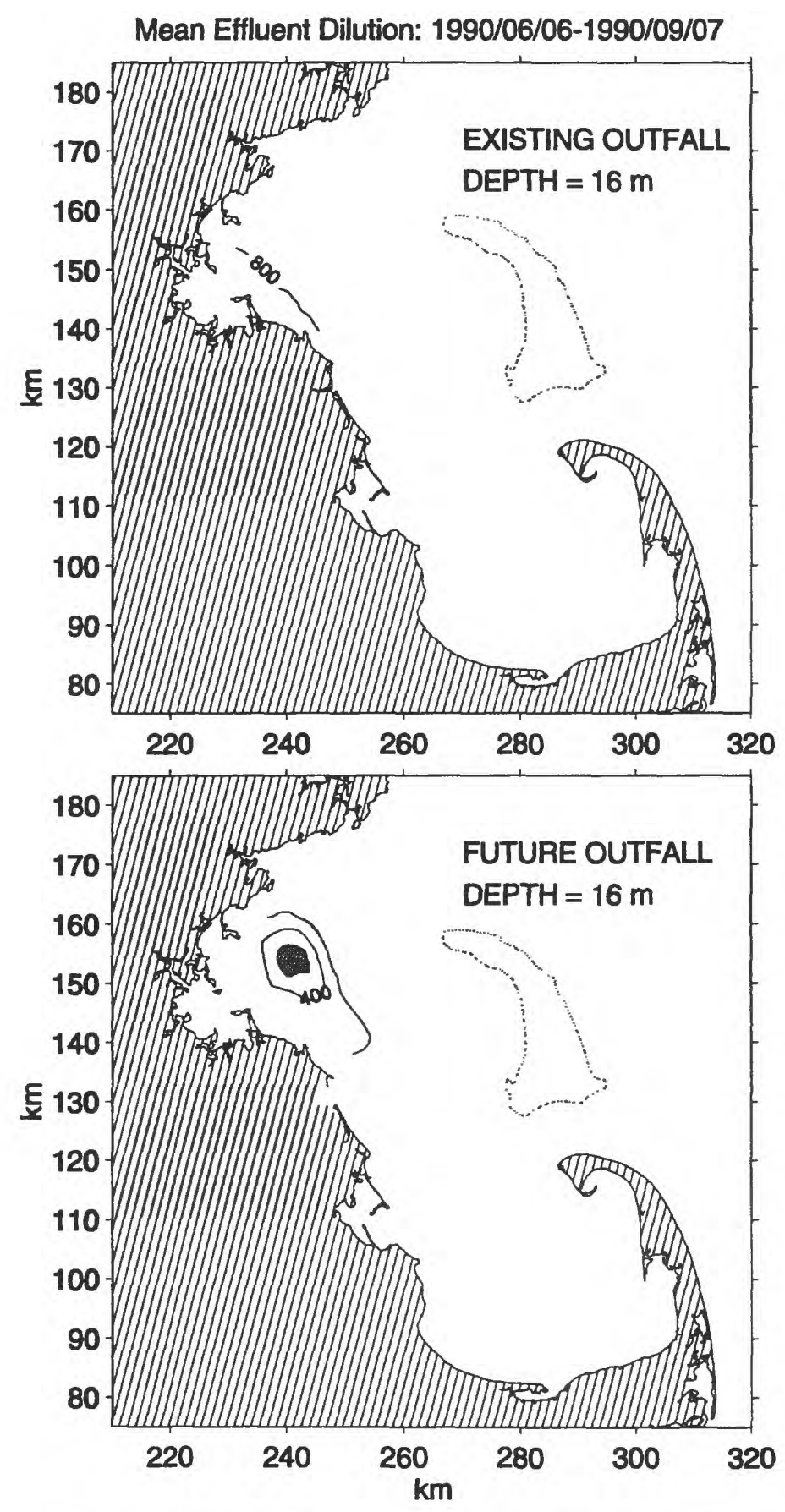

Figure C.6: Effluent comparison during Summer 1990 at $16 \mathrm{~m}$ depth. 

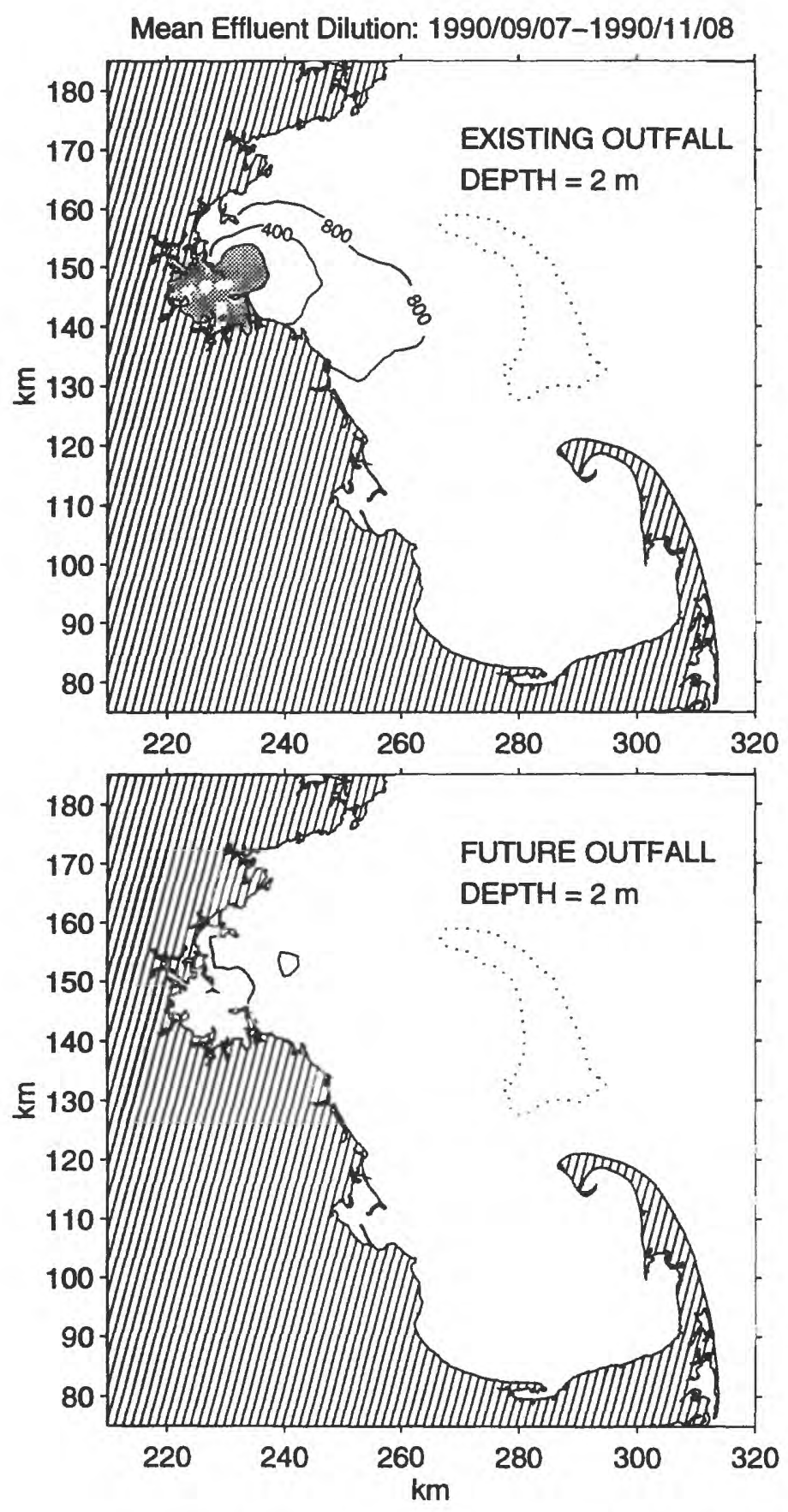

Figure C.7: Effluent comparison during Fall 1990 at $2 \mathrm{~m}$ depth. 

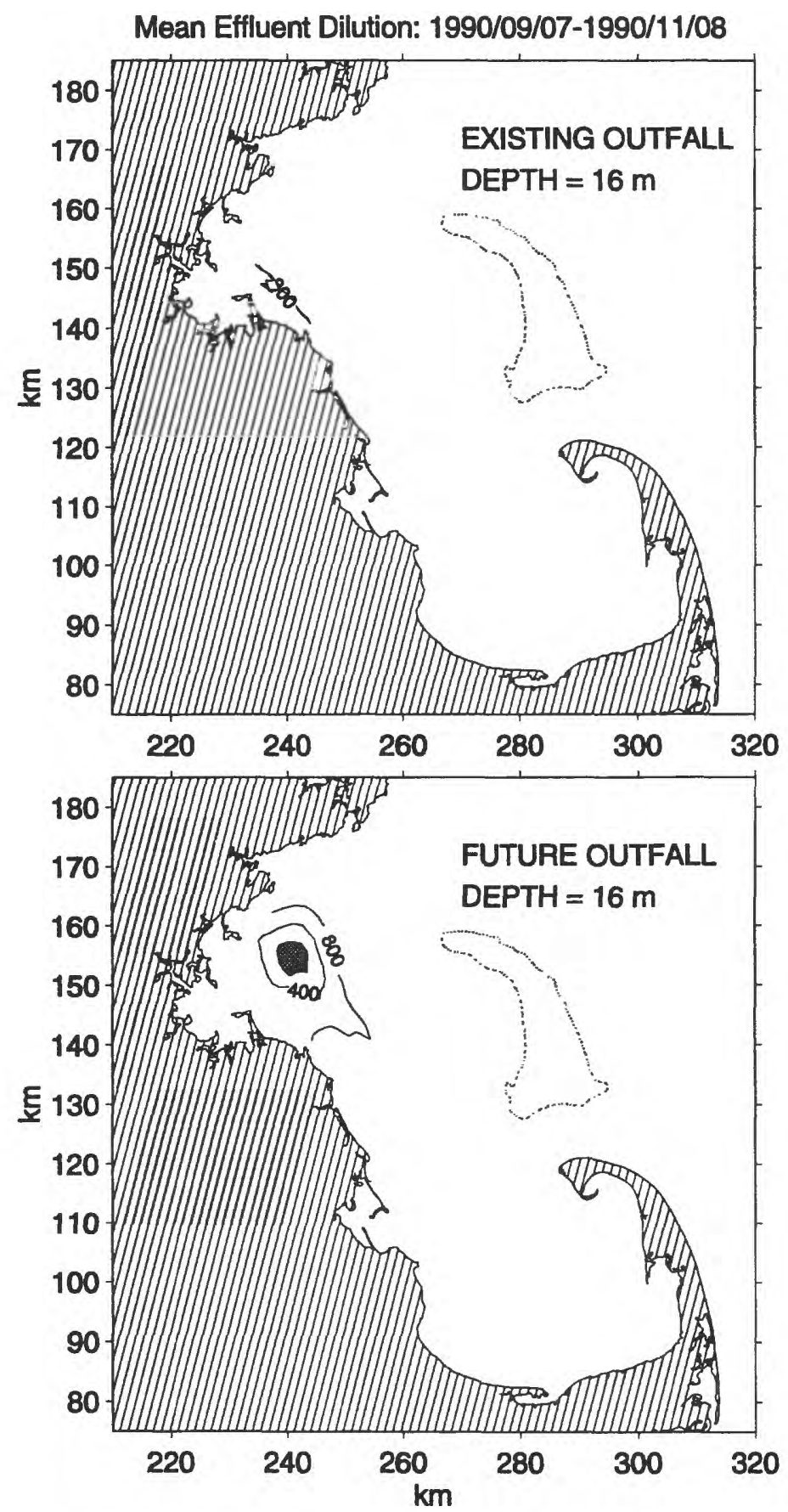

Figure C.8: Effluent comparison during Fall 1990 at 16 m depth. 

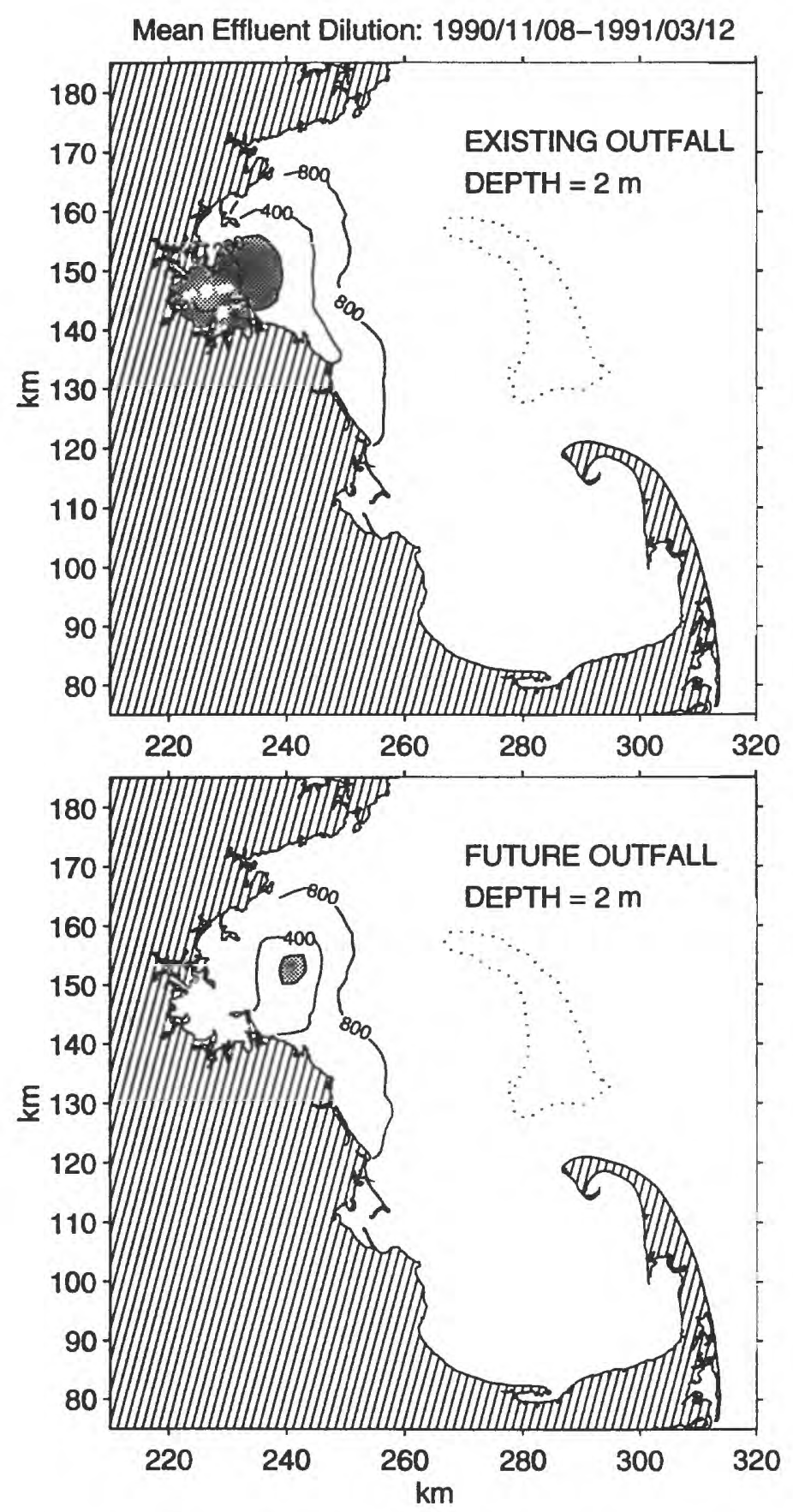

Figure C.9: Effluent comparison during Winter 1990-91 at $2 \mathrm{~m}$ depth. 


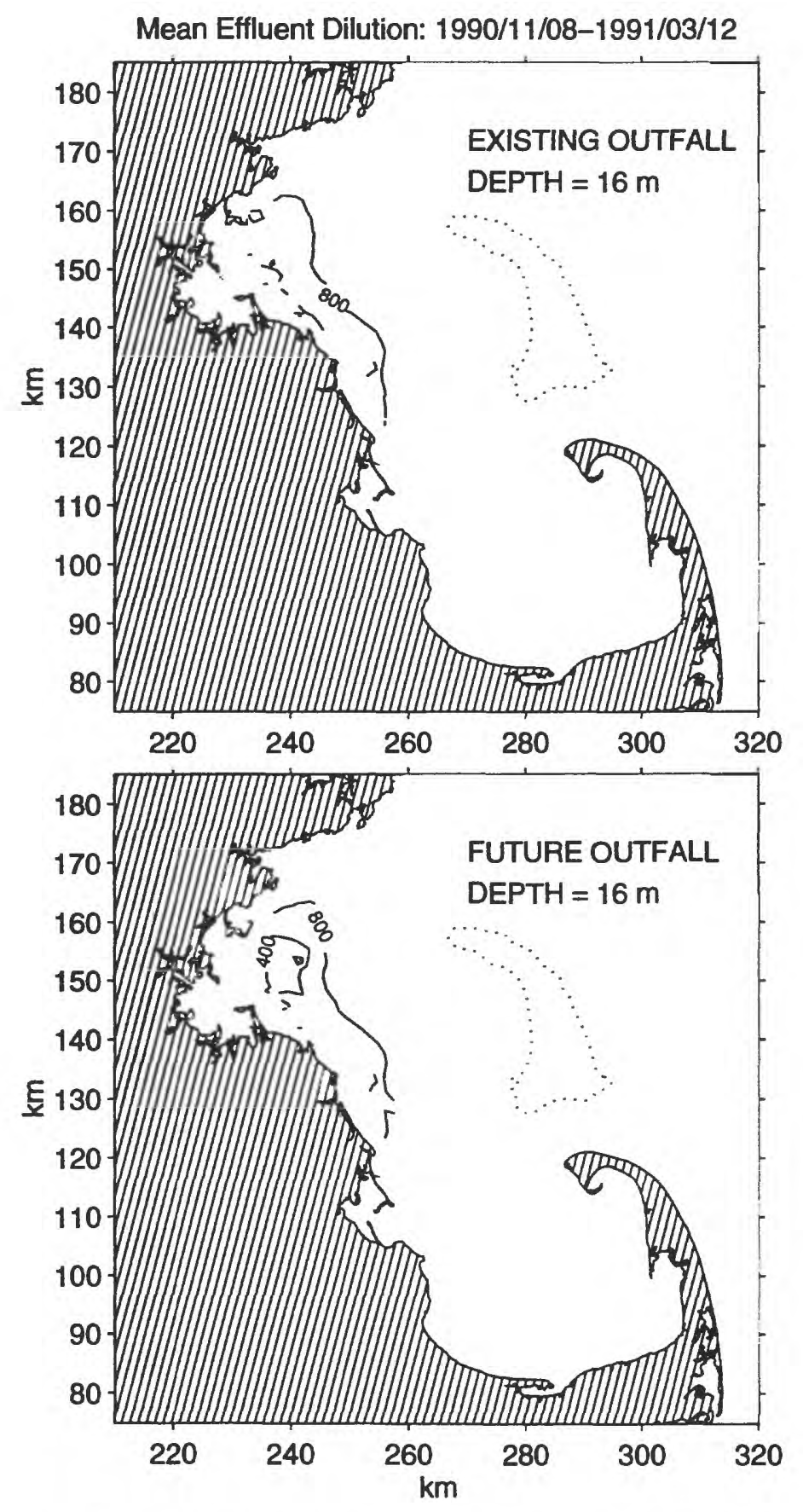

Figure C.10: Effluent comparison during Winter 1990-1991 at $16 \mathrm{~m}$ depth. 

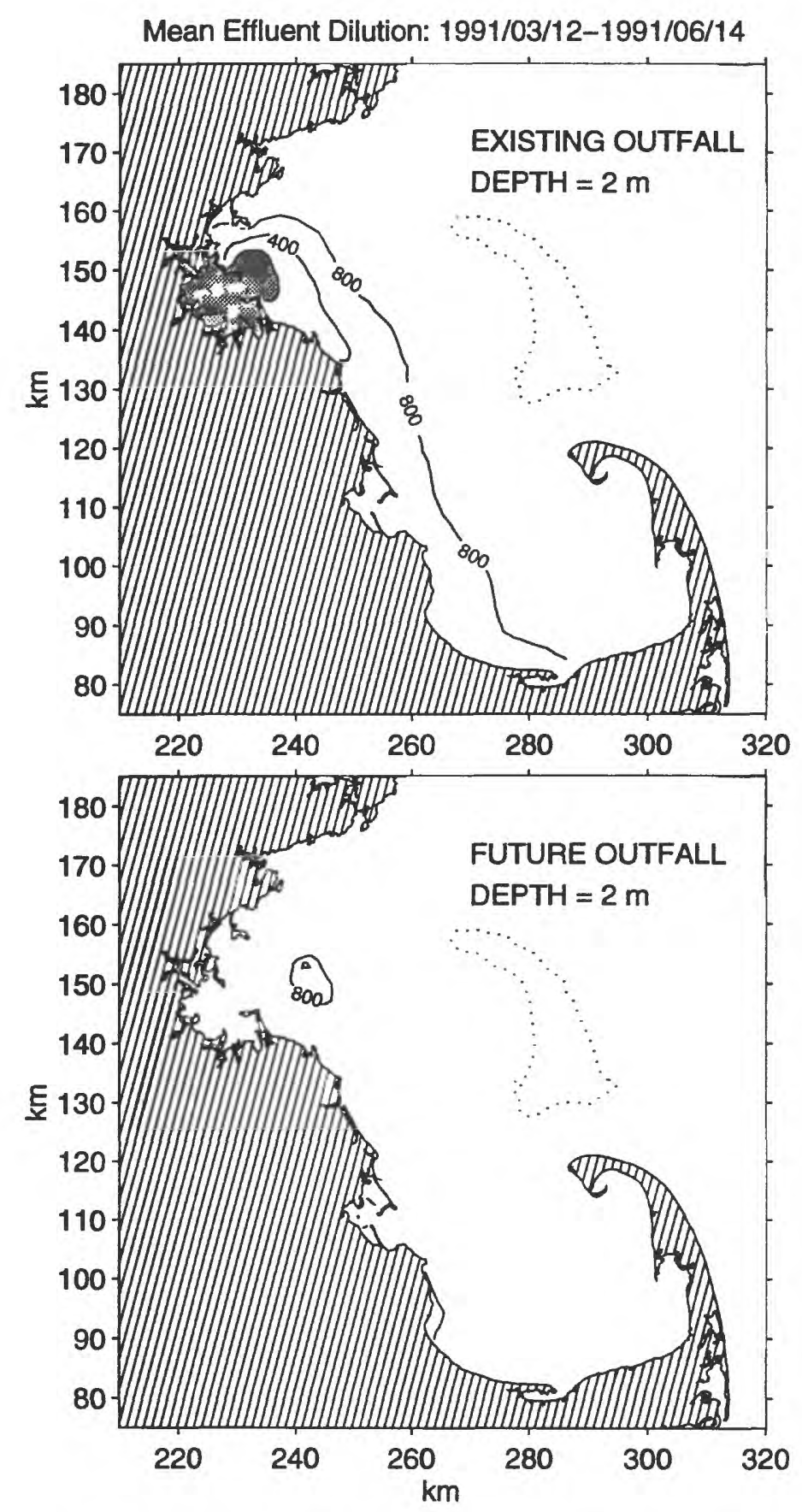

Figure C.11: Effluent comparison during Spring 1991 at $2 \mathrm{~m}$ depth. 


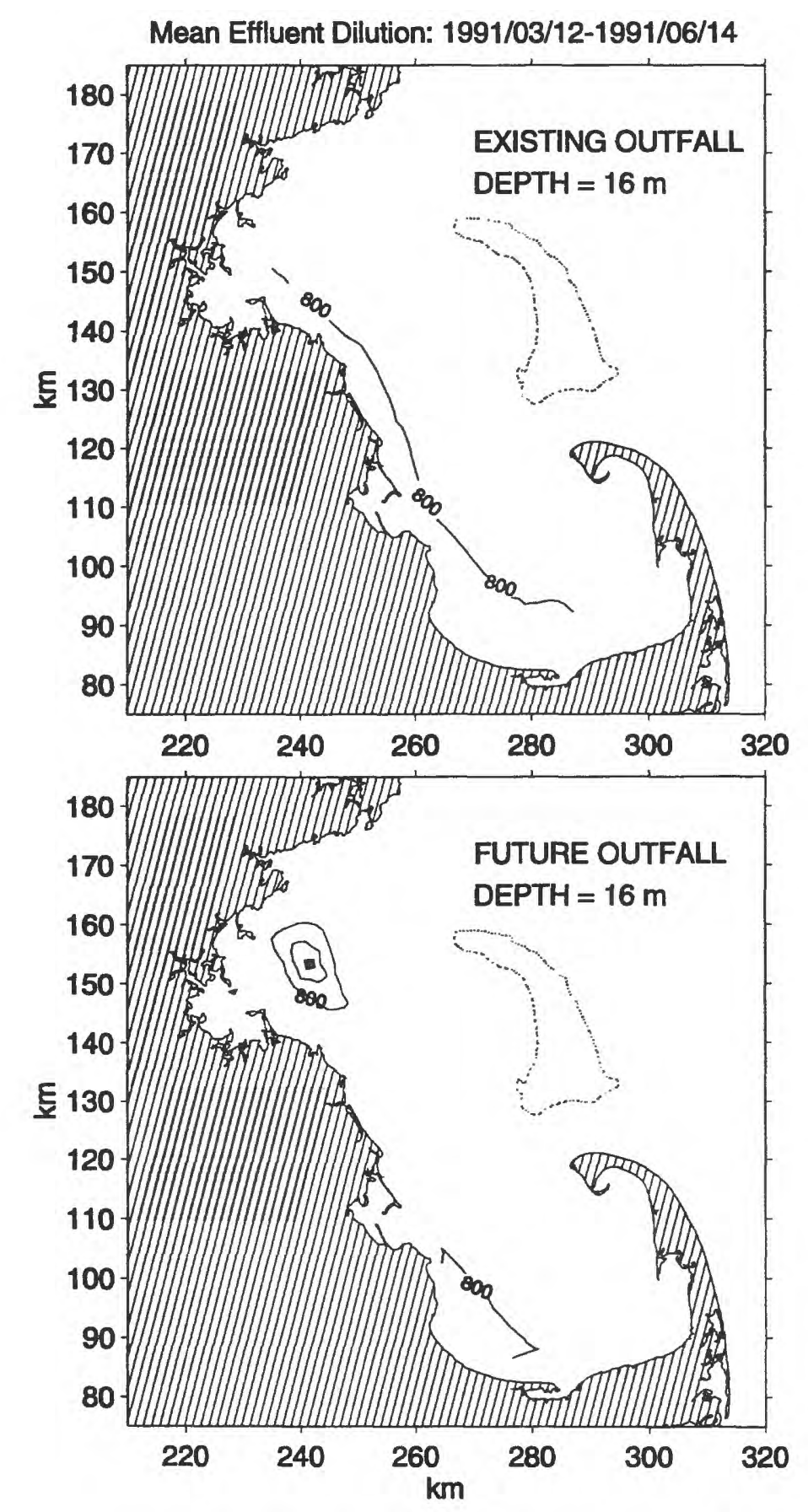

Figure C.12: Effluent comparison during Spring 1991 at $16 \mathrm{~m}$ depth. 


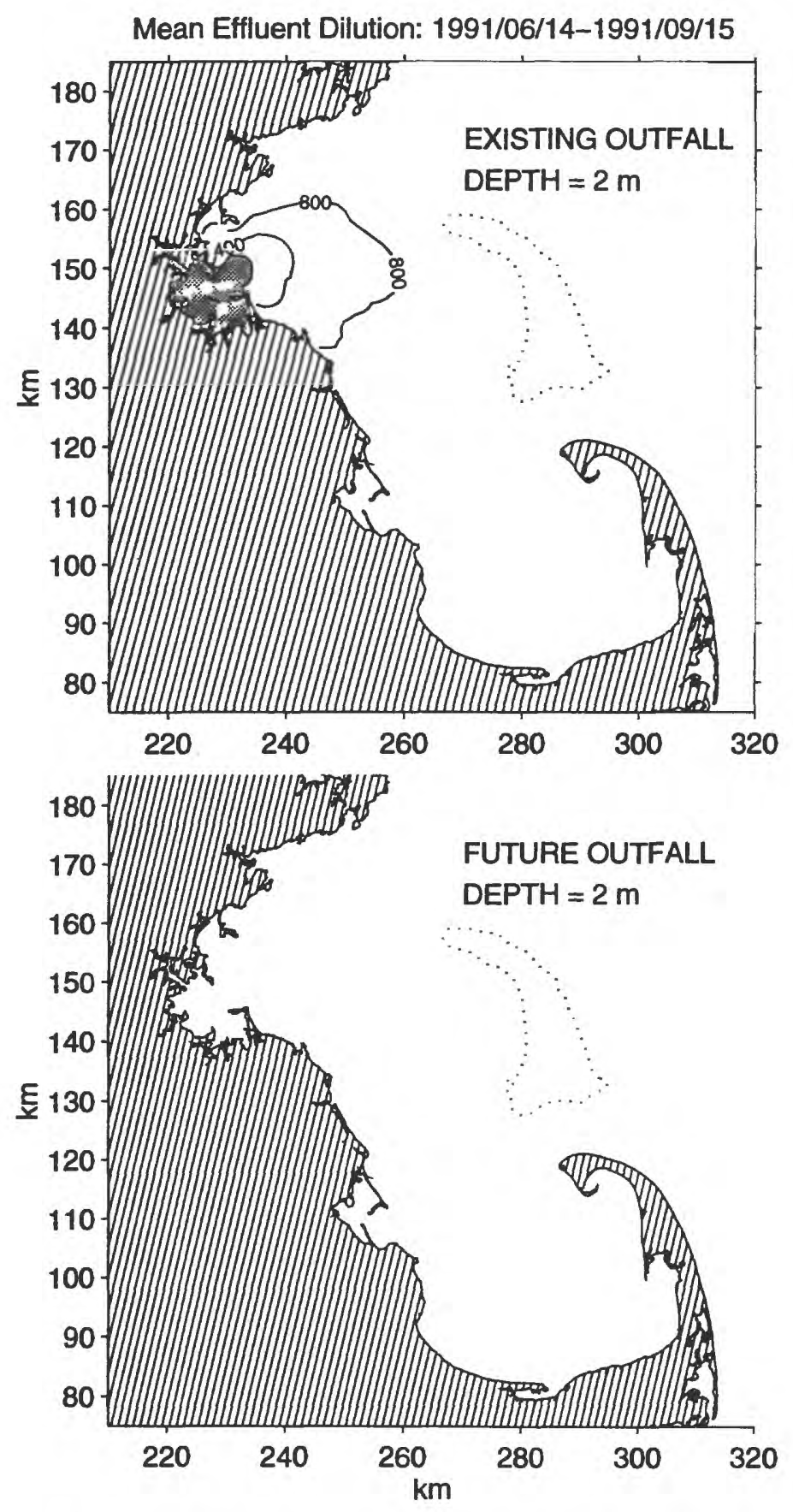

Figure C.13: Effluent comparison during Summer 1991 at $2 \mathrm{~m}$ depth. 

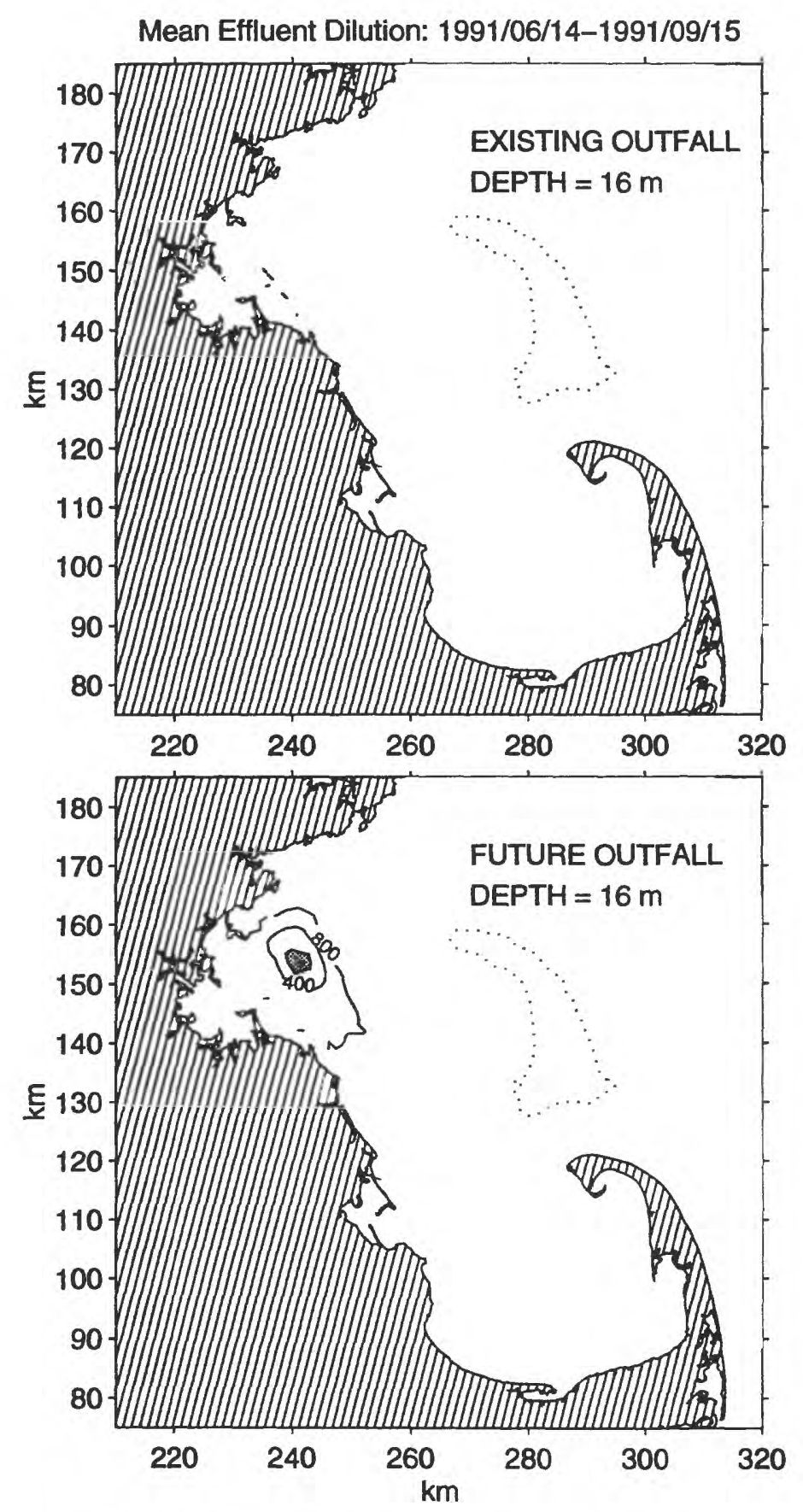

Figure C.14: Effluent comparison during Summer 1991 at $16 \mathrm{~m}$ depth. 


\section{Appendix D}

\section{References}

\section{REFERENCES}

Adams, E., R. Kossik, D. J. Cosler, J. K. MacFarlane, and P. M. Gschwend, Calibration of a Transport model using halocarbons, In Estuarine and Coastal Modeling, edited by M. L. Spaulding, pp. 380-389. American Society of Civil Engineers, ASCE press, New York, 1990.

Agency, E. P., Assessment of Potential Impact of the MWRA Outfall on Endangered Species, Technical report, EPA Region 1, JFK Federal Building, Boston, Massachusetts 02203, 1993.

Authority, M. W. R., Final Secondary Treatment Facilities Plan, Technical report, MWRA, 1988.

Beckmann, A. and D. B. Haidvogel, Numerical Simulation of Flow around a Tall Isolated Seamount. Part I: Problem Formulation and Model Accuracy, J. Phys. Oceanogr., 23, 1736-1753, 1993.

Blumberg, A., Z. Ji, and C. K. Ziegler, Confirmation of the Near Field Behavior from a far field circulation model of Massachusetts Bay, Technical report, Massachusetts Water Resources Authority, 1994. 25 pp.

Blumberg, A., R. Signell, and H. Jenter, Modeling Transport Processes in the Coastal Ocean, Journal of Environmental Engineering, 1, 31-52, 1993.

Blumberg, A. F. and L. H. Kantha, Open Boundary Condition for Circulation Models, J. Hydraulic Engineering, 111, 273-255, 1985.

Blumberg, A. F. and G. L. Mellor, A description of a three-dimensional coastal model, pp. 1-16, Coastal and Estuarine Sciences, Vol. 4. AGU, Washington, DC, 1987.

Bodgen, P., P. Malanotte-Rizzoli, and R. P. Signell, Open-ocean boundary conditions from interior data: Local and remote forcing of Massachusetts Bay, $J$. 
Geophys. Res., C12, submitted, 1995.

Casulli, V., Semi-implicit finite difference methods for the two-dimensional shallow water equations, J. Computational Physics, 86, 56-74, 1990.

Drinkwater, K., AFAP climate studies in the Scotia-Fundy Region, Technical Report $92 / 72$, N2126, NAFO SCR, 1992. 8 pp.

Galperin, B., L. H. Kantha, S. Hassid, and A. Rosati, A Quasi-equilibrium turbulent energy model for geophysical flows, J. Atmosph. Sci., 45, 55-62, 1988.

Geyer, W., G. Gardner, W. Brown, J. Irish, B. Butman, T. Loder, and R. Signell, Physical Oceanographic Investigation of Massachusetts and Cape Cod Bays, Technical Report MBP-92-03, Massachusetts Bays Program, U.S. EPA Region I/Massachusetts Coastal Zone Management Office, Boston, Massachusetts, 1992. $497 \mathrm{pp}$.

Geyer, W. R. and J. Ledwell, Massachusetts Bay dye study, 1994. Submitted to the Massachusetts Water Resources Authority, Charlestown, Massachusetts.

Holzwarth-Davis, T. and M. H. Taylor, Description of the 1992 Oceanographic Conditions on the Northeast Continental Shelf, Northeast Fisheries Science Center Reference Document 93-25, NOAA/National Marine Fisheries Service, 1993. $87 \mathrm{p}$.

HydroQual, I. and B. O. Sciences, A water quality model for Massachusetts and Cape Cod Bays: Calibration of the bays eutrophication model, Technical Report NAIC0103, Massachusetts Water Resources Authority, 1995.

Large, W. G. and S. Pond, Open ocean momentum flux measurements in moderate to strong winds, J. Phys. Oceanogr., 11, 324-336, 1981.

Lynch, D. and C. Naimie, The M2 tide and its residual on the outer banks of the Gulf of Maine, J. Phys. Oceanogr., 23, 2222-2253, 1993.

Mellor, G. and T. Yamada, Development of a turbulence closure model for geophysical fluid problems, Rev. Geophys. Space Phys., 20, 851-875, 1982.

Moody, J. A., B. Butman, R. C. Beardsley, W. S. Brown, P. Daifuku, J. D. Irish, D. A. Mayer, H. O. Mofjeld, B. Petrie, S. Ramp, P. Smith, and W. R. Wright, Atlas of tidal elevation and current observations on the Northeast American Continental Shelf and Slope, U. S. Geological Survey Bulletin 1611, U.S. Geol. Surv., 1984. U.S. Government Printing Office, 122 pp.

Shapiro, R., Linear Filtering, Mathematics of Computation, 29, 1094-1097, 1975.

Signell, R. P., Tidal dynamics and dispersion around coastal headlands, Ph. D. thesis, Woods Hole Oceanogr. Inst./Mass. Inst. of Technol. Joint Program in Oceanography, Cambridge, Mass., 1989. 159 pp.

Signell, R. P., Modeling the seasonal circulation in Massachusetts Bay, In Estuarine and Coastal Modeling, Proceedings of the 3rd International Conference, edited by M. L. Spaulding, pp. 578-590. American Society of Civil Engineers, ASCE, 
New York, 1994.

Signell, R. P. and B. Butman, Modeling tidal exchange and dispersion in Boston Harbor, Journal of Geophysical Research, 97, 15,591-16,606, 1992.

Smagorinsky, J., General Circulation Experiments with the Primitive Equations I. The Basic Experiment, Monthly Weather Review, 91, 99-164, 1963.

Vermersch, J., R. Beardsley, and W. Brown, Winter circulation in the western Gulf of Maine: Part 2. Current and pressure observations, J. Phys. Oceanogr., 9, 786-784, 1979.

Walton, R., R. Kossik, and R. Kapner, Bay-wide model studies for the Boston ocean outfall, In Estuarine and Coastal Modeling, edited by M. L. Spaulding, pp. 390-399. American Society of Civil Engineers, ASCE press, New York, 1990.

Weller, R., D. Rudnick, and N. J. Brink, Meteorological variability and air-sea fluxes at a closely spaced array of surface moorings, J. Geophys. Res., 100, $4867-4883,1995$. 